\title{
FAST REACTION NONPREMIXED COMBUSTION
}

\author{
G. M. FAETH* and G. S. SAMUELSEN $\dagger$ \\ *Department of Aerospace Engineering, The University of Michigan, Ann Arbor, MI 48109, U.S.A. \\ †Department of Mechanical Engineering, University of California. Irvine, CA 92717, U.S.A.
}

\begin{abstract}
Recent measurements in turbulent, single-phase, reacting flows are reviewed. Attention is confined to nonpremixed flows at the fast reaction limit, which is defined as conditions where rates of reaction are fast enough to maintain local equilibrium. Reactant combinations considered include: hydrogen/air. carbon monoxide/air, hydrogen/fluorine, nitric oxide/ozone, acid/base (in liquids) and the dissociation of nit rogen tetroxide in warm air. Criteria for the fast-reaction limit, as well as the laminar flamelet concept, are discussed in some detail. Other aspects of measurements in these systems are also discussed, e.g. effects of initial and boundary conditions; types of averaging; and the interpretation of velocity, temperature and other scalar property measurements. Existing measurements in round free jets, plane free shear layers and wall boundary layers are summarized and discussed. Experimental difficulties in controlling hydrodynamic and reaction variables are substantial, even in these relatively simple flows: therefore, no existing data set is completely satisfactory for definitive evaluation of methods of analyzing turbulent reaction processes at the fast-reaction limit. Recent measurements in round, free-jet. hydrogen/air diffusion flames, using optical diagnostics for structure measurements, come closest to this ideal; therefore, these results are discussed in detail and sources of tabulated data for use during model evaluation are cited.
\end{abstract}

\section{CONTENTS}

Nomenclature

1. Introduction

2. Experimental Considerations $\quad 307$

$\begin{array}{ll}\text { 2.1. Fast-reaction criteria } & 307\end{array}$

2.1.1. Hydrogen/air 309

2.1.2. Carbon monoxide/air 311

$\begin{array}{ll}\text { 2.1.3. Hydrocarbon/air } & 312\end{array}$

2.1.4. Hydrogen/fluorine 314

$\begin{array}{ll}\text { 2.1.5. Nitric oxide/ozone } & 314\end{array}$

2.1.6. Acid/base

$\begin{array}{ll}\text { 2.1.7. Nitrogen tetroxide dissociation } & 315\end{array}$

2.2. Flow Definition 315

$\begin{array}{ll}2.2 .1 \text {. Initial conditions } & 316\end{array}$

2.2.2. Boundary conditions 318

$\begin{array}{ll}\text { 2.3. Buoyancy } & 319\end{array}$

2.4. Averages 320

2.4.1. Velocity 320

2.4.2. Temperature 321

2.4.3. Other scalar properties

2.5. Visualization 323

2.6. Conservation checks

3. Available Experimental Data

3.1. Round free jets 324

3.1.1. University of Sydney studies

3.1.2. General Electric studies

3.1.3. Sandia studies 325

3.1.4. University of Osaka studies

3.1.5. Other studies 335

3.2. Plane free shear layers 336

3.2.1. Cal. Tech. studies 336

3.2.2. Other studies

3.3. Wall boundary layers 337

4. Concluding Remarks 337

5. Additional Data Needs

References

Appendix A-Recommended Format for Data Base Documentation 341

Appendix B-Example Case Study

\section{NOMENCLATURE}

a acceleration of gravity

jet diameter

D mass diffusivity, jet diameter

$f$ mixture fraction 


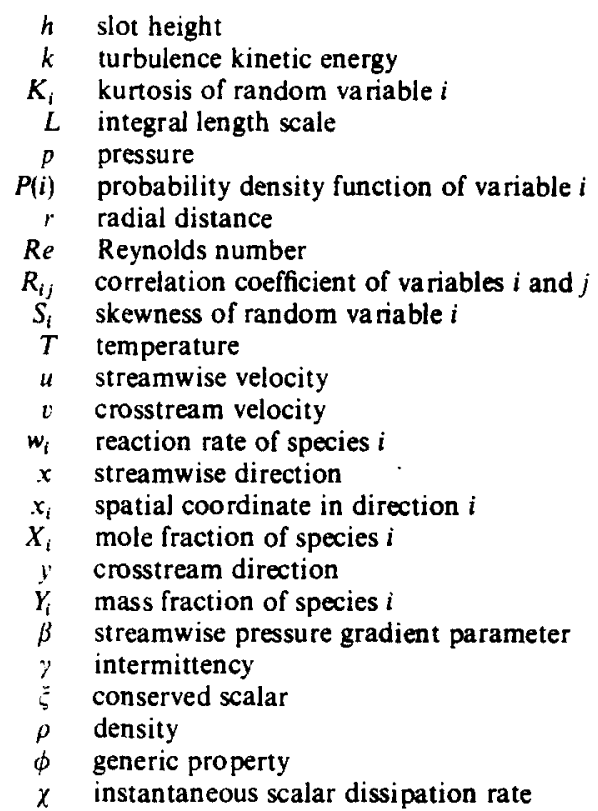

\section{INTRODUCTION}

Burke and Schuman ${ }^{1}$ were among the first to recognize that nonpremixed flames, or other nonpremixed reaction processes, could often be understood without detailed consideration of chemical kinetics. They defined the fast-reacting nonpremixed combustion limit, for classical diffusion flame, where reaction occurs only at a thin flame sheet. At this limit, reaction rates are fast and reactant concentrations are negligible in the flame sheet; therefore, overall rates of reaction and the position of the flame sheet can be found from transport principles alone. Subsequent work has demonstrated the practical utility of this concept, even for complex processes like tubulent fiames.

Consideration of flows at the fast-reacting nonpremixed combustion limit is a logical first step in the evaluation of methods proposed for analyzing tubulent reacting flow. At this limit, the reacting flow is only a modest extension of passive turbulent mixing; the main difference being the energy release at the flame sheet and the accompanying changes of scalar properties, e.g., density, temperature, composition, etc. The objective of this paper is to review past measurements of fast-reacting nonpremixed turbulent reaction processes in order to highlight data bases most suitable for evaluation of theories of turbulent reacting flow. Recommendations are also made concerning measurements that are needed for more definitive evaluation of analysis. Other papers in this series, by Gouldin et al., ${ }^{2}$ Drake and Kollmann, ${ }^{3}$ and Libby et al. ${ }^{4}$ have similar objectives for passive mixing, slow-reaction nonpremixed combustion and premixed combustion, respectively.

We take a broad definition of fast-reacting nonpremixed turbulent combustion processes. Turbulent

\section{Subscripts}

$\begin{aligned} c & \text { centerline } \\ e & \text { free stream } \\ f & \text { flame tip } \\ j & \text { jet or slot exit } \\ \max & \text { maximum value } \\ n & \text { nonturbulent fluid } \\ t & \text { turbulent fluid } \\ w & \text { wall exit } \\ 0 & \text { flow axis or plane of symmetry }\end{aligned}$

Superscripts

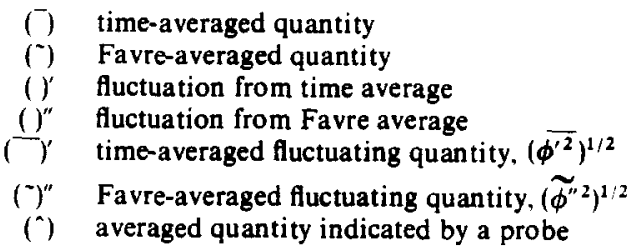

reaction processes are considered where chemical transformation is mixing controlled and local thermodynamic equilbrium is maintained (within experimental uncertainties) for major species and temperature. Thus we consider acid/base reactions in liquids, where effects of energy release are small; as well as gaseous diffusion flames, where free radicals and other trace species can be influenced by finiterate chemistry, even though the major species are often nearly in thermodynamic equilibrium. Reactant combinations in the latter category include hydrogen/air, hydrogen/fluorine, carbon monoxide/ air, nitric oxide/ozone and the dissociation of nitrogen tetroxide in warm air.

Similarly to the other papers in this series, ${ }^{2-4}$ attention has been limited to stationary turbulent flows (flows which are independent of time in the mean) which can be analyzed using a parabolic formulation of the governing equations (flows which satisfy the boundary layer approximations). For convenience, these flows are grouped into three categories, as follows: (1) round free jets, (2) plane free shear layers, and (3) wall boundary layers. Past measurements, however, have largely emphasized the round free jet configuration.

The paper begins with a general discussion of the properties of experiments involving fast-reacting nonpremixed turbulent combustion. This includes an operational definition of the fast-reaction limit, measured properties needed to properly define flows for evaluation of analysis, and the characteristics of various measurement techniques. The present discussion of measurement techniques is brief and primarily considers methods having particular interest for nonpremixed flows. Using principles developed in the section on experimental considerations, the experiments themselves are discussed. The objec- 
tive is not to discuss the physics and chemistry disclosed by the experiments; original sources serve best for this purpose. Rather, our intent is to determine available data bases which are most appropriate for evaluation of analysis at the fastreaction limit. The paper concludes with recommendations concerning existing measurements which are best suited for evaluation of analysis, suggestions for additional measurements, and use of a format for data base documentation.

\section{EXPERIMENTAL CONSIDERATIONS}

The general properties of experiments concerning fast-reacting nonpremixed turbulent combustion processes are discussed in this section, prior to describing the measurements themselves in the next. The objective is to point out properties of experiments which make them particularly suitable for evaluation of analysis. In doing this, we do not attempt to anticipate the kind of analysis to be evaluated, aside from the general limitation to stationary parabolic (in the mean) flows. Our view is that any practical analysis should yield information concerning operational properties of the process, i.e. those properties which can be measured in a welldefined manner. Therefore, we concentrate on the operational definition of the fast-reaction limit; the effect of potentially uncontrolled, or unreported, variables on flow properties; and the properties of measurements that have been made in the past.

\subsection{Fast-Reaction Criteria}

In this section, the present definition of the fastreaction limit is described. This is followed by an application of this definition to several reactant combinations that have been considered during past measurements.

The fast-reaction limit of nonpremixed combustion is reached when characteristic transport times of mass diffusion, thermal diffusion, and convection are large in comparison to all characteristic times of reactions in the chemical transformation mechanism. In this case, instantaneous thermodynamic equilibrium is maintained at each point in the flow and scalar properties are fixed by diffusion processes at the molecular level. The simplest realization of this limit occurs when chemical conversion only occurs in a reaction (or flame) sheet which is thin in comparison to other length scales of the process. For flames, this thin-flame limit is generally confined to cases where the activation energies of all relevant reactions are large.

No real nonpremixed reaction or combustion process satisfies the above prescription of the fastreaction limit for all species in all regions of the flow. Exceptions occur near regions of flame attachment, possibly throughout the flow for free radicals and other trace species (often pollutants), as well as the conventional exception when characteristics diffusion times become comparable to chemical times in a highly turbulent flow. Points of flame attachment fundamentally involve comparable transport and chemical times; therefore, the reaction zone is thick in comparison to local length scales and the full complexity of turbulent reaction processes must be considered. Naturally, all experiments have such a region; however, this zone is assumed to be small and measurements within it are excluded from consideration, for present purposes.

If measurements were excluded due to loss of local equilibrium for free radicals and trace species, there would be few, if any, candidate data bases for the fast-reaction limit. The major problem is that threebody recombination reactions of free radicals are often relatively slow and have low activation energies. This leads to superequilibrium of free radicals and relatively thick zones where their rates of reaction are significant in most flames. Nevertheless, these processes often have only a minor influence on the structure of the flow and with some lack of rigor we choose to ignore them in order to preserve the convenience of the fast-reaction limit. Thus, for present purposes, conditions where only major species (reactants and products) approach local equilibrium are accepted as part of the fast-reaction limit.

Given local thermodynamic equilibrium as a criterion for the fast-reaction limit, the next problem is to define an operational method for estimating when this limit is satisfied. Analysis provides one approach. Given information on turbulence scales, estimates of diffusion and convection times can be made. However, estimating characteristic chemical times is more difficult. First of all, a complex mechanism is usually involved, and not all reaction steps are well known. Next, nonpremixed combustion processes always involve local variations in the concentrations of elements, yielding a range of reaction conditions which only detailed analysis can resolve.

Activation energy asymptotics, along the lines discussed by Buckmaster and Ludford, ${ }^{5}$ and references cited therein, provide one means of treating changes in the local concentrations of elements within the flame sheet formalism, when examining conditions for the fast-reaction limit. However, this is often not appropriate for the processes which are the main issue, e.g. low activation energy reactions of three-body free radical recombination reactions. In such circumstances, perturbation methods or complete solution of the chemical mechanism offer alternatives. ${ }^{6}$ Some examples of the latter will be considered in the following.

Examination of conditions where the fast-reaction limit is appropriate is vastly simplified when conditions approximate the requirements of the conserved-scalar formalism described by Bilger. ${ }^{7,8}$ This implies that there are only two reactant streams 
(fuel-contained and oxidant containing); that flow velocities are low, so that the kinetic energy and viscous dissipation of the mean flow can be ignored; that the exchange coefficients of all species and heat (if appropriate) are the same; that energy exchange between elements of the flow by radiation is negligible; and that instantaneous local thermodynamic equilibrium is maintained. Then, all instantaneous scalar properties are only a function of the degree of mixing of the two streams. The degree of mixing can be represented by a number of parameters, the mixture fraction (the fraction of mass originating from the fuel stream) is a common choice. Relaxation of any of these approximations requires additional parameters to specify the local state of the flow, e.g. three reactant streams would require two mixture-fraction parameters to specify the state of mixing.

The type of failure of the conserved scalar formalism of greatest interest here involves loss of local thermodynamic equilibrium. The effect of turbulent mixing on thermodynamic equilibrium can be conveniently examined using an approach described by Bilger ${ }^{8}$ and Liew et al. ${ }^{9-11}$ First of all, we assume that the mass fraction of species $i, Y_{\mathrm{i}}$, is solely a function of the conserved scalar, $\xi$, e.g.

$$
Y_{i}=Y_{i}(\xi)
$$

Then the equation for conservation of $i$ can be written as follows ${ }^{8}$

$$
1 / 2 \rho \chi\left(\mathrm{d}^{2} Y_{i} / \mathrm{d} \xi^{2}\right)=-w_{i}
$$

where

$$
\chi=2 D\left(\partial \xi / \partial x_{k}\right)^{2}
$$

In a turbulent flow, $\chi$ is the scalar dissipation rate. This parameter reflects effects of flame stretch which lead to locally high values of $\chi$ and a tendency to depart from conditions of local thermodynamic equilibrium.

Computations of Liew et al. ${ }^{10}$ directly show the effect of flame stretch on approach to thermodynamic equilibrium. They consider laminar methane/ air diffusion flames, using a chemical reaction mechanism involving 38 reactions for 16 species developed from the mechanism proposed by Hahn and Wendt. ${ }^{12}$ The laminar flame is progressively stretched, parametrically considering maximum values of the scalar dissipation rate, $\chi_{\max }$, in the range $0-99 \sec ^{-1}$. Results of these calculations are illustrated in Fig. 1. For low values of $\chi_{\max }$, the profiles are nearly universal and the hypothesis that $Y_{i}=Y_{i}(\xi)$ is satisfied. As $\chi_{\max }$ increases, however, it exerts a greater influence on scalar properties, eventually causing the flame to extinguish. A measure of the approach to thermodynamic equilibrium can then be obtained by comparing $Y_{i}(\xi)$ from the finite-rate analysis with direct computations, using an equilibrium code such as Gordon and McBride, ${ }^{13}$ for various values of $\xi$ and the same inlet stream conditions.

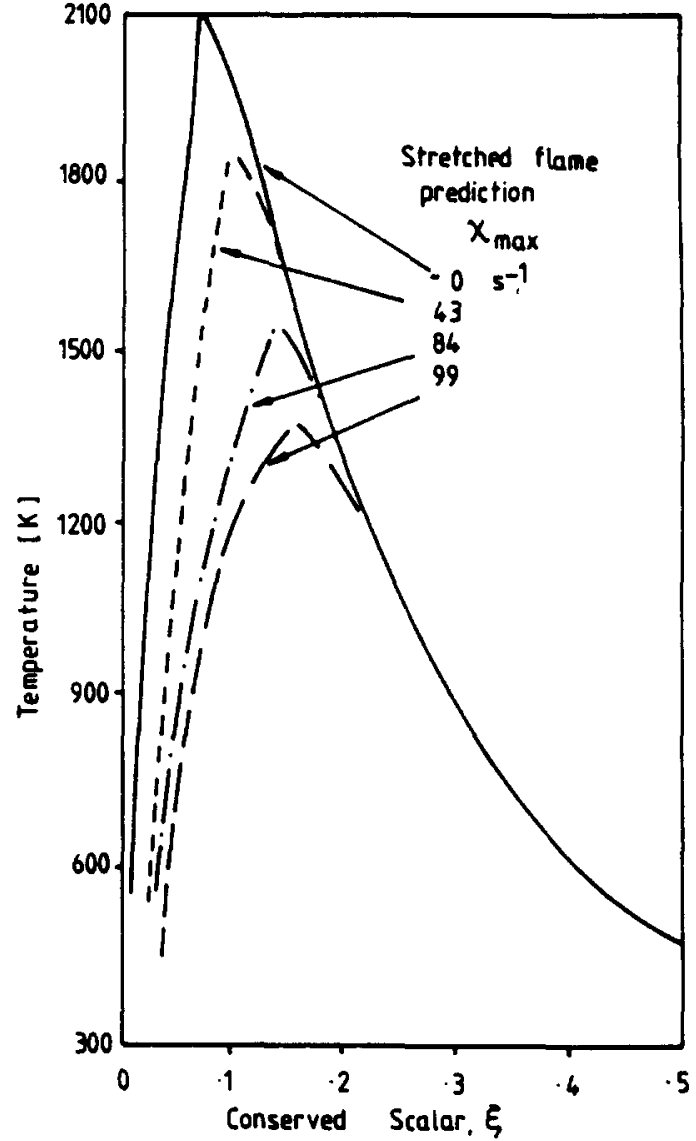

FIG. 1. Variation of temperature with the conserved scalar, $\xi$, for stretched methane/air diffusion flames. From Liew et al. ${ }^{10}$

Knowledge of mechanisms and rates are often not adequate for an analytical assessment of the fastreaction limit. More direct methods involving measurements in laminar and turbulent flames then provide an alternative. Laminar flames generally have a spatial variation of $\chi$; therefore, direct measurement of scalar properties in laminar flames can provide a test of the degree to which local equilibrium is approached for this range of $\chi$. In fact, this is the basis for the laminar flamelet concept of Bilger ${ }^{8}$ and Liew et al. ${ }^{9}$ They observe that plots of scalar properties as a function of $\xi$ frequently are nearly universal functions, even when local thermodynamic equilibrium is not maintained. However, by the present criterion for the fast-reaction limit, nonequilibrium situations would not be considered, even if they exhibited universality in $\xi$ coordinates.

A more convincing alternative for establishing conditions at the fast-reaction limit is to directly measure instantaneous scalar properties, sufficient to evaluate $\xi$, in the turbulent flow. This generally requires advanced experimental techniques, since information on mixing levels requires measurement of the concentrations of several species. Work along these lines, however, is beginning to appear, e.g. 


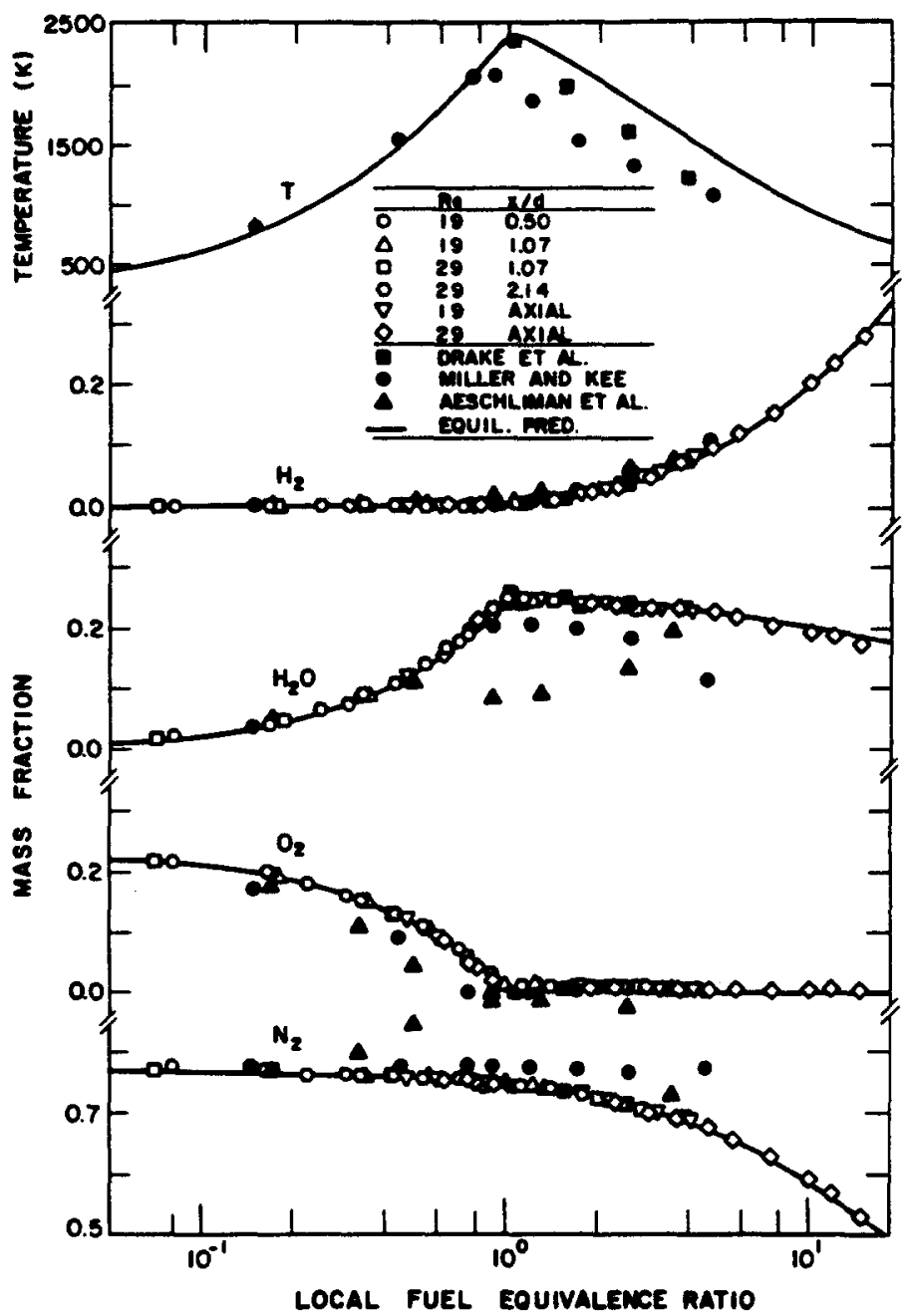

FIG. 2. State relationships for hydrogen/air diffusion flames. From Gore et al. ${ }^{31}$

Drake and coworkers ${ }^{14-20}$ and Dibble and coworkers. $^{21-30}$

In the following, several reactant combinations will be examined to see if they satisfy the criterion for the fast reaction limit, as follows: hydrogen/air, carbon monoxide/air, hydrocarbon/air, hydrogen/ fluorine, nitric oxide/ozone, acid/base, and nitrogen tetroxide dissociation.

\subsubsection{Hydrogen/air}

It is commonly thought that hydrogen oxidation kinetics are fast in comparison to transport processes in subsonic flows; therefore, hydrogen/air flames are logical candidates for study at the fast-reaction limit. Evidence both supporting this view and suggesting some limitations will be discussed in the following.

Figure 2 is an illustration of species concentrations and temperatures in several hydrogen/air diffusion flames plotted as a function of a conserved scalar (fuel-equivalence ratio). Measurements include results obtained at various points in laminar diffusion flames, ${ }^{31.32}$ and in turbulent diffusion flames at locations remote from the point of attachment. ${ }^{15.18^{4}}$ Two sets of predictions are shown, one considering finite-rate chemistry for $R e<100$ by Miller and $\mathrm{Kee},{ }^{33}$ the other based on local adiabatic equilibrium using the Gordon and $\mathrm{McBride}{ }^{13}$ computer code (CEC 76 Version). The laminar and turbulent experimental results of Gore et al. ${ }^{31}$ and Drake et al. ${ }^{15.17}$ exhibit close approach to thermodynamic equilibrium for major gas species, suggesting a relatively wide range of conditions where the criterion for the fast-reaction limit is satisfied. Equilibrium of temperature is not as well supported; this will be discussed subsequently. The earlier results of Aeschliman et al. ${ }^{32}$ and Miller and $\mathrm{Kee}^{33}$ also show significant departure from equilibrium. The reasons for this behavior are not known, but could be caused by differential diffusion which is a particular problem for this flame system due to the low molecular weight of hydrogen, e.g. another mixing

+The effect of position will be quantified later. 


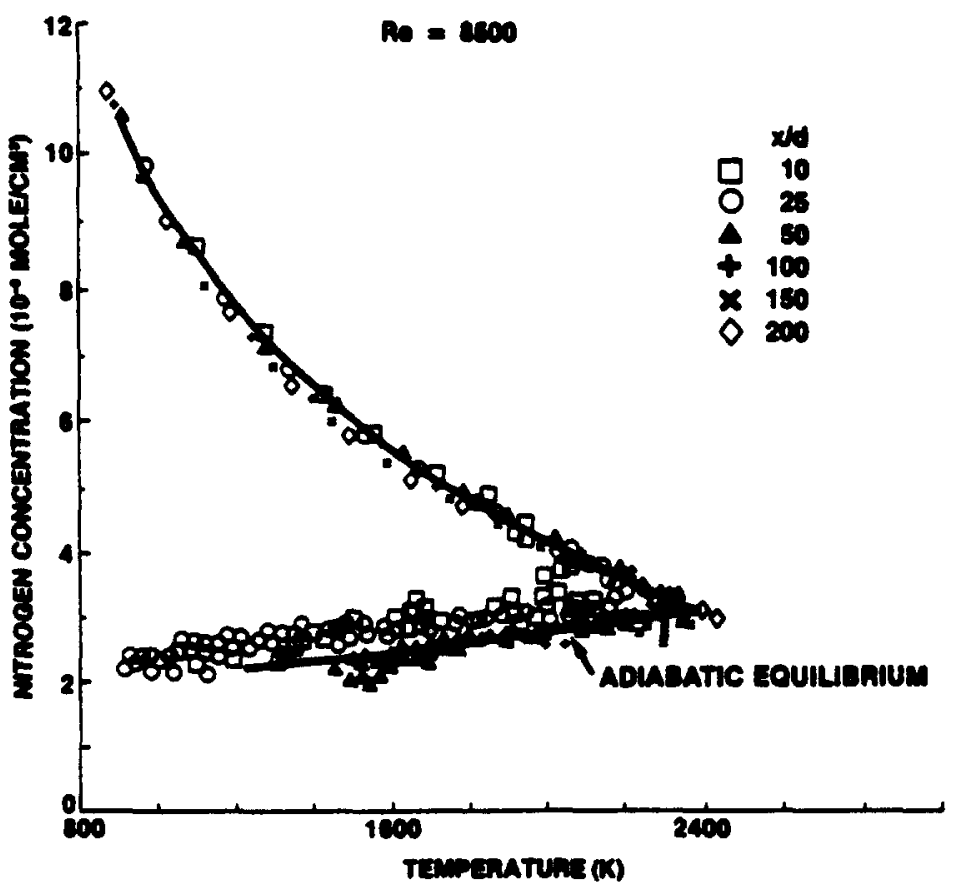

Fig. 3. Correlation of average values of nitrogen concentration and temperature at various streamwise positions in a coflowing turbulent hydrogen/air jet diffusion flame $\left(R e_{j}=8500\right)$. From Drake et al. ${ }^{18}$

parameter may be needed to properly represent all these results.

The effect of position on approach to local thermodynamic equilibrium can be seen from the results appearing in Fig. 3. Measurements of Drake et al., ${ }^{8}$ using Raman spectroscopy, for turbulent hydrogen jet flames in coflowing air are shown. Instantaneous temperature is plotted as a function of instantaneous nitrogen concentration-the latter representing a single-valued measure of the degree of mixing between the two reactant streams. The upper and lower portions of the figure, separated by the discontinuity at the maximum temperature position, represent lean and rich conditions. Results for lean conditions are relatively independent of position and agree with equilibrium predictions--satisfying the fast-reaction criterion and suggesting that effects of radiative heat losses from this flame are small. Results for near-stoichiometric and rich conditions, however, depart from equilibrium predictions near the injector and only satisfy the fast-reaction criterion for $x / d>50$.

Drake et al. ${ }^{18}$ attribute the reduced temperature levels near the injector, seen in Fig. 3, to finite-rate chemistry, e.g. superequilibrium of free radical concentrations. For example, they find that $\mathrm{OH}$ concentrations on the order of 2.5 times the equilibrium values are sufficient to explain the discrepancy between measured and equilibrium temperatures ( $c a$ $270 \mathrm{~K}$ ) at $x / d=10$. Direct measurements of $\mathrm{OH}$ concentration using laser saturated fluorescence, by Drake et al., ${ }^{19}$ support this view. Figure 4 is an illustration of measured $\mathrm{OH}$ concentrations along with thermodynamic equilibrium predictions based on the measured mixture fraction. A significant degree of $\mathrm{OH}$ superequilibrium is evident, but with a progressive decline of $\mathrm{OH}$ superequilibrium with increasing distance from the injector. However, superequilibrium levels are still on the order of $20 \%$

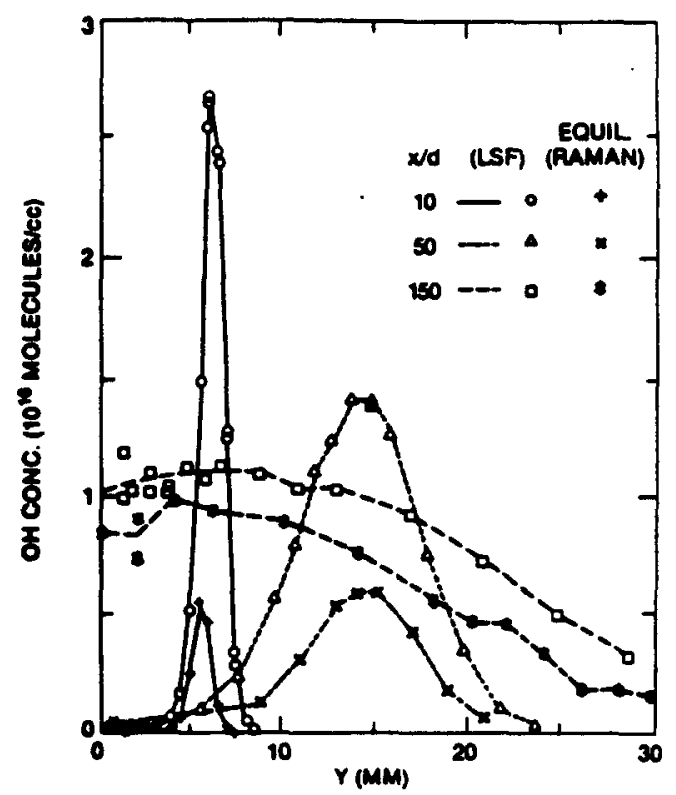

FIG. 4. Radial profiles of $\mathrm{OH}$ concentrations in a coflowing turbulent hydrogen/air jet diffusion flame $\left(R e_{j}=8500\right)$. From Drake et al. ${ }^{19}$ 
at $x / d=150$. Even though $\mathrm{OH}$ concentrations are small in comparison to major species, its presence has a significant effect on temperature due to its high enthalpy of formation. Naturally, these effects are greater for higher Reynolds numbers, using this jet diameter, as well as for the smaller length scales corresponding to smaller burner diameters.

Considering the effect of Reynolds number, highlights another problem with hydrogen/air diffusion flames. Some representative measurements, due to Drake et al. ${ }^{18}$ are illustrated in Fig. 5. Instantaneous temperature is plotted as a function of nitrogen concentration, which is taken to be the measure of mixing. The data were obtained at $x / d=50$ for jet Reynolds numbers of 1600,5200 and 8500 . Adiabatic equilibrium predictions and the finite-rate chemistry predictions of Miller and $\mathrm{Kee},{ }^{33}$ for $\mathrm{Re} \leq 100$, are also shown on the figure. Once again, lean conditions nearly satisfy equilibrium requirements. However, results at rich conditions show a progressive departure from equilibrium predictions toward the low Reynolds number estimates of Miller and $\mathrm{Kee}^{33}$ as the jet Reynolds number is reduced. This trend cannot be explained by finite-rate chemistry, since lower Reynolds numbers should provide operation closer to local equilibrium. Instead, effects of differential diffusion, described by Bilger, ${ }^{6}$ provide an explanation. At low Reynolds numbers, molecular transport becomes significant in comparison to turbulent transport; therefore, the unusually high molecuiar mass diffusivity of hydrogen in comparison to other species in the system influences the mixing. It is not known whether local equilibrium is still satisfied for the modified proportions of elements from the initial streams. The results illustrated in Fig. 3 suggest that this might be the case. In any event, proper treatment of differential diffusion, even at the fast-reaction limit, would require consideration of laminar transport effects that are generally ignored when the popular conserved-scalar formalism is used, cf., Lockwood and Naguib ${ }^{34}$ and Bilger $^{6}$

When assessing measurements, effects of differential diffusion will not be used as a basis for recommendations. Complete analysis at the fastreaction limit should be able to treat the phenomenon. However, the desirability of minimizing effects of laminar/turbulent transition and buoyancy in the flow field precludes most low Reynolds number measurements where differential diffusion is a problem. We conclude that the hydrogen/air diffusion flame results are representative of the fast-reaction limit with respect to major species and temperature, within experimental uncertainties typical of current practice.

\subsubsection{Carbon monoxide/air}

The diffusion coefficients of major gas species are more similar for carbon monoxide/air than for hydrogen/air diffusion flames, reducing difficulties due to differential diffusion. However, carbon monoxide oxidation is not generally thought to be fast in comparison to transport processes in flames. For example, several approximate finite-rate chemistry models for hydrocarbons specifically consider

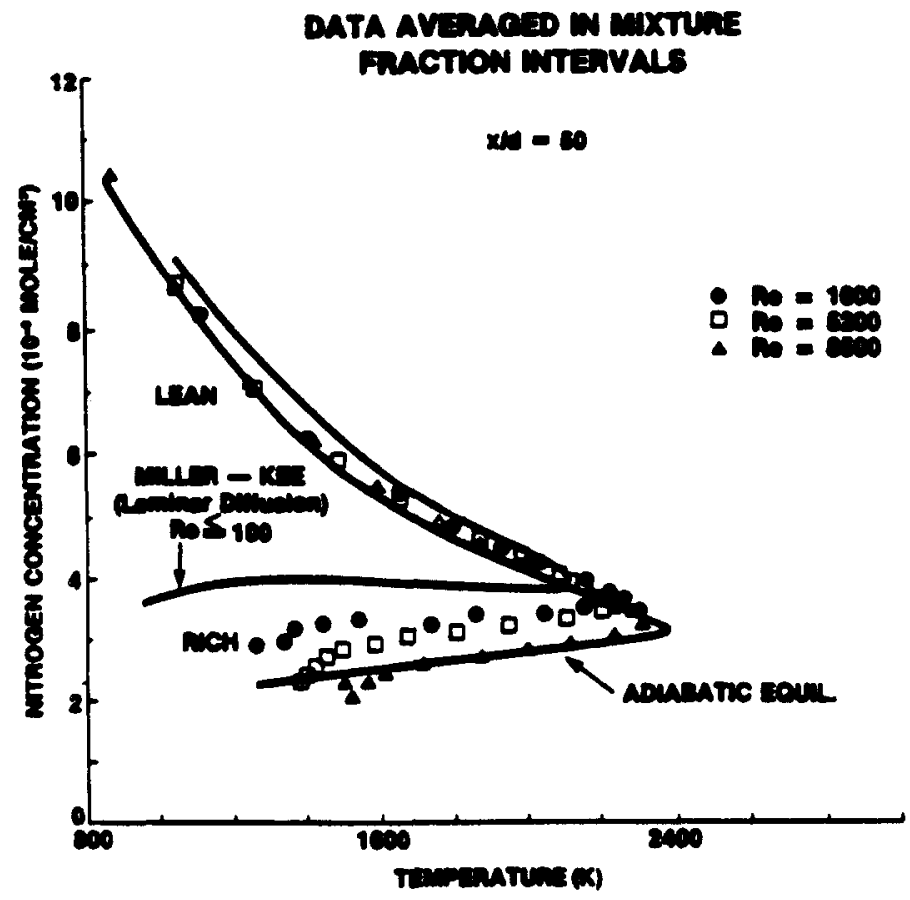

Fig. 5. Correlation of average values of nitrogen concentration and temperature at $x / d=50$ for coflowing turbulent hydrogen/air jet diffusion flames. From Drake et al. ${ }^{18}$ 
$\mathrm{CO}$ oxidation while assuming $\mathrm{H}_{2}$ oxidation is fast by comparison, e.g. Edelman and Fortune, ${ }^{35}$ and Westbrook and Dryer. ${ }^{36}$

Although oxidation of dry carbon monoxide is slow, the presence of trace amounts of hydrogen yields a wet oxidation mechanism which is reasonably fast. ${ }^{37}$ Most practical carbon monoxide supplies for turbulent flame experiments contain some hydrogen as a contaminant; therefore, there is evidence that carbon monoxide/air diffusion flames can approach the fast-reaction limit in the laboratory. Measurements of species concentrations and temperatures in laminar carbon monoxide (containing $1.12 \%$ hydrogen by volume)/air diffusion flames, by Gore et al., ${ }^{38}$ are illustrated in Figs 6 and 7 . The degree of mixing is represented by the fuel equivalence ratio (based on measured carbon and oxygen element concentrations). Predictions from the Gordon and McBride ${ }^{13}$ program (CEC 76 Version) are also shown on the figure. These were obtained assuming adiabatic equilibrium but omitting solid carbon as a potential substance in the system for fuelrich conditions.

For the conditions of Figs 6 and 7, the concentrations of major species do not depart very significantly from equilibrium predictions, supporting operation at the fast-reaction limit. Results are less satisfactory for temperature, but these flames are known to lose roughly $20 \%$ of their chemical energy release by radiation. Furthermore, temperature measurements were not corrected for errors due to thermocouple radiation. These radiation effects are sufficient to explain the discrepancies between equilibrium temperature predictions and measurements in Fig. 6.

Gore et $a .^{38}$ and Razdan and Stevens ${ }^{39}$ report measurements in a turbulent carbon monoxide/air diffusion flame. Gore et al., ${ }^{38}$ find that these measurements are consistent with the near equilibrium results of Figs 6 and 7; thus, the measurements are potentially representative of the fastreaction limit. Unfortunately, more definitive assessment directly in the turbulent flame, analogous to the results for hydrogen/air diffusion flames, is not available. Based on current evidence, we conclude that existing measurements for these flames are representative of the fast-reaction limit, within experimental uncertainty.

\subsubsection{Hydrocarbon/air}

Measurements in a variety of laminar hydrocarbon/air flames have been assessed during development of the laminar flamelet concept. This includes

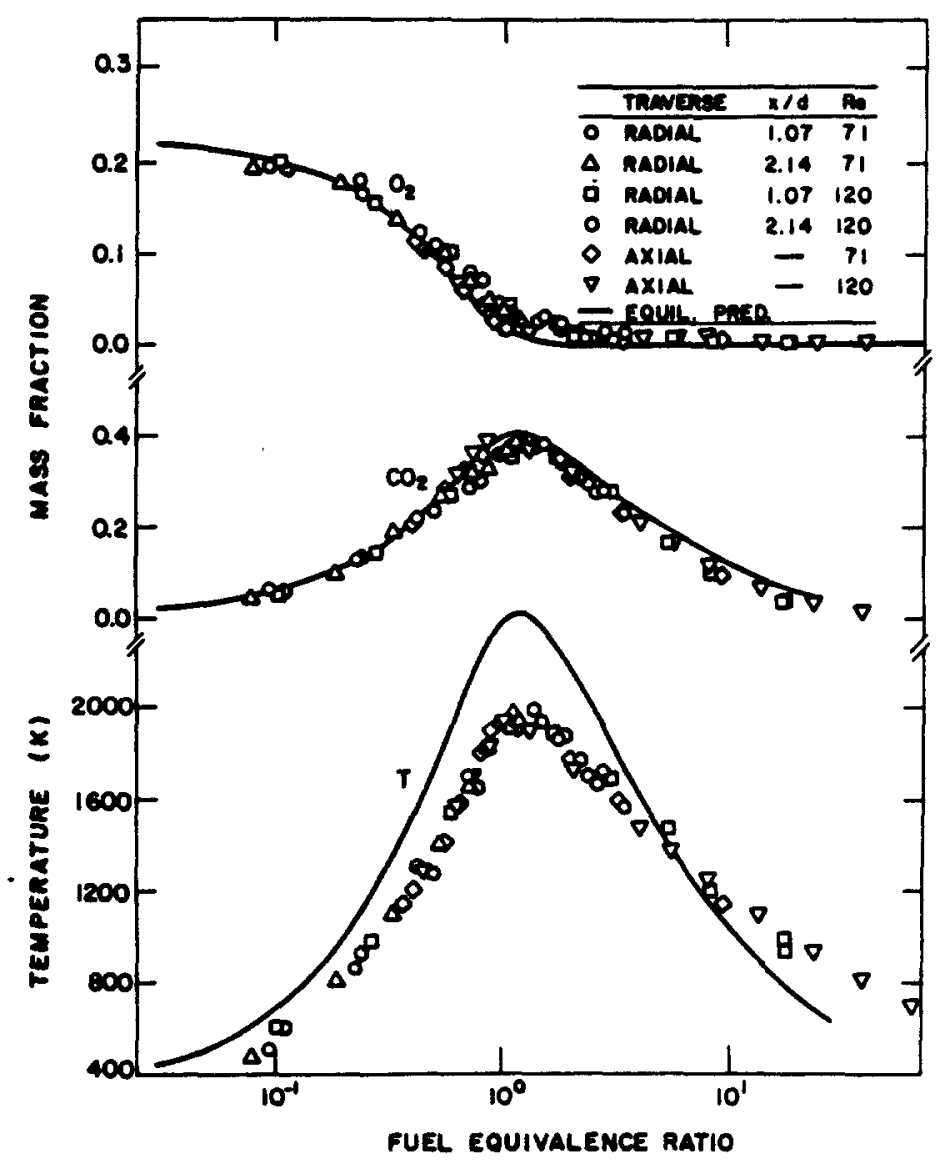

FIG. 6. State relationships for carbon monoxide/air diffusion flames. From Gore et al. ${ }^{38}$ 


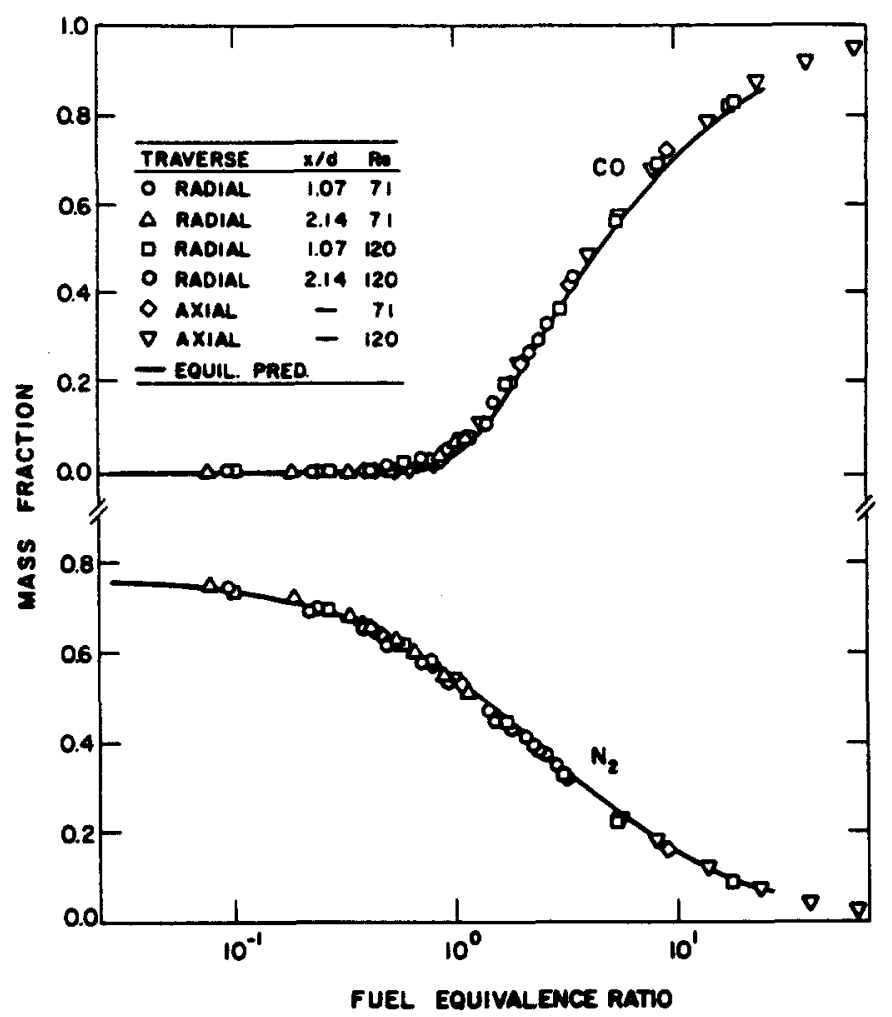

FIG. 7. State relationships for carbon monoxide/air diffusion flames (continued). From Gore et al. ${ }^{38}$

measurements in methane/air diffusion flames by Tsuji and Yamaoka, ${ }^{40-42}$ and for $n$-heptane/air diffusion flames by Abdel-Khalek et al., ${ }^{43}$ discussed by Bilger ${ }^{8}$; measurements in methane/air and propane/ air diffusion flames, discussed by Jeng and Faeth ${ }^{44.45}$ and Liew et al.,9.10 and measurements in ethylene/air diffusion flames, by Gore and Faeth. ${ }^{46}$

Hydrocarbon/air diffusion flames yield similar results when considered for the fast-reaction limit.
Representative findings for ethylene/air diffusion flames are illustrated in Figs 8 and 9. Concentrations of major gas species are plotted as a function of local fuel-equivalence ratio for various positions and conditions within laminar diffusion flames. Predictions, assuming local adiabatic equilibrium, are also shown on the plots. Similar to the cases considered earlier, properties approach thermodynamic equilibrium for lean conditions. Further-

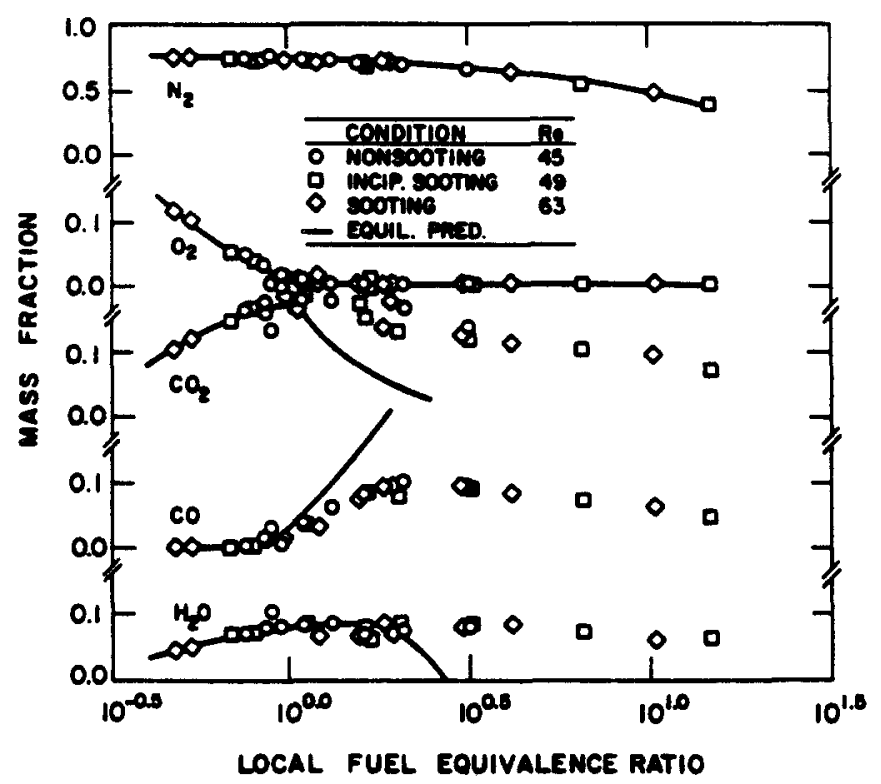

FIG. 8. State relationships for ethylene/air diffusion flames. From Gore and Faeth. ${ }^{46}$ 


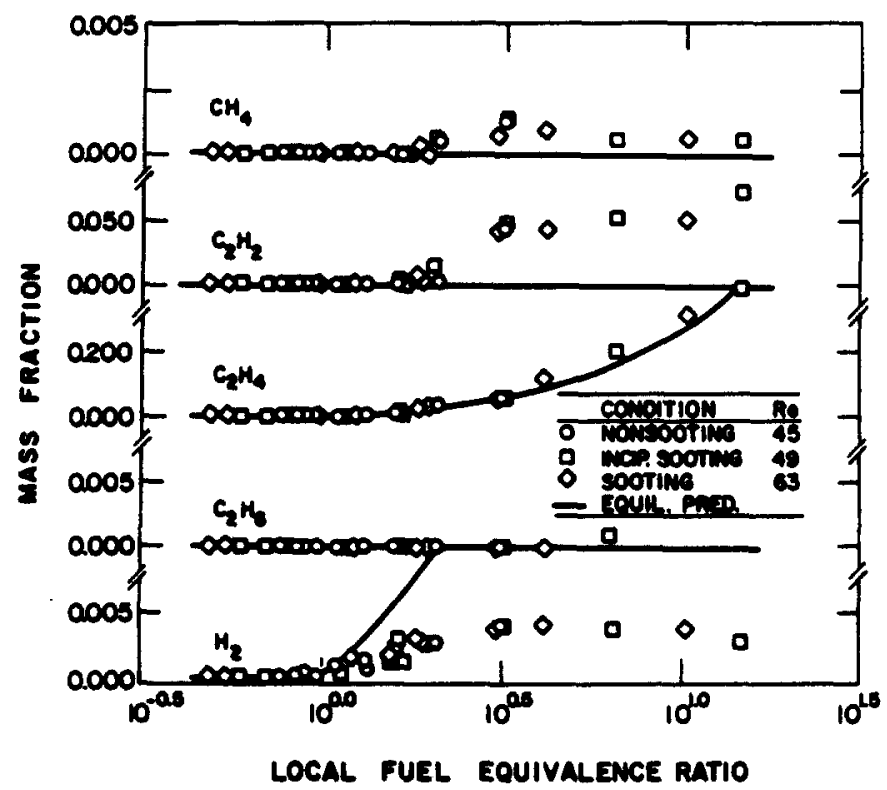

Fig. 9. State relationships for ethylene/air diffusion flames (continued). From Gore and Faeth. ${ }^{46}$

more, concentrations of $\mathrm{O}_{2}, \mathrm{C}_{2} \mathrm{H}_{4}$ and nitrogen roughly approximate equilibrium over the full range considered. However, concentrations of major product species, $\mathrm{CO}_{2}, \mathrm{CO}$ and $\mathrm{H}_{2} \mathrm{O}$, depart appreciably from equilibrium for fuel-rich conditions. While these major product species roughly follow universal correlations in terms of the conserved scalar, satisfying the laminar flamelet concept for this range of $\chi$, this type of quasi-equilibrium depends on finiterate chemistry effects. Furthermore, even quasiequilibrium is less evident for minor species. Thus, hydrocarbon flame systems do not satisfy the present criterion for the fast-reaction limit. Instead, they are considered by Drake and Kollmann ${ }^{3}$ along with other slow-reacting turbulent combustion processes.

\subsubsection{Hydrogen/fluorine}

Hydrogen/fluorine diffusion flames, with dilute reactants in inert gases, have been studied in a series of investigations at Cal. Tech. ${ }^{4-49}$ Reaction rates for this system are generally fast, but difficulties were still encountered in initiating the reaction at very dilute concentrations. This was resolved by adding trace amounts of nitric oxide to the fluorinecontaining stream.

Mungal $^{47}$ estimates the degree to which his test conditions approach the fast-reaction limit, by comparing characteristic large- and small-scale mixing times with the characteristic chemical reaction time For local fluorine concentrations of $1 \%$, the small-scale mixing time was estimated to be roughly an order of magnitude larger than characteristic reaction times. However, free-stream fluorine concentrations were only $1-2 \%$, and are necessarily much lower in the reaction zone itself; therefore, these computations are not a very convincing demonstration that the fast-reaction limit was reached.

\subsubsection{Nitric oxide/ozone}

Wallace $^{50}$ considers dilute nitric oxide/ozone diffusion flames with the reactants carried by inert gas flows. In this case, the reactants ignited spontaneously with no additives.

Wallace $^{50}$ estimates large and small scale mixing and chemical reaction times at his measurement location. The chemical and large-scale mixing times were comparable at reactant concentrations on the order of $0.3 \%$, while portions of the data involve free-stream reactant concentrations having the same order of magnitude. Although the spontaneous reaction suggests a high degree of reactivity for these reactants, this assessment is not very convincing evidence that these results approach the fast-reaction limit.

\subsubsection{Acid/base}

Koochesfahani ${ }^{51}$ and Dahm ${ }^{52}$ consider the acid/ base reaction involving dilute sulfuric acid and sodium hydroxide in water. Characteristic large- and small-scale mixing times are compared with the characteristic chemical time based on the lowest freestream reactant concentration. For a plane free shear layer configuration, Koochesfahani ${ }^{51}$ finds ratios of small-scale mixing to chemical times on the order of $10^{2}$ in the region of his measurements. For a round free jet configuration, $\mathrm{Dahm}^{52}$ finds values of this ratio in the range $10^{3 / 2}-10^{7}$. These results suggest reasonable prospects for close approach to the fastreaction limit, even though reaction zone concentrations are lower than free-stream values. These 
experiments, however, involve negligible effects of scalar property changes due to chemical reaction, since the reaction is primarily and indictor of mixing at the molecular level.

\subsubsection{Nitrogen tetroxide dissociation}

Batt $^{53}$ considers a reacting flow which involves dissociation of nitrogen tetroxide, originally in a cool stream, by higher-temperature air in a second stream. The equilibrium reaction is

$$
\mathrm{N}_{2} \mathrm{O}_{4} \Leftrightarrow 2 \mathrm{NO}_{2} \text {. }
$$

In this case, rough estimates suggested that characteristic mixing times were more than an order-ofmagnitude larger than characteristic chemical times. Computations employing a detailed mechanism as well as evidence obtained directly from measurements in the turbulent flow also supported the view that these results corresponded to the fast-reaction limit. $^{53}$

\subsection{Flow Definition}

Spalding ${ }^{54}$ has pointed out that turbulent mixing and reaction processes involve both local and history effects. Thus assessment of turbulent reaction analysis requires consideration of the development of the flow, rather than simply properties at a point. This imposes the need for proper initial and boundary conditions for the analysis. In the following, we examine experimental evidence showing the importance of these effects for turbulent reacting flows.

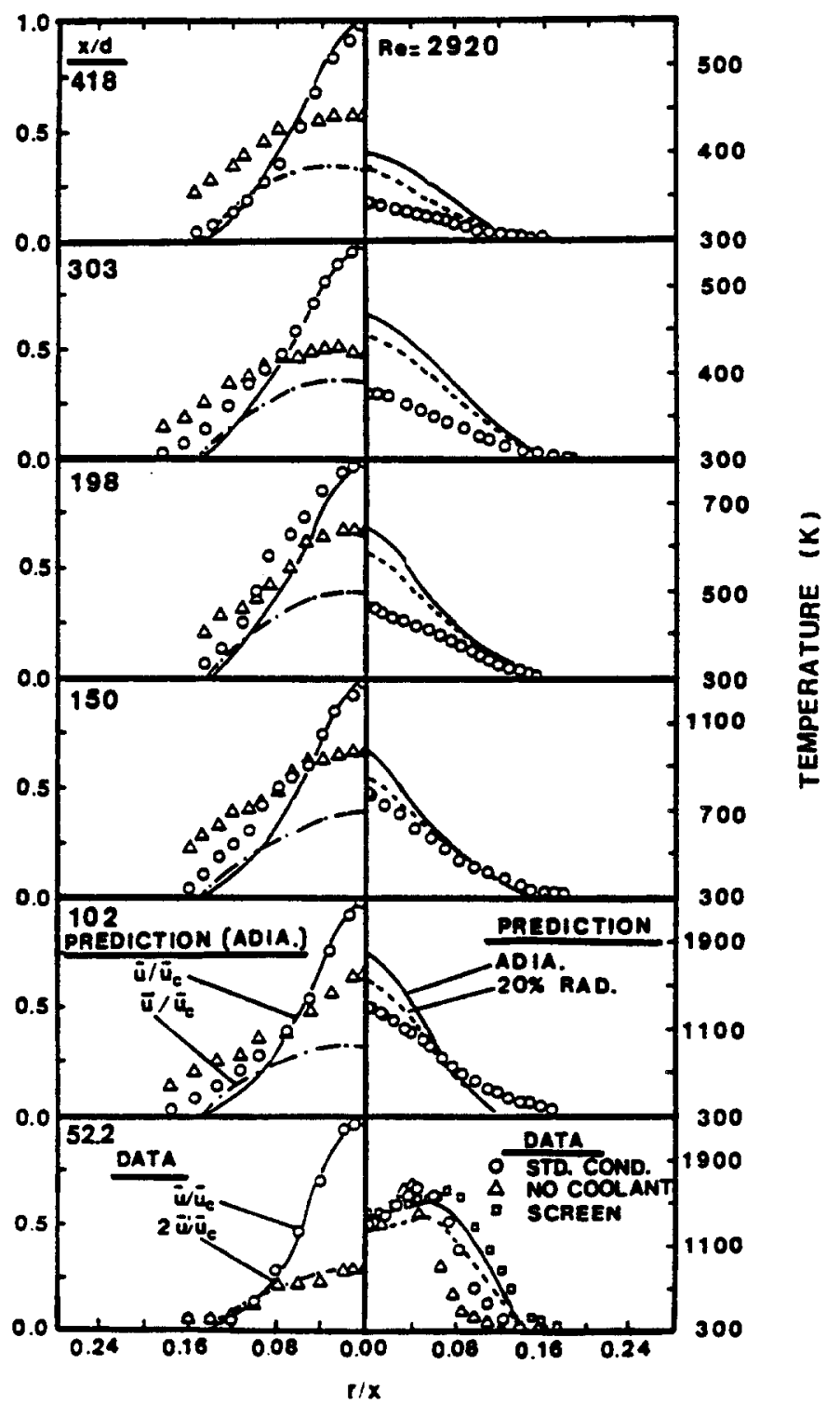

FIG. 10. Effect of initial conditions on the structure of a turbulent nonpremixed flame. From Jeng et al. ${ }^{55}$ 


\subsubsection{Initial conditions}

Initial conditions must be well-defined for all flow streams involved in the nonpremixed combustion process. Very few experiments are reported without some specification of overall average properties of these flows. Distributions of mean and turbulence quantities, however, are often unavailable. These properties can have effects which extend appreciable distances into the flow field; therefore, lack of such information raises questions concerning the use of such measurements for evaluation of turbulent reaction analysis. Experimental evidence demonstrating these effects will be discussed in the following.

Effects of minor changes in burner exit conditions have been measured by Jeng et al. ${ }^{55}$ The tests considered a methane/air round jet diffusion flame, with methane injected vertically upward in still air from a water-cooled bumer (where the cooled burner matched ambient temperatures). Turbulence levels at the burner exit were changed by installing a screen. These changes did not influence mean properties at the jet exit. Installing a screen, however, caused initial values of turbulence kinetic energy to increase by roughly $10 \%$. Without cooling, the burner surface was $32 \mathrm{~K}$ above the ambient temperature, which produced a thermal plume visible in shadowgraphs, placing the flame in a slight coflow.

The effect of these changes on mean temperatures
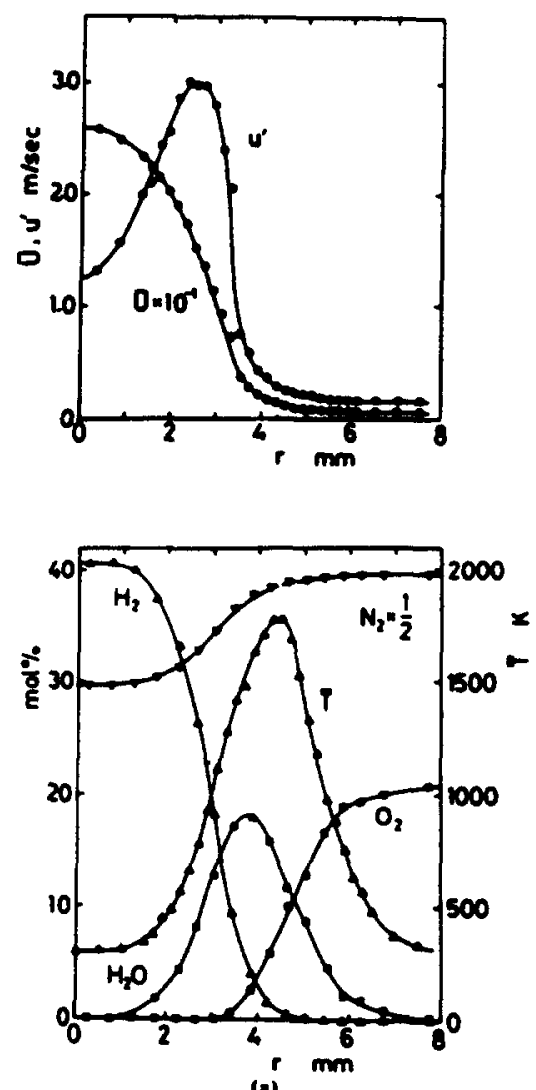

(a)

FIG. 11. Velocity and scalar properties within a hydrogen/nitrogen jet in coflowing air $\left(R e_{j}=4200, x / d=2\right)$ : (a) with flame, (b) without flame. From Takagi et al. ${ }^{56}$ and velocities are illustrated in Fig. 10. These results are for an initial jet Reynolds number of 2920 , with traverses plotted for $x / d=52.2-418$. With coflow present, by ending cooling, the flow predictably becomes narrower. Increasing turbulence levels by installing a screen, however, has an opposite effect which is quite significant in view of the relatively small increase in $k$. These effects were smaller at initial Reynolds numbers of 5850 and 11,700 , but clearly, initial turbulence properties and seemingly minor effects of burner conditions can have a significant effect on flow development.

Costly reactants, problems of flame attachment and approach to the fast-reaction limit, frequently conflict with the desire to provide reasonably high initial Reynolds numbers. In marginal situations, the increased temperature levels in flames causes increases in kinematic viscosities which tends to relaminarize even initially turbulent flows. Takagi et al. ${ }^{56.57}$ report measurements in low Reynolds number flames which exhibit relaminarization. The tests involve hydrogen-nitrogen fuel mixtures $(2 / 3$ volume ratio) injected vertically upward in still air. Turbulence within the jet tube was promoted; therefore, fuily-turbulent conditions were maintained even for tube Reynolds numbers as low as $\mathbf{4 2 0 0}$.

Test results from Takagi et al. ${ }^{56}$ are illustrated in Fig. 11, for a jet Reynolds number of 4200 . Mean and
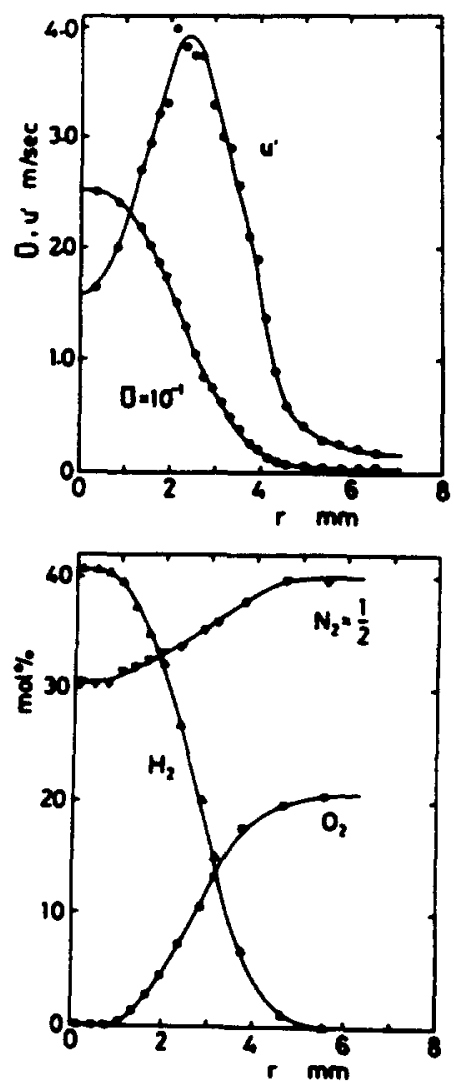

(b) 
fluctuating velocities and mean scalar properties are shown near the jet exit $(x / d \approx 2)$ both with and without a flame present. Even though the mean velocity gradient is somewhat greater when the flame is present, tending to promote production of turbulence, streamwise velocity fluctuations are significantly lower. Furthermore, values of $\overline{u^{\prime}}$ are clearly reduced in the high temperature region of the flame, strongly suggesting relaminarization due to increased viscosity at increased temperature levels. In spite of this, the flaming condition actually yields a wider flow than the inert flow, e.g. shadowgraphs indicate a somewhat bulbous flow near the jet exit for flaming conditions. This appears to be caused by the presence of the high-temperature region near the edge of the flow, causing diffusion of heat into the relatively slow entrainment flow at low Reynolds numbers. Computing these features represents a significant challange; therefore, even accurate knowledge of initial conditions would probably not make this flow a good candidate for evaluation of turbulent reaction models.

Properties of the air stream have similar importance. Numerous authors have pointed out problems of room disturbances for flames in still air-these effects always acting to increase the apparent rate of spread of the flow. Coflowing jets also exhibit effects of upstream boundary layers, cf. Kent and Bilger, ${ }^{58}$ and Stårner and Bilger. ${ }^{59.60}$

A more subtle effect involves the turbulence levels of the air stream. This has not been examined to a great degree for fast-reacting nonpremixed flames, but is well known from studies of noncombusting turbulent flows. A dramatic example is the plane free shear layer studies of Brown and Roshko, ${ }^{61}$ and Chandrasuda et al. ${ }^{62}$ The earlier experiments, involving streams having low turbulence levels, exhibit highly regular turbulent structures in the transitional flow regime, before the mixing transition is reached. In contrast, such structures were not at all evident when the turbulence levels of the streams were increased in the later study of Chandrasuda et al. ${ }^{62}$.

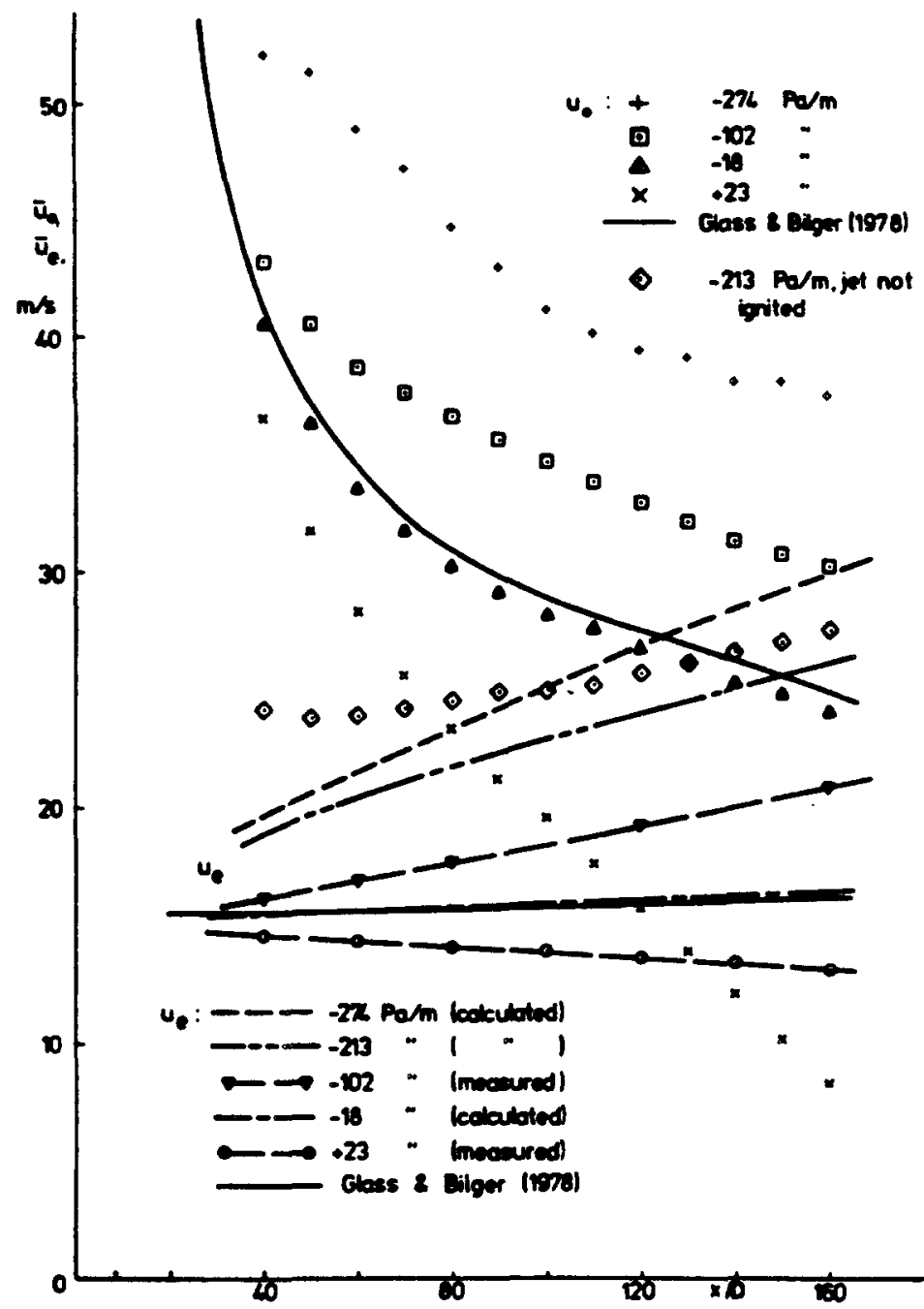

FIG. 12. Mean velocities along the axis of coflowing turbulent hydrogen/air jet diffusion flames as a function of streamwise pressure gradient. From Stårner and Bilger. ${ }^{59}$ Note, $u_{0}$ on this plot denotes centerline velocity. 


\subsubsection{Boundary conditions}

Flows in still environments have readily-defined boundary conditions aside from the difficulties of ambient disturbances noted earlier. Flows in channels, however, introduce effects of streamwise pressure gradients, as well as distortion when the crosssectional area of the flow is changed to control static pressure variations. Both effects will be considered in the following.

Stårner and Bilger $^{59}$ have reported an extensive study of effects of streamwise pressure gradients on a simple turbulent diffusion flame. The test configuration was a hydrogen jet flame in coflowing air within a rectangular duct. Two sides of the duct could be moved so that the average streamwise pressure gradient could be varied to yield values of $-274,-213,-102,-18$ and $+23 \mathrm{~Pa} / \mathrm{m}$. For all these cases, however, there were local variations of $\pm 30 \%$ of these values, due to the development of the flow in the duct. These conditions gave values of the pressure-gradient parameter

$$
\beta=\left(\mathrm{d} / \rho u_{j}^{2}\right)[\mathrm{d} p / \mathrm{d} x]
$$

in the range $(-1.1$ to 0.9$) \times 10^{-3}$.

Mean centerline and free-stream velocities, from Ståmer and Bilger, ${ }^{39}$ are illustrated in Fig. 12. Clearly, these mean velocities are strongly influenced by the streamwise pressure gradient, even for the relatively small values of $\beta$ which were considered. Positive pressure gradients are particularly problematical. For a pressure gradient of $23 \mathrm{~Pa} / \mathrm{m}$, the velocity defect is negative at $x / d=160$, since the lowdensity gas near the axis is rapidly decelerated by the pressure gradient. In fact, evidence for flow separation near the axis was observed farther downstream for this condition.

Effects of mean streamwise pressure gradients on turbulence properties, from Starner and Bilger, ${ }^{59}$ are illustrated in Fig. 13. Streamwise velocity fluctuations along the axis, for different mean streamwise pressure gradients, are illustrated as a function of distance from the jet exit. Again, even small values of $\beta$ cause significant changes in $\overline{u^{\prime}}$, particularly for $x / d>60$. For mean pressure gradients of -109 and $-274 \mathrm{~Pa} / \mathrm{m}, \bar{u}_{0}^{\prime}$ increases for a time for $x / d$ in the range $40-80$. This is probably due to turbulence production by the interaction between the mean pressure gradient and the turbulence. ${ }^{59}$ Similar increases in velocity fluctuations are also observed in vertical buoyant diffusion flames due to hydrostatic pressure variation s. ${ }^{5 s}$ Such effects clearly indicate the need for specification of streamwise pressure gradients in flames. Cases where this phenomenon is significant are also problematical for analysis at present, since such interactions for variable-density flows are not well understood. ${ }^{\top}$

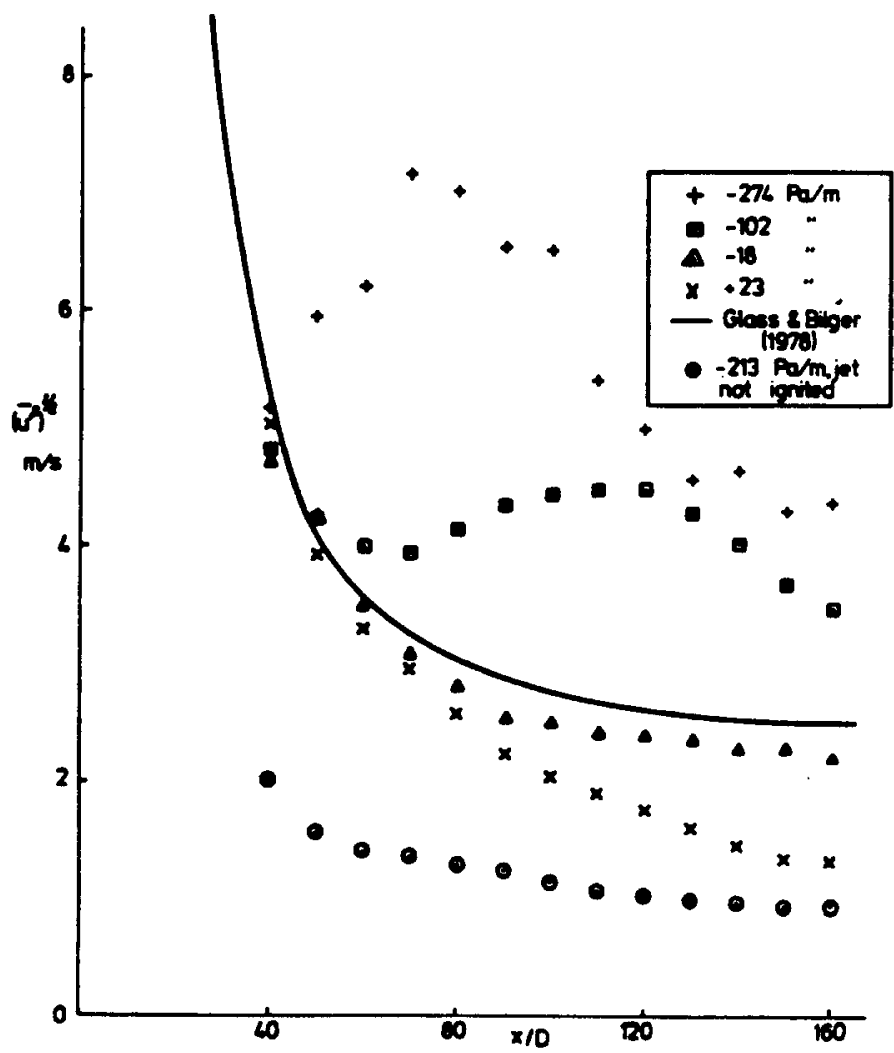

Fig. 13. Streamwise turbulence intensities along the axis of coflowing turbulent hydrogen/air jet diffusion flames as a function of streamwise pressure gradient. From Starner and Bilger. ${ }^{59}$ 
Attempts to control streamwise pressure gradients in ducts generally involve changes in the crosssectional area of the duct. This is frequently accomplished by adjusting the position of two opposite sidewalls. The resulting loss of symmetry distorts ambient velocities and causes elliptical, as opposed to axially-symmetric, profiles. ${ }^{59}$ Most existing measurements in ducts involve only vertical traverses; therefore, the extent of this problem cannot be evaluated without further study.

Similar effect have not been reported for plane shear layers, but differential boundary layer growth and secondary flows can cause distortion as well. The extent of such effects, however, cannot be evaluated from existing documentation.

\subsection{Buoyancy}

The main issue is to evaluate methods for analyzing turbulent reacting flows; therefore, it is desirable to minimize complications of the turbulence structure. Buoyancy represents such an unwanted effect, since current understanding of buoyancy/turbulance interactions in flows having large density variations is very limited.

Becker and coworkers ${ }^{63.64}$ have investigated effects of buoyancy on vertical turbulent diffusion flames in still environments. Using integral theory, they develop a simple method for evaluating effects of buoyancy. The results show that most existing data under these conditions are influenced by buoyancy to some extent, particularly near the tip of the flame. The effect is often not detected when considering only mean properties, although turbulence quantities exhibit significant changes as noted earlier. Such changes in the turbulent environment affect processes of turbulent reaction and must be considered when evaluating analysis of reactive flow.

Numerous measurements of jet flames in coflowing air also involve effects of buoyancy which can limit their value for assessing models of turbulent reaction. Authors generally note gross effects, such as the rise of the flame axis above the geometric cen terline, and avoid operation at conditions where effects of buoyancy dominate. Nevertheless, there are more subtle effects on turbulence properties which are often overlooked.

Recent measurements by Dibble et al. ${ }^{24}$ provide insight concerning effects of buoyancy in horizontal flows. The tests involved hydrogen (containing $22 \%$ Argon on a molar basis) round jet diffusion flames in coflowing air. Initial jet Reynolds numbers were $24,000\left(u_{j}=154 \mathrm{~m} / \mathrm{sec}, u_{c}=8.5 \mathrm{~m} / \mathrm{sec}\right)$; therefore, effects of buoyancy near the injector might be expected to be small. A combined laser Doppler anemometer (LDA)/Rayleigh scattering (RS) system was used to measure velocities, densities and their correlations.

Measurements which highlight effects of buoyancy are illustrated in Figs 14 and 15 from Dibble et al. ${ }^{24}$ Vertical traverses of streamwise mean and fluctuating

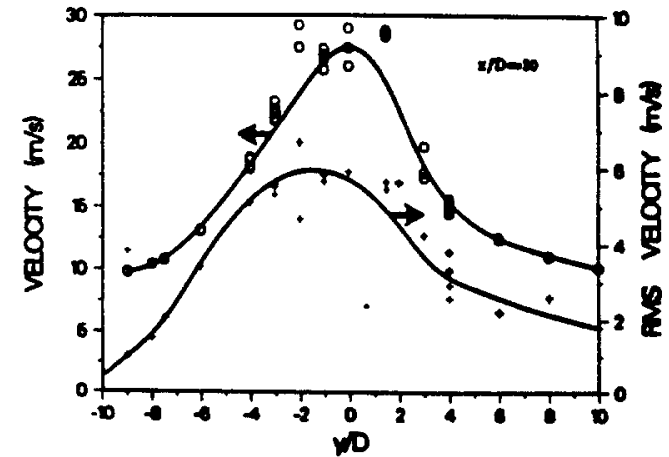

Fig. 14. Measured streamwise mean and fluctuating velocities in a turbulent horizontal hydrogen-argon/air jet diffusion flame. Vertical traverse at $x / d=50$. From Dibble et al. ${ }^{24}$

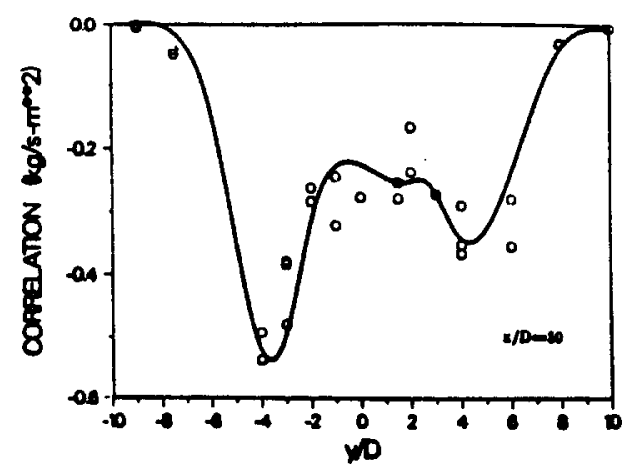

FIG. 15. Measured velocity-density correlation $\rho^{\prime} u^{\prime}$ in a turbulent horizontal hydrogen-argon/air jet diffusion flame. Vertical traverse at $x / d=50$. From Dibble et al. ${ }^{24}$

velocities and their correlation, $\overline{\rho^{\prime} u^{\prime}}$, are illustrated for $x / d=50$. This position is just beyond the flame tip. A Cartesian coordinate system is used for distances, positive and negative values represent positions above and below the axis. Mean velocity profiles have unusually large scatter; however, they roughly indicate a somewhat steeper profile above the axis than below. Velocity fluctuations exhibit greater asymmetry, having maximum values below the axis and trailing off to higher ambient values above the axis. The correlation $\overline{\rho^{\prime} u^{\prime}}$ has the greatest asymmetry, having its largest absolute value below the axis and a relatively complex variation over the flow.

The effects seen in Figs 14 and 15 are primarily attributable to buoyancy. The high-temperature lowdensity gas near the axis has stable and unstable stratification on its lower and upper surfaces. This has a direct effect on turbulence properties even at $x / d=50$. Farther downstream, effects of buoyancy on mean properties are clearly observed. Such threedimensional effects will clearly complicate analysis of this and other similar flows. Similar experiments in vertical flow, e.g. Dibble et al. ${ }^{23,25.28 .29}$ reduce the effect of buoyancy to a symmetric field, providing a more at tractive configuration for analysis. 


\subsection{Averages}

A complete understanding of turbulent reaction processes would provide a means of calculating moments of velocities and scalar properties using any desired averaging procedure. This is generally not possible at present; therefore, it is necessary to specify the type of averages obtained by both theory and experiment if they are to be properly compared. In cases where they are not the same, estimates of the differences between them must be available.

Two types of averages most commonly appear in current analysis and experiments: (1) conventional unweighted (Reynolds) averages, and (2) densityweighted (Favre) averages. For unweighted averages, the instantaneous value of any generic quantity, $\phi$, is decomposed into time-averaged and fluctuating components, as follows:

$$
\phi=\bar{\phi}+\phi^{\prime}
$$

Clearly, $\vec{\phi}^{\prime}=0$ under this definition. Favre or densityweighted averages have the following definition.: 8

$$
\bar{\phi}=\overline{\rho \phi} / \bar{\rho} \text {. }
$$

The density-weighted mean and fluctuating components become

$$
\rho \phi=\bar{\rho} \bar{\phi}+\rho \phi^{\prime \prime}
$$

In this case, $\overline{\rho \phi^{\prime \prime}}=0$, but $\overline{\phi^{\prime \prime}} \neq 0$ in general. Conventional and Favre averages are identical in constant-density flows, but can be appreciably different in the variable-density flows characteristic of flame environments.

Conditional averages are often reported from experiments, although they play a lesser role in current analysis of fast-reacting turbulent flows. Such averages can be conditioned on turbulent and nonturbulent fluid, in cases when a turbulent stream is mixing with an environment having small turbulence levels; or on mixed and unmixed fluid, in cases where both streams are turbulent. Conditional averages can also be defined in terms of either conventional or Favre averages, yielding a potentially large assortment of properties. In terms of Reynolds averages, we have

$$
\bar{\phi}=\gamma \bar{\phi}_{1}+(1-\gamma) \bar{\phi}_{n}
$$

where $\bar{\phi}_{1}$ and $\bar{\phi}_{n}$ are conditional averages appropriate to turbulent and nonturbulent fluids, while $\gamma$ represents turbulence intermittency, e.g. the fraction of time when turbulent fluid is present at the point in question. An analogous equation can be written using averages conditioned on mixing.

\subsubsection{Velocity}

Fortunately, conventional- and Favre-averaged mean velocities are not very different in turbulent reacting flows, in view of the experimental uncer- tainties of typical measurements. From the basic definition of a Favre average, Eq. (6), the difference between these averages is

$$
(\bar{u}-\tilde{u}) / \bar{u}=-\overline{\rho^{\prime} u^{\prime}} / \overline{\rho u} .
$$

Potential differences can be examined by introducing the $\rho^{\prime} u^{\prime}$ correlation, $R_{p i l i}$, as follows

$$
(\bar{u}-\tilde{u}) / \bar{u}=-\left(\overline{\rho^{\prime}} / \bar{\rho}\right)\left(\overline{u^{\prime}} / \bar{u}\right) R_{\rho i u}
$$

In Eq. (10), and in the following, we have adopted the notational convenience that $\left(\overline{\phi^{\prime 2}} / \overline{\phi^{2}}\right)^{1 / 2} \equiv\left(\overline{\phi^{\prime}} / \bar{\phi}\right)$; this should not be confused with the fundamental requirement that $\overline{\phi^{\prime}}=0$. The correlation $R_{p^{\prime} \text { it }}$ has been measured by Stäner and Bilger ${ }^{59.60}$ Schefer and Dibble, 22.26 and Dibble et al. ${ }^{24}$ for round jet diffusion flames in coflow; and Liburdy et al. ${ }^{65}$ and Lai and Faeth ${ }^{66}$ for plane buoyant flows. The behavior is similar in both flows with maximum absolute values on the order of 0.5 and values approaching zero near the edge of the flow, cf. Fig. 15. Conservatively estimating $\overline{\rho^{\prime}} / \bar{\rho}=1$ and $\overline{u^{\prime}} / \bar{u}=0.2$, which are typical of flame environments, yields potential differences between conventional and Favre averages on the order of $10 \%$. Starner and Bilger $^{60}$ report direct measurements of $\bar{u}$ and $\tilde{u}$ in round jet diffusion flames in coflow, yielding differences on the order of $5 \%$ which are well within this limit.

Differences between conventional and Favre averages are larger for velocity fluctuations, and probably for other turbulence quantities as well. Taking streamwise velocity fluctuations as an example, it can be shown that

$$
\begin{gathered}
{\left[\left(\overline{u^{\prime}}-\tilde{u}^{\prime \prime}\right) /\left(\overline{u^{\prime}}\right)\right]=} \\
\left.\left.\left[\overline{\left(u^{\prime}\right.}\right) /\left(\overline{u^{\prime}}+\tilde{u}^{\prime \prime}\right)\right]\left(\overline{\rho^{\prime}} / \bar{\rho}\right)\left[\overline{\rho^{\prime}} / \bar{\rho}\right) R_{\mu^{\prime} u^{\prime}}{ }^{2}-R_{j^{\prime} u^{\prime}}{ }^{2}\right]
\end{gathered}
$$

Stårner and Bilger ${ }^{60}$ have measured $R_{p^{\prime}{ }^{\prime}}{ }^{2}$ in round jet flames; it is relatively small near the axis and decreases monotonically toward -1 near the edge of the flow. Taking mean values across the flow as follows:

$$
\overline{\rho^{\prime} / \rho}=1, \quad \overline{u^{\prime}} /\left(\overline{u^{\prime}}+\tilde{u}^{\prime \prime}\right)=0.5, \quad R_{p i l i}=R_{p^{\prime} u^{2}}{ }^{2}=-0.3,
$$

yields differences between $\overline{u^{\prime}}$ and $\tilde{u}^{\prime \prime}$ on the order of $20 \%$. This estimate is comparable to direct measurements by Starner and Bilger, ${ }^{60}$ although higher values, up to $40 \%$, were observed near the flow edge. These considerations imply that mass weighting has a significant effect on turbulent velocities in flames and strict correspondence with the method of averaging is required for definitive evaluation of analysis.

Velocity measurements are most often made with hot-wire anemometry, Pitot probes and laser Doppler anemometry (LDA). Hot wire anemometry is generally limited to characterization of initial conditions, where the constant density flows present 
few problems. Pitot probes and LDA, however, are often used to measure flow structure and will be considered in the following.

Becker and Brown ${ }^{67}$ discuss errors and uncertainties associated with the use of Pitot probes. In general, such probes are not very reliable when local turbulence intensities are high, eg. greater than $20 \%$, due to effects of flow inclination on their reading and the disturbances they introduce. Bilger ${ }^{68}$ suggest that Pitot probes indicate a type of density-weighted velocity, eg.

$$
\hat{u}=\left(\overline{\rho u}^{2}\right)^{1 / 2} / \bar{\rho}^{1 / 2}
$$

which is neither a conventional nor a Favre average. The difference between $\bar{u}$ and $\hat{u}$ can be formulated as follows

$$
\begin{aligned}
(\bar{u}-\hat{u}) / \bar{u}= & (-\bar{u} /(\bar{u}+\hat{u}))\left(\overline{u^{\prime}} / \bar{u}\right)^{2}\left[1+R_{\rho^{\prime} u^{\prime}}{ }^{2}\left(\overline{\rho^{\prime}} / \bar{\rho}\right)\right. \\
& \left.+2 R_{\rho^{\prime} u}\left(\overline{\rho^{\prime}} / \bar{\rho}\right)\left(\bar{u} / \overline{u^{\prime}}\right)\right] .
\end{aligned}
$$

Using the same estimates of mean and fluctuating quantities, and their correlations, as before, yields differences between $\bar{u}$ and $\hat{u}$ on the order of $5 \%$.

Errors associated with measurements using LDA are discussed by Libby $e t$ al. ${ }^{4}$ and references cited therein. If the instrument is properly frequencyshifted, errors due to directional bias and directional ambiguity can be eliminated; if not, loss of accuracy is comparable to probes and measurements where turbulence intensities exceed $20 \%$ have considerable uncertainty. The response of the seeding particles is usually adequate for the characteristic flow lengths and velocities of existing measurements in diffusion flames. However, problems of velocity and concentration bias must be addressed.

If the reactant flow of a premixed flame is uniformly seeded and if the molecular weights of all species are the same, then the concentration of seeding particles is proportional to the density. In this case, if each particle gives only one velocity output upon passing through the measuring volume, a particle-average velocity is equivalent to a Favreaveraged velocity. ${ }^{4}$ Similarly, if the data density is high, implying small time intervals between valid velocity signals in comparison to characteristic flow times, time-averaging the low-pass filtered processor output yields a conventional average Diffusion flames involve at least two reactant flows, however, and these conveniences are not generally applicable. If both streams are seeded to yield a high data density, then a proper time average is obtained. If high data densities can't be maintained, then the uniform time-interval sampling advocated by Stevenson et al. ${ }^{69}$ and Craig et al. ${ }^{70}$ or archiving of the time-of-event and subsequent analysis with uniform time intervals as advocated by Brum and Samuelsen, ${ }^{71}$ can be used to obtain a reliable time average as well as a direct estimate of potential bias errors. These approaches, however, have not been used for any of the measurements considered here.
If only one stream is seeded, but seeding densities are high and the signal is conditionally averaged to eliminate periods when only unseeded fiuid is present, then a conditional time average is obtained. LDA measurements by Glass and Bilger, ${ }^{72}$ Starner and Bilger ${ }^{59.60}$ and Starner ${ }^{33.74}$ were carried out under such conditions. Furthermore, the unseeded flow had a low turbulence level; therefore, these measurements correspond to conditional turbulent fluid averages, which are appreciably different from conventional averages when intermittencies are large. Data of this type, as well as particle-averaged quantities when only one stream is seeded, are not very convenient for evaluation of analysis. Dibble $e t$ al. ${ }^{23}$ establish the limits of the potential bias in the vertical flow of a jet of gaseous fuel into coflowing air. Distributions of velocity and mixture fraction are measured when only the fuel is seeded, when only the air flow is seeded, and when both the fuel jet and coflowing air are seeded. Bias of the data is clearly evident although differences are modest except for the mean and rms radial velocities.

\subsubsection{Temperature}

Conventional and Favre averages of temperature are appreciably different in flames-up to several hundred degrees Kelvin. Most temperature measuring systems yield values which approach time averages, although optical techniques have the capability to find both types of average Thermocouple probes and optical methods will be briefly discussed in the following.

Bilger ${ }^{68}$ points out that thermocouple probes yield a heat-transfer weighted mean temperature. If the probe is small, this approaches a time-averaged temperature modified by radiation and conduction errors. Whether correcting such readings in the mean is appropriate, due to the nonlinearities associated with radiation and flame structure, has not been assessed to our knowledge; however, this practice is commonly accepted. Errors in such procedures are unlikely to be greater than a fraction of the correction.

Thermocouple probes are generally too large to provide adequate frequency response to measure temperature fluctuations in gaseous flames; therefore several workers have used compensation circuits to improve frequency response. This procedure is only accurate if the appropriate instantaneous time constraint of the thermocouple is known. In flame environments, the time constant varies with instantaneous mixture fraction and velocity as well as the state of thermodynamic equilibrium-all of which vary with time; therefore, use of an unvarying time constant in the compensation circuit yields questionable results. Some authors attempt to correct for this by periodically measuring the time constant. Since compensation seeks to increase response, however, such determinations clearly cannot be made rapidly 


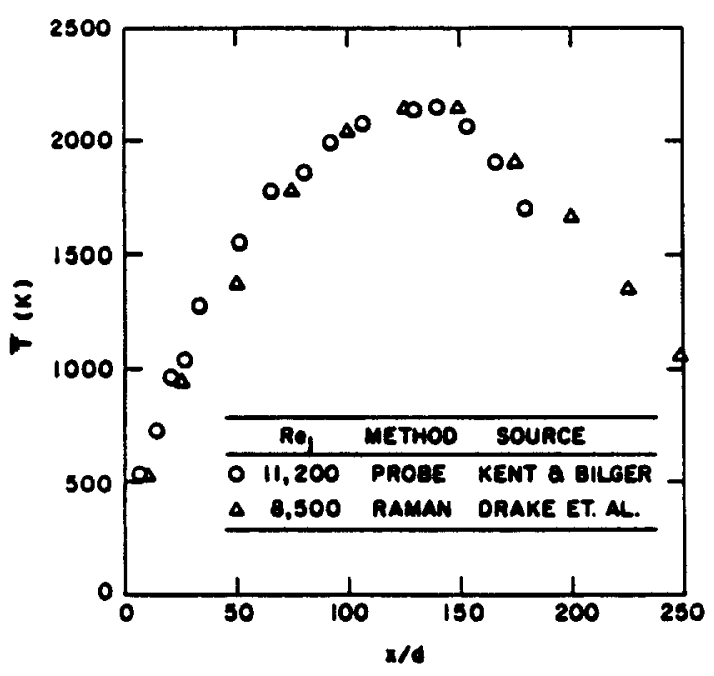

Fig. 16. Mean temperatures along the axis of hydrogen/air jet diffusion flames using a thermocouple probe and spontaneous Raman scattering. Data from Kent and Bilger $^{58}$ and Drake $e t$ al. ${ }^{18}$

enough to provide reliable compensation for the full range of frequencies in the flow. As a result, we feel that compensated thermocouple measurements provide useful qualitative results concerning temperature fluctuations in reacting gases, but uncertainties in these measurements cannot be specified well enough for their use in definitive assessment of analysis.

Optical techniques for temperature measurements include Rayleigh scattering (for appropriate gas mixtures), spontaneous Raman scattering, and coherent anti-Stokes Raman scattering (CARS). These measurements are normally processed to yield timeaveraged mean and fluctuating values. In some cases, sufficient information is available for finding instantaneous density and Favre-averaged values are computed as well.

Kent and Bilger ${ }^{58}$ and Drake et al. ${ }^{18}$ have made measurements in round jet hydrogen/air diffusion flames, for similar conditions, which provide a means of directly comparing results from thermocouple probes and Raman scattering measurements. The results are illustrated in Fig. 16. Differences between the two sets of measurements are similar to experimental uncertainties. The advantage of the Raman measurements, however, is that temperature fluctuations can also be accurately obtained.

\subsubsection{Other scalar properties}

Other scalar properties of interest include mixture fraction, species concentrations and density. Methods most frequently used for these measurements are sampling probes and optical scattering techniques (Mie, Rayleigh and Raman scattering; CARS; and laser-induced fluorescence). Sampling has slow response and has only been used for mean properties in reactive environments. The optical

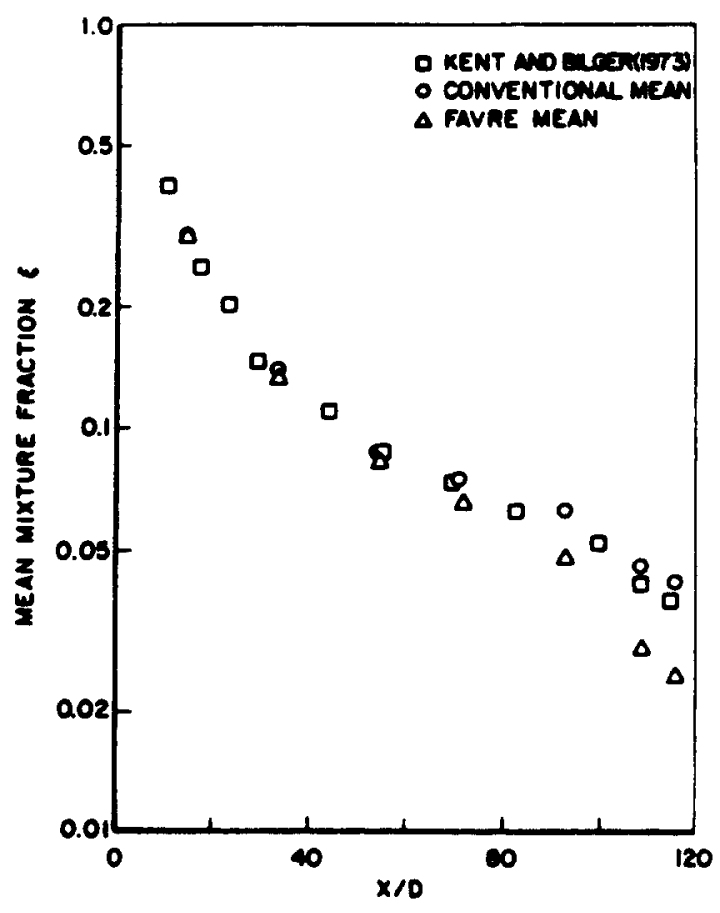

FIG. 17. Measurements of mixture fraction along the axis of coflowing turbulent hydrogen/air jet diffusion flames. Comparison of Favre, Reynolds and probe averages. From Kennedy and Kent. ${ }^{75}$

methods can provide temporal, and in some cases Favre, averages of mean and fluctuating quantities.

Sampling is generally thought to provide values which approach Favre averages. ${ }^{4,68}$ The evidence for this, however, is limited and the difference between conventional and density-weighted averages can be large. The behavior of a particular species or density depends on the state relationship of the reactant system; therefore, we consider mixture fraction as a represen tative scalar property to examine the differences between these averages. From the basic definitions

$$
(\bar{f}-\bar{f}) / \bar{f}=-\left(\overline{f^{\prime}} / \bar{f}\right)\left(\overline{\rho^{\prime}} / \bar{\rho}\right) R_{p},
$$

At the fast-reaction limit, the difference can also be conveniently stated in terms of mixture fraction and the state relationship for density, as follows:

$$
(\bar{f}-\bar{f}) / \bar{f}=-[(\partial \ln \rho) /(\partial \ln f)]\left(\overline{f^{\prime}} / \bar{f}\right)^{2} .
$$

Measurements of Ståmer and Bilger ${ }^{60}$ indicate maximum values of $\overline{f^{\prime}} / \bar{f} \approx \overline{\rho^{\prime}} / \bar{\rho} \approx R_{p}, \approx 1$, suggesting differences comparable to the value of the mixture fraction itself. The same conclusion is reached from their direct measurements of $\vec{f}$ and $\vec{f}$.

Kennedy and Kent ${ }^{75}$ provide results where probe measurements can be compared with Mie-scattering measurements of both conventional- and Favreaveraged mixture fraction. These results are illustrated in Fig. 17. Probe measurements of Kent and Bilger $^{58}$ as well as Mie scattering measurements of $\bar{f}$ 
and $\mathcal{J}$ (assuming an equilibrium flame) of Kennedy and Kent, ${ }^{75}$ all for the same flame conditions and test apparatus, are illustrated. Near the jet exit, $\bar{f}$ and 7 don't differ appreciably and all methods are in reasonably good agreement. Near the flame tip, however, intermittency appears at the axis and the Favre-averaged value is roughly half the conventional-averaged value. The probe values fall between the Favre and conventional averages; however, they are generally closer to the conventional average, which is opposite to most current opinion.

Drake et al. ${ }^{16}$ point out that mixture fraction measurements using Mie scattering yield larger differences between conventional- and Favreaveraged values than Raman measurements in hydrogen/air diffusion flames. They suggest effects of differential diffusion as a possible cause for this behavior, e.g. molecular diffusion rates of hydrogen are greater than other permanent gases while particles have negligibly-slow rates of molecular diffusion. In spite of this, however, recent Raman measurements in turbulent hydrogen/air diffusion flames, by Drake et al. ${ }^{20}$ yield conclusions similar to the Mie-scattering findings. Their mixture fraction measurements, reduced to yield both $\bar{f}$ and $\bar{f}$ along the flame axis, are summarized in Table 1 . For $x / d \leq 150$, differences between $\bar{f}$ and $\hat{f}$ are generally less than $10 \%$. However, at $x / d=200$, where intermittency becomes significant on the axis, there is roughly a $50 \%$ difference between $\bar{f}$ and $\bar{f}$. Other areas of high intermittency, which incorporates most of the region where reaction is significant, exhibit similarly large differences between $\bar{f}$ and $\bar{f}$.

In agreement with Drake et al. ${ }^{16}$ we conclude that probe measurements yield results having indeterminate levels of density weighting, generally lying between conventional and Favre averages. Furthermore, differences between these averages are large (greater than $30 \%$ ) in the region where reaction is significant. The reason that probe measurements do not reliably indicate Favre averages is not known at present. More attention to the flow response of specific sampling probes, for typical turbulent flame environments, should be pursued to clarify this issue.

Probe measurements of specific concentrations also appear to have limited accuracy when local turbulence intensities are high (greater than $20 \%$ ), similar to Pitot probes, Direct evidence of this is

TABLE 1. Conventional- and Favre-averaged mixture fractions in a turbulent round-jet diffusion flame ${ }^{\dagger}$

\begin{tabular}{ccccccc}
\hline$x / d$ & 10 & 25 & 50 & 100 & 150 & 200 \\
\hline $\bar{f}$ & 0.463 & 0.203 & 0.110 & 0.0540 & 0.0315 & 0.0173 \\
$\bar{f}$ & 0.461 & 0.201 & 0.109 & 0.0536 & 0.0290 & 0.0126 \\
\hline
\end{tabular}

†Along the axis of a hydrogen/air diffusion flame, $R e_{j}=8500$. From Drake et al. ${ }^{20}$ presented by Lai et al., ${ }^{76}$ where sampling measurements of mean mixture fraction are compared with LIF and laser absorption measurements in turbulent wall plumes. The optical techniques agreed reasonably well with each other, however, the probe measurements were biased upward near the freestream edge of the flow. Based on the indeterminacy of density weighting and effects of turbulence intensity, it is unlikely that probe measurements can provide a definitive test of turbulent reaction analysis at the fast-reaction limit.

Mie scattering measurements of mixture fraction also exhibit difficulties which limit their usefulness for definitive evaluation of analysis. Use of titanium dioxide particles gives high seeding levels, but these particles undergo light-scattering property changes in flames which complicates interpretation of such measurements, cf. Kennedy and Kent. ${ }^{75}$ Use of aluminum oxide particles avoids the property change effect; however, uniform seeding rates at sufficiently high levels to control shot noise are difficult to provide. Effects of differential diffusion and the need to invoke the equilibrium flame assumption to compute other scalar properties also limit the effectiveness of these results-particularly for fluctuating properties. In summary, only carefully-conducted Rayleigh, Raman, LIF and CARS measurements, or other nonintrusive techniques providing a direct measurement of mixture properties, have the potential to provide measurements of scalar properties for definitive evaluation of turbulent reaction analysis.

\subsection{Visualization}

Visualization is a useful and necessary augmentation of the measurements described above. First, "still" photographs complement the experimental schematic by providing a characterization of the physical hardware. Second, still photographs of the flame provide a time-averaged view that is desirable for direct comparison to the spatial distribution of the time-averaged mean measurements. An important corollary to the time-averaged visualization is a documentation of the flame dynamics and scales of turbulent mixing Although not quantitative, successive frames from a high-speed photographic sequence provides a visual indication of the dynamics underlying the time-averaged field and the scales of turbulent mixing, both of which are critical to the interpretation of a modeling data base. Such photographs also provide a means of detecting nonturbulent periodic disturbances that may be present in the flow field.

\subsection{Conservation Checks}

The accuracy of structure measurements is frequently evaluated by examining streamwise con- 
servation of mass, momentum and mixture fraction. Reacting flows, however, introduce considerable uncertainties in conservation checks due to effects of density fluctuations and flow acceleration resulting from streamwise pressure gradients and buoyancy. In the following, we examine these uncertainties for fast-reacting turbulent flows.

Stårner and Bilger ${ }^{60}$ provide information which is useful for assessing effects of density fluctuations. Conservation of momentum and mixture fraction are taken as examples. Common to most of the current data base, we assume that the following properties are available: time-averaged velocities, time- or Favre-averaged mixture fractions (to cover the potential limits of probe measurements) and timeaveraged density.

The principle term to be evaluated for momentum conservation is the momentum flux. In terms of the variables listed above, this can be written ${ }^{60}$

$$
\begin{gathered}
\left.\overline{\rho u\left(u-u_{e}\right)}=\overline{\rho u(u}-u_{e}\right)+ \\
\left(2 \bar{u}-u_{e}\right) \overline{\rho^{\prime} u^{\prime}}+\overline{\rho u^{\prime}}{ }^{2}+\overline{\rho^{\prime} u^{\prime 2}}
\end{gathered}
$$

where $u_{e}$ is included to allow for the presence of a nonzero free-stream velocity. Except in the few cases where density/velocity correlations are available, the conservation check would have to be based on the first term on the RHS of Eq. (16). For their round-jet hydrogen/air diffusion flame, Stårner and Bilger ${ }^{60}$ find that use of only the first term yieids an overestimation of momentum flux of roughly $30 \%$ at a half-width location near the tip of the flame. They indicate that the discrepancy would be even greater near the edge of the flow.

The difficulties in momentum conservation checks multiply when streamwise pressure gradients or buoyancy is a factor. Accelerations due to pressure gradients can only be evaluated when static pressure distributions are reported, which is rarely the case. Evaluation of these effects also requires a reasonable number of cross-stream traverses in the range of interest. In general, few traverses are available, particularly in cases where vital density/velocity correlations are reported. Finally, a momentum conservation check requires good documentation of initial conditions, particularly any wake effects from upstream components. Such information is only occasionally reported.

The principle term to be evaluated for conservation of mixture fraction is the mixture fraction flux. In terms of the variables listed earlier, this can be written as either ${ }^{60}$

$$
\overline{\rho u f}=\bar{\rho} \bar{u} \bar{f}+\bar{\rho} \overline{u^{\prime} f^{\prime}}+\bar{u} \overline{\rho^{\prime} f^{\prime}}+\bar{f} \rho^{\prime} \overline{u^{\prime}}+\overline{\rho^{\prime} u^{\prime} f^{\prime}}
$$

in terms of $\hat{f}$, or

$$
\overline{\rho u f}=\bar{\rho} \bar{u} \bar{f}+\bar{\rho} \overline{u^{\prime} f^{\prime \prime}}+\overline{f \rho^{\prime} u^{\prime}}+\overline{\rho^{\prime} u^{\prime} f^{\prime \prime}}
$$

in terms of $\bar{f}$. Once again, only the first terms on the RHS of Eqs (17) and (18) are generally available, while probe measurements yield values which are indeterminate between them. Stärner and Bilger ${ }^{60}$ find that use of $\bar{\rho} \overrightarrow{u f}$ gives values within a few percent of the correct mixture fraction flux. However, $\bar{\rho} \bar{u} \bar{f}$ is almost four times the correct value at a comparable location. Clearly, the indeterminate nature of the probe measurements, or the unavailability of Favreaveraged measurements, introduces substantial uncertainties in mixture fraction fluxes.

Examination of existing data indicates that no data set has sufficient information to provide a definitive (within 20-30\%) conservation check. Checks made by various authors are reported in the following; however, we did not attempt to apply this normally elementary assessment to any of the data, due to the absence of appropriate information.

\section{AVAILABLE EXPERIMENTAL DATA}

The discussion of available experimental data is divided into three main categories: (1) round free jets, (2) plane free shear layers, and (3) wall boundary layers. Within each category the existing studies are organized according to individual laboratories, when several studies were undertaken by a particular research group, or in a general category where single studies are reported.

\subsection{Round Free Jets}

Table 2 is a summary of studies of turbulent reaction in round free jets at the fast-reaction limit. Most of the work involves round jets in coflow. However, a few studies of round fuel jets in still air are also reported. Much of this work has been carried out by research groups using a particular apparatus for a series of studies, e.g. work at the University of Sydney, General Electric, Sandia, and University of Osaka. These studies are grouped according to the organization at the front of the table, while individual studies are at the back.

\subsubsection{University of Sydney studies}

Studies of round-jet hydrogen/air diffusion flames have been carried out by Bilger and coworkers at the University of Sydney for more than a decade. The bulk of this work has involved round jets in a horizontal coflow using the same apparatus; however, a few studies considered vertical upflow in nearly stagnant air (Bilger and Beck, ${ }^{77}$ and Kennedy and $\mathrm{Kent}^{73}$ ). The combined measurements for the coflow configuration, particularly for $\overline{u_{j}} / \overline{u_{e}}=$ $151.1 / 15.1 \mathrm{~m} / \mathrm{sec}$, are very extensive. This includes initial conditions; streamwise pressure variations; mean and fluctuating velocities; mean and fluctuating mixture fraction; mean temperatures and concentrations of major species; density, mixture 
fraction and velocity cross-correlations; and probability density functions of velocity and mixture fraction. Much of what is currently known concerning this flame system, particularly the hydrodynamic aspects, can be attributed to these experiments.

Nevertheless, the data base measured at the University of Sydney has significant limitations for evaluation of turbulent reaction analysis. The difficulties involve the limited range of conditions tested, relatively low Reynolds numbers, potential effects of buoyancy, and aspects of the instrumentation. Although several operating conditions were considered, only one condition, $\bar{u}_{j} / \bar{u}_{e}=$ $151.1 / 15.1 \mathrm{~m} / \mathrm{sec}$, has a full range of velocity and scalar properties reported. This flow has an initial Reynolds number of 11,200 , which is lower than desirable due to the tendency toward relaminarization in flaming regions. The authors point out the tendency for the flame tip to rise above the axis of the injector, due to the horizontal configuration, suggesting some influence of buoyancy on mean properties. The findings of Dibble et al. ${ }^{23.24}$ suggest that effects of buoyancy on turbulence properties are probably even more substantial. This loss of symmetry poses increased problems of numerical closure, aside from the obvious difficulties of adequately analyzing the turbulence/buoyancy interaction. Except for limited early measurements of mean velocities using a pitot-static probe (Kent and Bilger $^{58}$ ) most velocity measurements were made using an LDA. The authors were careful to provide time-averaged velocities, however, only the fuel flow was seeded; therefore, these measurements have concentration bias. This presents significant difficulties for evaluation of most theoretical methods in regions where intermittency is significant. Mixture fractions were measured using Mie scattering. Kennedy and $\mathrm{Kent}^{75}$ encountered problems of surface property changes with this technique using titanium dioxide particles; therefore, these measurements are questionable. Later use of aluminum oxide particles avoided the property change problem; however, mechanical difficulties of maintaining. uniform seeding and avoiding shot noise in low mixture fraction regions introduces undesirable uncertainties-particularly for mix ture fraction fluctuations. Early probe measurements of mean species concentrations by Kent and Bilger ${ }^{58}$ have indeterminate levels of density weighting which cause significant uncertainties near the flame zone, as noted earlier.

\subsubsection{General Electric studies}

Studies at General Electric, by Drake and coworkers, involved a coflowing jet apparatus, buming hydrogen/air, very similar to that used at the University of Sydney. One difference was that apparatus dimensions were reduced by roughly a factor of two. Limitations in flame attachment resulted in a somewhat lower maximum Reynolds number for the smaller injector diameter, e.g. $R e_{j \max }=8500$ as opposed to 11,200 . Instrumentation was improved for these measurements, however, employing Rayleigh and Raman scattering for density and species concentrations along with LDA for velocity measurements. Thus, the scalar property measurements avoid uncertainties due to probes, seeding fluctuations and shot noise; therefore, either Favre or conventional averages can be reported. Both the fuel and air streams were seeded; thus, problems of concentration bias were eliminated as well. Similar to the work at Sydney, initial and boundary conditions were well known, with resolution of pressure $c a \mathrm{~Pa} / \mathrm{m}$. The highest Reynolds number used, 8500 , yields fewest problems with relaminarization and the most complete measurements are available for this case. As discussed earlier, the higher velocities and smaller injector used in these tests tended to increase problems of reaching the fast-reaction limit. Departure from equilibrium is well documented, however, and the effect of this could be taken into account when assessing analysis at the fast-reaction limit. Effects of buoyancy, similar to Dibble et al., ${ }^{24}$ are probably present in these data due to the horizontal configuration. The smaller injector diameter tends to reduce the effect; however, the investigators still note an appreciable rise, ca 10-15 mm, of the apparent flame axis at the flame tip. LDA measurements of velocity are limited to mean and fluctuating streamwise velocities; therefore, the hydrodynamic properties of these flames are not as well-documented as the University of Sydney work. These difficulties aside, the data set appears to be valuable for development of analysis, if not definitive evaluation.

\subsubsection{Sandia studies}

Recent work at Sandia, ${ }^{21-30}$ employs nonintrusive instrumentation for hydrogen/air round jet flames in coflow, similar to the General Electric Studies. The earliest work (Driscoll et al., ${ }^{21}$ Dibble et al., ${ }^{24}$ Schefer and Dibble, ${ }^{26}$ and Dibble and Schefer ${ }^{30}$ ) employed a jet/duct configuration in horizontal flow having similar dimensions to the apparatus at the University of Sydney. The fuel flow, however, was diluted with argon in order to provide desirable mixture properties for direct measurement of mean and fluctuating density using Rayleigh scattering. Mean and fluctuating velocities were measured using LDA as well as density/velocity fluctuation correlations by combined LDA/Rayleigh scattering measurements. These results are relatively complete and characterization of initial and boundary conditions is available. However, velocity data shows a relatively large degree of scattering, and buoyancy clearly influences turbulence properties in this flow-as noted earlier. 
TABLE 2. Measurements in round free jets

\begin{tabular}{|c|c|c|c|c|}
\hline Ref. & Flow & Velocity & Scalars & \\
\hline \multicolumn{5}{|l|}{$\begin{array}{l}\text { University of } \\
\text { Sydney studies : }\end{array}$} \\
\hline Kent \& Bilger 58 & $\begin{array}{l}\text { Fuel jet in coflow; } \\
\text { hydrogen/air; } \\
d=7.62 \mathrm{~mm} ; \\
305 \text { min square } \\
\text { duct; horizontal; } \\
u_{J} / u_{e}(\mathrm{~m} / \mathrm{sec})= \\
48.8 / 24.4,107.1 / \\
21.4,147.0 / 18.4 \\
151.1 / 15.1 ; \\
p(x) \text { known } \\
\bar{u}_{e}^{\prime} / \bar{u}_{e}=0.1 \%\end{array}$ & $\begin{array}{l}\overline{\rho u}^{2} \text { and } \bar{v}^{\prime} \text { along } \\
\text { axis, } x / d \leq 160 ; \\
\overline{\rho u}^{2} \text { traverses at } \\
x / d=40,80 \\
120 \text { and } 160 . \\
\bar{u}, \bar{u}^{\prime} \text { traverses } \\
\text { at } x=0 .\end{array}$ & $\begin{array}{l}T \text { and mean con- } \\
\text { centrations of } \mathrm{H}_{2}, \\
\mathrm{H}_{2} \mathrm{O} \text { and } \mathrm{O}_{2} \text { at } \\
x / d=40,80 \text { and } \\
160 ; \text { all for } \\
\bar{u}_{j} / \bar{u}_{e}=10 .\end{array}$ & \\
\hline \multirow[t]{2}{*}{ Bilger \& Beck ${ }^{77}$} & $\begin{array}{l}\text { (i) Same as Kent } \\
\text { and Bilger, } \\
\bar{u}_{s} \sqrt{u}_{e}(\mathrm{~m} / \mathrm{sec})= \\
151.1 / 15.1\end{array}$ & & $\begin{array}{l}\text { (i) Mean concen- } \\
\text { trations of } \mathrm{H}_{2} \text {, } \\
\mathrm{H}_{2} \mathrm{O} \text { and } \mathrm{O}_{2} \\
\text { along axis, } \\
x / d=45-190 \\
\text { and traverse, } \\
x / d=80 \text {. }\end{array}$ & $\cdot$ \\
\hline & $\begin{array}{l}\text { (ii) Fuel jet in still } \\
\text { air; hydrogen/air; } \\
d=1.53-6.35 \mathrm{~mm} ; \\
450 \mathrm{~mm} \text { round duct; } \\
\text { vertical. }\end{array}$ & & $\begin{array}{l}\text { (ii) Same measurements, } \\
x / d=15-110 \text {. }\end{array}$ & \\
\hline Glass \& Bilger $^{72}$ & $\begin{array}{l}\text { Same as Kent } \\
\text { and Bilger } \\
\bar{u}_{j} / \bar{u}_{e}\left(\mathrm{~m} / \mathrm{sec}^{\mathrm{B}}\right)= \\
151.1 / 15.1\end{array}$ & $\begin{array}{l}\bar{u}, \bar{u}^{\prime} \text { and } \bar{v}^{\prime} \text { along } \\
\text { axis, } x / d<200 ; \\
\bar{u}, \overline{u^{\prime}}, \overline{v^{\prime}} \text { and } \overline{u^{\prime} v^{\prime}} \\
\text { traverses at } x / d= \\
40,80,120 \text { and } \\
160 ; P(u) \text { traverses } \\
\text { at } x / d=80 .\end{array}$ & & \\
\hline Kennedy \& Kent ${ }^{75}$ & $\begin{array}{l}\text { Fuel jet in still air; } \\
\text { hydrogen/air; } \\
d=4.36 \mathrm{~mm}, \bar{u}_{j}= \\
160 \mathrm{~m} / \mathrm{sec} ; d=6.35 \mathrm{~mm} \text {. } \\
\bar{u}_{j}=68 \mathrm{~m} / \mathrm{sec} ; 1000 \mathrm{~mm} \\
\text { square screen enclosure. }\end{array}$ & & $\begin{array}{l}\bar{f}, \bar{f}^{\prime}, f \text { and } \tilde{f}^{\prime \prime} \text { along } \\
\text { axis, } x / d=5-120, \\
\text { and traverses at } x / d= \\
40,80, \text { and } 110 \\
\bar{P}(f) \text { and } \widetilde{P}(f) \text { along } \\
\text { axis and traverses at } \\
x / d=12,32,40,60, \\
80 \text { and } 100 \text {. }\end{array}$ & \\
\hline $\begin{array}{l}\text { Ståmer \& } \\
\text { Bilger }^{59}\end{array}$ & $\begin{array}{l}\text { Same as Kent and } \\
\text { Bilger, }{ }^{\text {s8 }} \\
\bar{u}_{\sqrt{u}} \bar{u}_{e}(\mathrm{~m} / \mathrm{sec})=151.1 / \\
15.1 ; \text { streamwise } \\
\text { pressure gradients } \\
\text { from }-274 \text { to } 23 \\
\mathrm{~Pa} / \mathrm{m} .\end{array}$ & $\begin{array}{l}\bar{u}, \overline{u^{\prime}}, \bar{v}, \overline{v^{\prime}} \text { and } \overline{u^{\prime} v^{\prime}} \\
\text { along axis, } x / d< \\
160, \text { and traverses } \\
\text { at } x / d=40,60,80, \\
120 \text { and } 160 ; K_{u}, S_{u} \\
\text { tra verse at } x / d=80 .\end{array}$ & & \\
\hline$\underset{\text { Kent }^{75}}{\text { Kennedy } \&}$ & $\begin{array}{l}\text { Same as Kent and } \\
\text { Bilgersg } \\
\bar{u}_{j} / \bar{u}_{e}(\mathrm{~m} / \mathrm{sec})= \\
151.1 / 15.1\end{array}$ & & $\begin{array}{l}\bar{f}, \bar{f}^{\prime} \bar{f} \text { and } \bar{f}^{\prime \prime} \text { along axis, } \\
x / d<120 ; f \text { traverses at } \\
x / d=34,55 \text { and } 93 ; \bar{f}^{\prime} \text { and } \\
\mathcal{f}^{\prime \prime} \text { traverses at } x / d=55 . \\
\vec{P}(f) \text { and } \bar{P}(f) \text { along axis, } \\
x / d<109, \text { and traverse } \\
\text { at } x / d=55 . \text { Other scalar } \\
\text { properties computed from } \\
f(\text { equilibrium flame). }\end{array}$ & \\
\hline
\end{tabular}




\begin{tabular}{ccc}
\hline Other & Instrument properties & Comments \\
\hline
\end{tabular}

(ii) Flame length based on stoichiometric mean composition on

ax is.
Pitot-static probe; bare-

wire thermocouple corrected

for radiation; isokinetic

sampling with water-cooled

probe (1.2 $\mathrm{mm}$ inlet); $\bar{v}^{\prime}$ using

NPL static-pressure tube,

Same as Kent and

Bilger $^{58}$

Same as Kent and

Bilger $^{58}$

Single-channel LDA $(0.25 \times$

$1 \mathrm{~mm}$ probe volume), no frequency

shifting, only hydrogen

flow seeded.

Mie scattering using titanium dioxide particles $(1.4 \times 2.5$ $\mathrm{mm}$ probe volume).

Surface properties of titanium dioxide changed in flame causing experimental uncertainties.

Same as Glass and Bilger ${ }^{72}$
Measurements have

concentration bias.
Same as Glass and Bilger

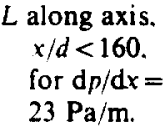

Same as Glass \& Bilger $^{72}$

Mie scattering using aluminum oxide particles $(1.4 \times 0.9 \mathrm{~mm}$ probe volume). Upper bound for shot noise of $20 \%$ for $\bar{f}$ and 7 : 
TABLE 2. (continued)

\begin{tabular}{|c|c|c|c|}
\hline Ref. & Flow & Velocity & Scalars \\
\hline $\begin{array}{l}\text { Stämer \& } \\
\text { Bilger }^{60}\end{array}$ & $\begin{array}{l}\text { Same as Kent and } \\
\text { Bilger, }{ }^{8} \\
\bar{u}_{\mathrm{j}} / \bar{u}_{\mathrm{c}}(\mathrm{m} / \mathrm{sec})=151.1 / \\
15.1 ; \text { streamwise } \\
\text { pressure gradients } \\
\text { from }-102 \text { to } 23 \\
\mathrm{~Pa} / \mathrm{m} .\end{array}$ & $\begin{array}{l}\bar{u} \text { and } \bar{u} \text { along axis. } \\
x / d<160, \text { and } \\
\text { tra verses at } x / d=40, \\
80 \text { and } 120 ; \bar{u} \text { and } \tilde{u}^{\prime \prime} \\
\text { tra verse at } x / d=120 .\end{array}$ & $\begin{array}{l}\bar{f}, \bar{f}, \bar{f}^{\prime} \text { and } \bar{f}^{\prime \prime} \text { traverse } \\
\text { at } x / d=102 ; \bar{\rho} \text { and } \rho \\
\text { traverses at } x / d=40, \\
80 \text { and } 120 \text { computed } \\
\text { from } f \text { (equilibrium } \\
\text { flame). }\end{array}$ \\
\hline Stämer ${ }^{74}$ & $\begin{array}{l}\text { Same as Kent and } \\
\text { Bilger, } \\
\bar{u}_{j 8} / \bar{u}_{\mathrm{e}}(\mathrm{m} / \mathrm{sec})=151.1 / \\
15.1 ; \mathrm{d} p / \mathrm{dx}=-18 \\
\mathrm{~Pa} / \mathrm{m} .\end{array}$ & $\begin{array}{l}\bar{v}, \bar{v}^{\prime}, S_{v}, K_{v} \text { traverse } \\
\text { at } x / d=50 ; \\
\bar{v}^{\prime} \text { traverses at } x / d=40, \\
80,120 \text { and } 160 .\end{array}$ & $\begin{array}{l}\bar{f}, \bar{f}^{\prime}, \bar{f}, \bar{f}^{\prime \prime} . \bar{\rho} \text { and } \bar{\rho}^{r} \\
\text { traverses at } x / d=80 .\end{array}$ \\
\hline
\end{tabular}

Stamer ${ }^{78}$

$$
\text { Same as Ståmer }{ }^{74}
$$

Fuel jet in coflow; hydrogen/air; $d=3.2 \mathrm{~mm} ; 150 \mathrm{~mm}$ square duct; horizontal; $\bar{u}_{j} / \bar{u}_{\mathrm{e}}(\mathrm{m} / \mathrm{sec})=50 / 10$. $75 / 15 ; R e_{j}=1500$ and 2000; $\bar{p}(x)$ known.

Drake et al. ${ }^{16}$

Drake et al. ${ }^{18}$

\section{Same as Drake et al. ${ }^{14}$ $\bar{u}_{j} / \bar{u}_{\mathrm{e}}(\mathrm{m} / \mathrm{sec})=$ $53.6 / 8.8,174 / 13.1$ and $285 / 12.5$; corresponding mean streamwise pre- sure gradients of -10 , -32 and $-51 \mathrm{~Pa} / \mathrm{m}$.}

Same as Drake et al. ${ }^{14}$ $\bar{u}_{i} / \bar{u}_{\mathrm{p}}(\mathrm{m} / \mathrm{sec})=$ 22/9.3, 53.6/8.8, $174.2 / 13.3$ and 285/12.5; corresponding $R e_{j}=660$, 1600,5200 and 8500 .

\section{Traverses of ensemble- averaged $u$ and $v$ at $x / d=40,80$ and 120 .}

Traverses of ensembleaveraged $f$ at $x / d=40$, 80 and 120 .
PDF and mean values of temperature and the concentrations of $\mathrm{N}_{2}, \mathrm{H}_{2}$ and $\mathrm{H}_{2} \mathrm{O}$ at $x / d=10$ and $100\left(R e_{j}=1500\right)$ and $50\left(R e_{j}=2200\right)$.

$\bar{f}, \bar{f}$ and $\bar{f}$ " along axis $x / d=10-200$ and traverse at $x / d=50$ $\vec{P}(f), \bar{P}(f)$ and $\bar{P}(T)$ traverse at $x / d=50$.

$\vec{u}$ and $\vec{u}^{\prime}$ along axis, $x / d=10-220$, for $R e_{j}=1600,5200$ and 8500 .
$\bar{T}$ and $\bar{T}^{\prime}$ along axis, $x / d=10-250\left(R e_{j}=\right.$ 1600 and 8500$) ; \bar{\rho}$. $\bar{T}, \bar{T}^{\prime}$ and mean concentrations of $\mathrm{H}_{2}$, $\mathrm{H}_{2} \mathrm{O}, \mathrm{N}_{2}$ and $\mathrm{O}_{2}$ traverses at $x / d=10$. 50 and $150\left(R e_{j}=\right.$ 8500); $\vec{P}(T), \vec{P}_{,}(T)$. and $\bar{P}_{n}(T)$ traverse at $x / d=50\left(R e_{j}=1600\right.$ and 8500 ).
Sandia-Livermore

st udies

Driscoll et al. ${ }^{21}$

\footnotetext{
Fuel jet in coflow; hydrogen-argon (22\%) /air; $d=5.3 \mathrm{~mm}$; $300 \mathrm{~mm}$ square duct; horizontal; $u_{j} / u_{*}(\mathrm{~m} / \mathrm{sec})$ $=154 / 8.5$; $R e_{j}=18000$.
}

$\bar{\rho}$ along axis, $x / d \leq$ $160 ; \bar{\rho}, \bar{\rho}$, traverses at $x / d=10,30,50$, 70 and 150 . 


\begin{tabular}{|c|c|c|}
\hline Other & Instrument properties & Comments \\
\hline $\begin{array}{l}f^{\prime}, \bar{\rho}, \overline{u^{\prime}} \text { and } \bar{u}^{\prime \prime} f^{\prime \prime} \\
\text { along axis. } x / d= \\
40-160 ; R_{u(f, \cdot} \\
R_{\rho^{\prime \prime \prime \prime}} \text { traverses } \\
\text { at } x / d=40 \text { and } 80 .\end{array}$ & $\begin{array}{l}\text { LDA same as Glass \& Bilger } 72 \\
\text { uncertainty in } \bar{u} \text { and } \bar{u} \text { of } 3 \text { and } \\
5 \% \text { of centerline values. } \\
\text { Mie scattering using aluminum } \\
\text { oxide particles ( } 1 \times 1.5 \mathrm{~mm} \\
\text { probe volume } 1.4 \mathrm{~mm} \text { down- } \\
\text { stream of LDA probe volume); } \\
\text { uncertainties in mean and fluctuating } \\
\text { scattered light intensities } \\
<15 \%\end{array}$ & $\begin{array}{l}\text { All data tabulated in Stămer } \\
\text { LDA measurements } \\
\text { have concentration bias. } \\
\text { Scalar properties from } \\
\text { equilibrium flame assumption. }\end{array}$ \\
\hline \multirow[t]{3}{*}{$\begin{array}{l}\overline{v^{\prime} f^{\prime}} \text { and } v^{\prime \prime} f^{\prime \prime} \\
\text { traverses at } x / d= \\
40,80,120 \text { and } \\
160 .\end{array}$} & $\begin{array}{l}\text { Single-channel LDA }(0.2 \times 1 \mathrm{~mm} \\
\text { probe volume), frequency shifted, } \\
\text { only hydrogen flow seeded, uncertainty } \\
\text { of } \bar{v}^{\prime} \text { less than } 6 \% \\
\text { centerline value; Mie scattering } \\
\text { using aluminum oxide particles } \\
\text { (1.3 } \times 1.5 \mathrm{~mm} \text { probe volume) } \\
\text { coincident wih LDA. }\end{array}$ & $\begin{array}{l}\text { Effects of differential diffusion } \\
\text { estimated to increase } v^{\prime} f \text { and } \\
v^{\prime \prime} f^{\prime \prime} \text { by } 10 \%(x / d=40) \text { and } \\
25 \%(x / d=160) \text {. Scalar properties } \\
\text { using equilibrium flame } \\
\text { assumption. LDA measurements } \\
\text { have concentration bias. }\end{array}$ \\
\hline & $\begin{array}{l}\text { LDA same as Stámer }{ }^{74} \\
\text { but two-channel system. }\end{array}$ & $\begin{array}{l}\text { Study emphasizes large-scale } \\
\text { motions and is not suited for } \\
\text { evaluation of moments. Data } \\
\text { decomposed into low- } \\
\text { frequency, large-scale and } \\
\text { small-scale turbulence. }\end{array}$ \\
\hline & $\begin{array}{l}\text { Raman scattering }(0.3 \times 0.7 \mathrm{~mm} \text { probe } \\
\text { volume, 1000-2000 nsec pulse duration). } \\
\text { Standard deviations: T/4\%@1500 K, } \\
>10 \% @ 950 \mathrm{~K} ; \mathrm{N}_{2} / 3 \% @ 1500 \mathrm{~K} ; \\
\mathrm{H}_{2} \mathrm{O} / 6 \% \text { \% } 1550 \mathrm{~K} ; \mathrm{H}_{2} / 6 \% @ 2 \times 10^{-6} \mathrm{O} \\
\mathrm{gmol} / \mathrm{cm}^{3}\end{array}$ & \\
\hline Favre intermittency & $\begin{array}{l}\text { Same as Drake et al. }{ }^{14} \\
\text { Uncertainties: } \\
T /+50 \mathrm{~K}, X_{i} / \pm 1 \mathrm{~mol} \%\end{array}$ & \\
\hline $\begin{array}{l}\text { Pulsed laser } \\
\text { schlieren and } \\
\text { shadowgraph } \\
\text { photographs; } \\
\text { planar OH fluorescence } \\
\text { images; } \\
\gamma \text { traverses for } \\
x / d=50,100 \\
150, \text { and } 200 \\
\left(R e_{j}=8500\right)\end{array}$ & Same as Drake et al. ${ }^{10}$ & \\
\hline $\begin{array}{l}\overline{\rho^{\prime} u^{\prime}} \text { along axis, } \\
x / d=30-150 \\
\overline{\rho^{\prime} u^{\prime}} \text { and } \overline{\rho^{\prime} v^{\prime}} \\
\text { traverses at } \\
x / d=30 \text { and } 50\end{array}$ & $\begin{array}{l}\text { Single-channel LDA }(0.5 \times 2 \mathrm{~mm}) \\
\text { frequency shifted; cw Rayleigh scattering } \\
(60 \mu \mathrm{sec} \text { integration time). }\end{array}$ & $\begin{array}{l}\text { Dibble et al. }{ }^{24} \\
\text { indicate that processing } \\
\text { problem limited the } \\
\text { frequency response of } \\
\text { these measurements. }\end{array}$ \\
\hline
\end{tabular}


TABLE 2. (continued)

\begin{tabular}{|c|c|c|c|}
\hline Ref. & Flow & Velocity & Scalars \\
\hline Dibble et al. ${ }^{24}$ & $\begin{array}{l}\text { Same as Driscoll } \\
\text { et al. }{ }^{21}\end{array}$ & $\begin{array}{c}\bar{u} \text { and } \bar{u} \text { traverse } \\
\text { at } x / d=50 .\end{array}$ & $\begin{array}{l}\bar{\rho} \text { along axis. } x / d \leq \\
180 ; \bar{\rho}, \bar{\rho}^{\prime}, \bar{f} \text { and } \bar{f}^{\prime} \\
\bar{T} \text { and } \bar{X}_{i} \text { found at } \\
\text { these positions as- } \\
\text { suming equilibrium } \\
\text { flame. }\end{array}$ \\
\hline $\begin{array}{l}\text { Scheffer \& } \\
\text { Dibble }^{26}\end{array}$ & $\begin{array}{l}\text { Same as Driscoil } \\
\text { et al. }{ }^{21}\end{array}$ & $\begin{array}{l}\bar{u} \text { and } \bar{u}^{\prime} \text { along axis, } \\
x / d \leq 160, \text { and traverses } \\
\text { at } x / d=30, \\
50,70,100 \text { and } 150 \\
P(u), P_{1}(u) \text { and } P_{n}(u) \\
\text { traverse at } x / d=150 .\end{array}$ & $\begin{array}{l}\bar{\rho} \text { and } \bar{\rho}^{\prime} \text { along axis, } \\
x / d \leq 160 . \text { and } \\
\text { traverses at } x / d=30, \\
50.70 \text { and } 150 ; \rho, \\
\bar{\rho}_{n}, \bar{\rho}_{n}, \bar{\rho}^{\prime}, \bar{\rho}^{\prime}, \text { and } \\
\bar{\rho}_{n}^{\prime} \text { traverse at } x / d=50\end{array}$ \\
\hline $\begin{array}{l}\text { Dibble \& } \\
\text { Scheffer }^{30}\end{array}$ & $\begin{array}{l}\text { Same as Driscoll } \\
\text { et al. }{ }^{21}\end{array}$ & $\begin{array}{l}\bar{u} \text { and } \bar{u}^{\prime} \text { traverses at } \\
x / d=50 .\end{array}$ & $\begin{array}{l}\bar{T} \text { and } \bar{T}^{\prime} \text { traverses at } \\
x / d=50 .\end{array}$ \\
\hline Dibble et al. ${ }^{23}$ & $\begin{array}{l}\text { Fuel jet in coflow: } \\
\text { hydrogen-argon } \\
(22 \%) / \text { air; } d= \\
5.25 \mathrm{~mm} ; 300 \mathrm{~mm} \\
\text { square duct; } \\
\text { vertical; } \bar{u}_{j} / \bar{u}_{e}(\mathrm{~m} / \mathrm{sec}) \\
=75 / 9.2 ; 150 / 9.2 ; \\
225 / 9.2 ; R_{j}=9000 \\
18,000,27,000 .\end{array}$ & $\begin{array}{l}\bar{u}, \bar{v}, \bar{u}^{\prime}, \bar{v}^{\prime}, \overline{u^{\prime} v^{\prime}} \\
\text { traverses at } \\
x / d=30,50\end{array}$ & $\begin{array}{l}\text { No scalars for } \\
\text { reacting flow. }\end{array}$ \\
\hline Dibble et al. ${ }^{29}$ & $\begin{array}{l}\text { Same as Dibble et } \\
\text { al. }^{23} \text { except } R e_{j}= \\
\quad 18,000 \text {. }\end{array}$ & None & $(\hat{c} \rho / \partial r)^{2}$ at $x / d=50$ \\
\hline \multicolumn{4}{|l|}{$\begin{array}{l}\text { University of } \\
\text { Osaka studies }\end{array}$} \\
\hline Takagi et al..$^{79}$ & $\begin{array}{l}\text { Fuel jet in coflow; } \\
\text { hydrogen/air; } d=2 \\
\text { mm; } 133 \mathrm{~mm} \text { round } \\
\text { duct; vertical; } \bar{u}_{j} / \bar{u}_{e} \\
(\mathrm{~m} / \mathrm{sec})=108 / 0.15 .\end{array}$ & $\begin{array}{c}\bar{u} \text { traverse at } \\
x / d=50\end{array}$ & $\begin{array}{l}\bar{T} \text { and mean concentrations } \\
\text { of } \mathrm{H}_{2}, \mathrm{H}_{2} \mathrm{O}, \mathrm{O}_{2} \\
\text { and } \mathrm{N}_{2} \text { traverse at } \\
x / d=50 \text {. }\end{array}$ \\
\hline Takagi et al. ${ }^{56}$ & $\begin{array}{l}\text { Fuel jet in coflow; } \\
\text { hydrogen-nitrogen } \\
(60 \%) / \text { air; } d=4.9 \\
\text { mm; vertical; } \bar{u}_{j} / \bar{u}_{\mathrm{r}} \\
(\mathrm{m} / \mathrm{sec})=20-90 / 0.65 \\
R e_{j}=4200-1800 .\end{array}$ & $\begin{array}{l}\bar{u} \text { and } \bar{u}^{\prime} \text { traverses } \\
\text { at } x / d=2,10.2 \\
\text { and } 27.1\end{array}$ & $\begin{array}{l}\bar{T} \text { and mean concentrations } \\
\text { of } \mathrm{H}_{2}, \mathrm{H}_{2} \mathrm{O}, \mathrm{O}_{2} \\
\text { and } \mathrm{N}_{2} \text { traverses at } \\
x / d=2,10.2 \text { and } 27.1\end{array}$ \\
\hline Takagi et al. ${ }^{57}$ & $\begin{array}{l}\text { Same as Takagi et al. }{ }^{56} \\
\bar{u}_{j} / \bar{u}_{e}=20.4 \\
\text { and } 55.7 / 5.1 \\
R e_{j}=4200 \text { and } 11000 .\end{array}$ & $\begin{array}{l}u, \bar{u}^{\prime} \text { and } v^{\prime} \text { along axis, } \\
x / d \leq 51 ; \bar{u}, \bar{u}^{\prime}, \bar{v}^{\prime}, \bar{w}^{\prime}, \\
\overline{u^{\prime} v^{\prime}}, \bar{P}(u) \text { and } R_{u u}(t) \\
\text { traverses at } x / d=18.4 \\
\left(R e_{j}=4200\right) ; L_{u} \text { along } \\
\text { axis, } x / d \leq 51, \text { and } \\
\text { traverses at } x / d=6.1 \\
12.2,18.4 \text { and } 32.6 \\
\text { power spectra along axis, } \\
x / d \leq 32.6, \text { and traverse } \\
\text { at } 18.4 .\end{array}$ & $\begin{array}{l}\bar{T} \text { mean concentrations } \\
\text { of } \mathrm{H}_{2}, \mathrm{H}_{2} \mathrm{O} \text {, } \\
\mathrm{O}_{2} \text { and } \mathrm{N}_{2} \text { along axis, } x / d \\
\leq 51, \text { and traverses at } \\
x / d=6.1,12.2,18.4 \\
\text { and } 32.6\end{array}$ \\
\hline Takagi et al..$^{80}$ & $\begin{array}{l}\text { Same as Takagi et al. }{ }^{56} \\
\bar{u}_{j} / \bar{u}_{e}(\mathrm{~m} / \mathrm{sec}) \\
=20.4 / 5.1 \\
R e_{j}=4200\end{array}$ & $\begin{array}{c}\bar{u}, \bar{u}^{\prime} \text { and } \bar{v}^{\prime} \text { traverses at } \\
x / d=18.4 \text { and } 32.7\end{array}$ & $\begin{array}{l}\bar{T}, \bar{T}^{\prime}, \bar{P}(T) \text { and mean } \\
\text { concentrations of } \mathrm{H}_{2}, \\
\mathrm{H}_{2} \mathrm{O}, \mathrm{O}_{2}, \text { and } \mathrm{N}_{2} \text { at } \\
x / d=18.4 \text {. }\end{array}$ \\
\hline
\end{tabular}




\begin{tabular}{ll}
\hline \multicolumn{1}{c}{ Other } & Instrument properties \\
\hline$\overline{\rho^{\prime} u^{\prime}, \overline{f^{\prime} u^{\prime}} \text { and } \overline{T^{\prime} u^{\prime}}}$ & $\begin{array}{l}\text { Single-channel LDA }(0.5 \times 2 \mathrm{~mm}) \\
\text { frequency shifted; Raman } \\
\text { scattering } 2 \mu \mathrm{sec} \text { pulse. }\end{array}$
\end{tabular}

$\bar{P}(\rho, u)$ and $\gamma$
traverse at
$x / d=50$.

$\overline{\rho^{\prime} u^{\prime}}$ at $x / d=50$.
$y / d=4$.

$$
y / d=4 \text {. }
$$

\section{Schlieren photographs at nozzle exit.}

Schlieren photographs.

\author{
Same as Driscoll et al. ${ }^{23}$
}

Same as Dibble et al. ${ }^{24}$

Dual channel LDA $(0.5=2.0 \mathrm{~mm})$; dual Bragg shift; coincidence $10 \mu \mathrm{sec}$; LDA seed particles added to air only, jet fiuid only, and then both.

Imaged segment of pulsed laser beam onto 500 element Optical Multichannel Analyzer.

Pitot-static probe; bare-wire thermocouple $(0.05$ and 0.10 $\mathrm{mm}$ coated bead) corrected for radiation; isokinetic sampling.

\section{Single-channel LDA $(0.12=1.4$ $\mathrm{mm}$ probe volume) frequency shifted; bare-wire thermocouple ( $0.1 \mathrm{~mm}$ bead diameter); sampling probe $(0.3 \mathrm{~mm}$ port) analyzed on dry basis with $\mathrm{H}_{2} \mathrm{O}$ computed.}

LDA same as Takagi et al. ${ }^{56}$ with macroscales using Taylor's hypothesis; temperature and gassampling probes same as Takagi et al. ${ }^{56}$
Comments

Asymmetrical $\rho^{\prime} u^{\prime}$ suggests effect of buoyancy. $f^{\prime} u^{\prime}$ correlations within $40 \%$ of those of Stamer and Bilger ${ }^{59}$ but only within a factor of 3 for $\rho$

Effects of buoyancy on turbulence properties observed at $x / d=50$.

Investigation of velocity bias due to particle origin; velocity data from both reacting and nonreacting jets.
Initial velocity profiles and streamwise pressure gradient are unknown. $\bar{\gamma}, \bar{\gamma}^{\prime}$, and $\bar{P}(\gamma)$ traverses
at $x / d=18.4$ and 32.7

\footnotetext{
LDA and gas sampling same as Takagi et al. ${ }^{56}$; bare-wire thermocouple $(0.025 \mathrm{~mm}$ bead diameter) with electrical compensation using mean response time.

Electrostatic probe for positive ions $(0.1 \times 1.5 \mathrm{~mm}$ probe volume $)$.
}

Uncertainties in temperature fluctuation measurements due to compensation circuit are difficult to evaluate. 
TABLE 2. (continued)

\begin{tabular}{|c|c|c|c|}
\hline Ref. & Flow & Velocity & Scalars \\
\hline $\begin{array}{l}\text { Other studies } \\
\text { Hawthorne, } \\
\text { et al. }\end{array}$ & $\begin{array}{l}\text { Fuel jet in furnace } \\
\text { or unconfined; } \\
\text { vertical; } \\
\text { (i) hydrogen/air; } d=3.2 \\
-6.4 \mathrm{~mm} ; \bar{u}_{j}=49.4- \\
152.4 \mathrm{~m} / \mathrm{sec} \text {. } \\
\\
\text { (ii) carbon monoxide/air; } \\
d=6.4 \mathrm{~mm}, R_{j}=5095 \text {, } \\
\text { lifted frame. }\end{array}$ & & $\begin{array}{l}\text { (i) } \bar{f} \text { along axis, } x / d=10-75 ; \\
\bar{f}, \overline{f^{\prime}}: \text { and mean concentrations } \\
\text { of } \mathrm{H}_{2}, \mathrm{O}_{2} \text { and } \mathrm{H}_{2} \mathrm{O} \text { at } x / d= \\
32,48 \text { and } 66 .\end{array}$ \\
\hline $\begin{array}{l}\text { Takeno \& } \\
\text { Kotani }^{82}\end{array}$ & $\begin{array}{l}\text { Fuel jet in coflow; } \\
\text { hydrogen } / \text { air } ;=1 \mathrm{~mm} ; \\
\text { vertical; } \bar{u}_{j} / \bar{u}_{\mathrm{c}}(\mathrm{m} / \mathrm{sec})=157 \\
-598 / 5 ; R e_{j}=1431-5439 \\
T_{e}=300-700 \mathrm{~K}\end{array}$ & & \\
\hline $\begin{array}{l}\text { Becker \& } \\
\text { Liang }^{63}\end{array}$ & $\begin{array}{l}\text { Fuel jet in still air; } \\
\text { hydrogen/air; carbon } \\
\text { monoxide/air; } d=0.69- \\
4.57 \mathrm{~mm} ; \text { vertical; } \\
\left(\pi a \rho_{\mathrm{o}} / 4 M_{j}\right)^{1 / 3} x_{f}=2.1- \\
7.7 \text { for hydrogen, } 1.1- \\
4.1 \text { for carbon monoxide. }\end{array}$ & & \\
\hline Gore et al. ${ }^{31}$ & $\begin{array}{l}\text { Fuel jet in still air, hydrogen/ } \\
\text { air; } d=5 \mathrm{~mm} ; \text { vertical; } \\
\bar{u}_{j}(\mathrm{~m} / \mathrm{sec})=66,108 \\
R e_{j}=3000,5722\end{array}$ & $\begin{array}{l}\bar{u} \text { and } \bar{u}^{\prime} \text { at jet } \\
\quad \text { exit and along } \\
\text { axis. }\end{array}$ & $\begin{array}{l}\text { Mean concentrations of } \\
\mathrm{H}_{2}, \mathrm{O}_{2}, \mathrm{~N}_{2} \text { and } \mathrm{H}_{2} \mathrm{O} \\
\text { and mean temperature } \\
\text { along axis. }\end{array}$ \\
\hline $\begin{array}{c}\text { Schoenung \& } \\
\text { Hanson }^{83}\end{array}$ & $\begin{array}{l}\text { Fuel jet in still air; carbon } \\
\text { monoxide/air; } d=15 \mathrm{~mm} \text {; } \\
\text { vertical; } \bar{u}_{j}=10 \mathrm{~m} / \mathrm{sec} ; 1 \% \\
\mathrm{H}_{2} \text { in } \mathrm{CO} \text {. by volume, } \\
\text { to stabilize flame. }\end{array}$ & $\begin{array}{l}\bar{u} \text { and } \bar{u}^{\prime} \text { at jet } \\
\text { exit. }\end{array}$ & $\begin{array}{l}\text { Mean concentration of } \mathrm{CO} \\
\text { and } \mathrm{CO}_{2} \text { and concentration } \\
\text { fluctuations of } \mathrm{CO} \\
\text { traverses at } x / d=2 \text { and } 5 \\
P(\mathrm{CO}) \text { traverses at } x / d=2 \text {. } \\
\text { Power spectral density of } \\
\text { CO at } x / d=5 \text {. }\end{array}$ \\
\hline $\begin{array}{l}\text { Razdan \& } \\
\text { Stevens } \\
\end{array}$ & $\begin{array}{l}\text { Fuel jet in coflow; } \\
\text { carbon monoxide/air; } \\
d=5 \mathrm{~mm} ; 300 \mathrm{~mm} \\
\text { round duct; vertical; } \\
\bar{u}_{j} / \bar{u}_{\mathrm{e}}(\mathrm{m} / \mathrm{sec})=37.5 / \\
0.13 ; R e_{j}=11400 .\end{array}$ & $\begin{array}{l}\bar{u}, k \text { along axis; } \\
x / d=20-100, \text { and } \\
\text { traverses at } x / d= \\
20,40,50 \text { and } 60 .\end{array}$ & $\begin{array}{l}\tilde{f}, \vec{T} \text { and mean concentrations } \\
\text { of } \mathrm{CO}, \mathrm{CO}_{2} \text { and } \\
\mathrm{O}_{2} \text { along axis; } x / d=20- \\
100, \text { and traverses at } x / d \\
=20,40,50 \text { and } 60 .\end{array}$ \\
\hline Gore et al..$^{3 \mathrm{~g}}$ & $\begin{array}{l}\text { Fuel jet in still air; } \\
\text { carbon monoxide/air; } \\
d=5 \mathrm{~mm} \text {, vertical; } \\
u_{j}(\mathrm{~m} / \mathrm{sec})=24.8 \\
51.5 ; R e_{j}=7470 \\
13140 .\end{array}$ & $\begin{array}{l}\bar{u} \text { and } \bar{u}^{\prime} \text { at jet } \\
\text { exit and long } \\
\text { axis. }\end{array}$ & $\begin{array}{l}\text { Mean concentrations of } \\
\mathrm{CO}, \mathrm{O}_{2}, \mathrm{~N}_{2} \text { and } \mathrm{CO}_{2}, \\
\text { and mean temperature } \\
\text { along axis. }\end{array}$ \\
\hline Dahms 2 & $\begin{array}{l}\text { Fuel jet in still } \\
\text { envi ronment; dilute } \\
\text { acid/base reaction } \\
\text { in water; } d=2.54 \mathrm{~mm} \text {; } \\
850 \times 850 \times 1590 \mathrm{~mm} \\
\text { rectangular enclosure; } \\
\text { vertical; } R e_{j}=1000- \\
20000 \text {. }\end{array}$ & & $\begin{array}{l}\bar{f}, \bar{f}^{\prime} \text { and } \bar{P}(f) \text { along axis, } \\
x / d \leq 300\left(R e_{j}=1500\right. \\
\text { and } 3000) . \text { Several } \\
\text { instantaneous radial } \\
\text { concentration profiles } \\
\text { at } x / d=300 \\
\left(R e_{j}=5000\right) .\end{array}$ \\
\hline $\begin{array}{l}\text { Dahm \& } \\
\text { Dimotakis }^{84}\end{array}$ & $\begin{array}{l}\text { Same as Dahm } \\
\qquad R e_{j}=1500-10000\end{array}$ & & $\begin{array}{l}\bar{f} \text { and } \bar{f}^{\prime} \text { traverse at } x / d= \\
300\left(R e_{j}=1500 \text { and }\right. \\
3000) ; \text { instantaneous } \\
\text { concentration profiles at } \\
x / d=300\left(R e_{j}=5000\right) .\end{array}$ \\
\hline
\end{tabular}




\begin{tabular}{l} 
Other \\
\hline Visible flame length. \\
Dark-field and shadow-graph \\
photographs; length to \\
transition.
\end{tabular}

\author{
Instruinent Properties
}

Sampling and analysis for $\mathrm{H}_{2}$ and $\mathrm{O}_{2}$ on a dry basis, computation of $\mathrm{H}_{2} \mathrm{O} ; f^{\prime}$ found from local mean mixture fraction and concentrations assuming Gaussian PDF and fiame sheet.
Comments

Traverses made for confined configuration which authors felt influenced the results. Only visible flame length for one condition measured for carbon monoxide/air flame.

Visible flame length

Spectral radiation intensities (1-4 $\mu \mathrm{m}$ wa velength range) and radiative heat fluxes.

Spectral radiation intensities (1-6 $\mu \mathrm{m}$ wavelength range) and radiative heat fluxes.
Visible reaction-zone length and its PDF.

\section{LDA $(0.24 \times 0.72 \mathrm{~mm}$ probe volume) frequency shifted; bare-wire thermocouple $(0.150$ mm bead diameter); sampling probe $(0.1-0.2 \mathrm{~mm}$ port).}

Mean concentrations by sonic probe (0.4 mm inlet, water-cooled); carbon monoxide absorption probe ( $5 \mathrm{~mm}$ path length).

\section{Single-channel LDA $(0.065 \times 0.75 \mathrm{~mm}$} probe volume) frequency shifted; bare-wire thermocouple ( $0.25 \mathrm{~mm}$ bead diameter) corrected for radiation; water-cooled sampling probe $(1.2 \mathrm{~mm}$ inlet). Momentum balance within $30 \%$ (ignoring buoyancy). Enthalpy balance within $30 \%$. Element balance within $20 \%$.

Same as Gore et al. ${ }^{31}$

Same as Gore et al. ${ }^{31}$

LIF $(0.6 \times 0.5-1 \mathrm{~mm}$ probe volume) both at a point and along a line.
See references cited therein for earlier similar work.

Primarily a study of transition to turbulent flow.

Estimates of differences between Reynolds and Favre-averaged scalar properties provided. Experimental uncertainties estimated. 
The most recent work at Sandia removes the buoyancy difficulties and expands the variables measured (Dibble et al. ${ }^{23,29}$ ). The hydrogen/jet diffusion flame in coflow was observed for the vertically upward flow configuration. Thus, asymmetries due to buoyancy were eliminated, although effects of buoyancy still influenced flow properties near the flame tip. LDA and Rayleigh scattering were used as before; however, Raman scattering measurements were added to provide instantaneous mixture fraction. Data are available for three injector conditions yielding $R e_{j}=9000,18,000$ and 27,000 . In addition to the impressive list of point measurements obtained in the flow, one-dimensional imaging of the Rayleigh scattering laser beam was also undertaken. This yielded instantaneous radial nrofiles of density at $x / d=50$. Radial derivatives were obtained from these data. In our opinion, the measurements of
Dibble et al. ${ }^{23.29}$ can serve for definitive evaluation of analysis at the fast-reaction limit-subject only to some uncertainty concerning the degree to which this limit was approached. It is likely, however, that approach to equilibrium is closer than the conditions considered by Drake and coworkers, ${ }^{14-18}$ since injector dimensions are larger and flow velocities are somewhat lower.

\subsubsection{University of Osaka studies}

Three studies of hydrogen/air diffusion flames have been reported by Takagi et al..$^{56.57 .59}$ at the University of Osaka. A vertical orientation with coflow was used. Measurements primarily considered the near-injector region, $x / d<51$, and included: mean and fluctuating velocities, using a single-channel LDA; mean and fluctuating temperatures, using a

TABLE 3. Measurements in plane free shear layers

\begin{tabular}{|c|c|c|c|}
\hline Reference & Flow & Velocity & Scalars \\
\hline \multicolumn{4}{|l|}{$\begin{array}{l}\text { Cal. Tech. } \\
\text { studies }\end{array}$} \\
\hline Mungal ${ }^{47}$ & $\begin{array}{l}\text { Shear layer in duct; dilute } \\
\text { hydrogen/fluorine in nitrogen } \\
\text { or helium; } 200 \times 50 \mathrm{~mm} \text { and } \\
200 \times 100 \mathrm{~mm} \text { high- and low- } \\
\text { speed sides; horizontal; } \\
\bar{u}_{j} / \bar{u}_{\mathrm{e}}(\mathrm{m} / \mathrm{sec})=23 / 8.8 ; R_{x}= \\
4 \times 10^{5} ; 120 \mathrm{~K} \text { maximum } \\
\text { temperture rise. }\end{array}$ & $\begin{array}{l}\bar{u} \text { traverses at one } \\
\text { station for three } \\
\text { cases (one non- } \\
\text { combusting). }\end{array}$ & $\begin{array}{l}\bar{T} \text { traverses at one } \\
\text { station. }\end{array}$ \\
\hline Mungal et al. ${ }^{48}$ & Same as Mungal ${ }^{47}$ & Same as Mungal ${ }^{47}$ & Same as Mungal ${ }^{47}$ \\
\hline Mungal et al..$^{49}$ & $\begin{array}{l}\text { Same as Mungal }{ }^{47} \\
\bar{u}_{j} / \bar{u}_{\mathrm{e}}(\mathrm{m} / \mathrm{sec})=85 / 13.5\end{array}$ & & $\begin{array}{l}\bar{T} \text { traverse at one } \\
\text { location. }\end{array}$ \\
\hline Koochesfahani ${ }^{51}$ & $\begin{array}{l}\text { Shear layer in duct; dilute } \\
\text { acid/base }\left(\mathrm{H}_{2} \mathrm{SO}_{4} / \mathrm{NaOH}\right) \\
\text { reaction in water; } \\
\bar{u}_{j}, \bar{u}_{e}(\mathrm{~m} / \mathrm{sec})=3-7 \\
\bar{u}_{j} / \bar{u}_{e}=0.38-0.45\end{array}$ & & $\begin{array}{l}\bar{f} \text { and } \bar{P}(f) \text { at one } \\
\text { location. }\end{array}$ \\
\hline $\begin{array}{l}\text { Koochesfahani } \\
\text { \& Dimotakis }\end{array}$ & Same as Koochesfahani ${ }^{51}$ & & Same as Koochesfahani ${ }^{51}$ \\
\hline \multicolumn{4}{|l|}{ Other Studies } \\
\hline Batt $^{53}$ & $\begin{array}{l}\text { Wall jet in still air; dilute } \\
(0.005 \%) \text { nit rogen tetroxide } \\
\text { dissociation; } 127 \times 610 \mathrm{~mm} \\
\text { slot; vertical; } u_{j}=7 \mathrm{~m} / \mathrm{sec} \text {. }\end{array}$ & & $\begin{array}{l}\text { Time-averaged mean } \\
\text { and fluctuating } \mathrm{NO}_{2} \\
\text { concentrations at } \\
x=453 \mathrm{~mm} .\end{array}$ \\
\hline Wallace $^{50}$ & $\begin{array}{l}\text { Shear layer in duct; dilute } \\
\text { nitric oxide/ozone in helium, } \\
\text { nitrogen or argon. } 100 \times 25 \\
\text { mm and } 100 \times 50 \mathrm{~mm} \text { low- } \\
\text { and high-speed sides; } \\
\text { horizontal; } \bar{u}_{j} /{ }_{\mathrm{u}}(\mathrm{m} / \mathrm{sec}) \\
=25 / 5 ; \operatorname{Re}=5 \times 10^{4}, 200 \mathrm{~K} \\
\text { maximum temperature rise. }\end{array}$ & $\begin{array}{l}\bar{u} \text { traverse at one } \\
\text { station. }\end{array}$ & $\begin{array}{l}\bar{T} \text { traverse at one } \\
\text { station. }\end{array}$ \\
\hline
\end{tabular}


compensated thermocouple; and mean concentrations of major species, using a sampling probe. Initial conditions and streamwise pressure gradients for these flows are unknown, the sampling measurements have uncertain levels of density weighting, and the temperature fluctuation measurements with compensation are difficult to assess. Thus, use of these data for model evaluation is problematical, even though it is extensive.

\subsubsection{Other studies}

Several other studies have been reported. The classical work of Hawthorne et al. ${ }^{81}$ is well known, but uncertainties in these measurements and the definition of operating conditions are large by today's standards. The work of Takeno and Kotani ${ }^{82}$ was limited to flow visualization in a study primarily considering transition to turbulence near the exit of a jet flame. Becker and Liang ${ }^{63}$ measure flame lengths for hydrogen/air and carbon monoxide/air flames; however, it is difficult to associate flame luminosity with parameters computed by typical analysis.

Gore $e t$ al. ${ }^{31,38}$ report stucture measurements of vertical hydrogen and carbon monoxide diffusion flames in still air. The main objective of these studies involved flame radiation properties; however, mean and fluctuating velocity distributions were measured across the jet exit and velocities and scalar properties were measured along the axis. Differences between Reynolds- and Favre-averaged scalar properties are estimated. These results could be useful for model development; however, structure data is limited and Reynolds numbers are low, introducing complications due to buoyancy.

Schoenung and Hanson ${ }^{83}$ and Razdan and

\begin{tabular}{lll}
\hline Other & Instrument properties & Comments \\
\hline
\end{tabular}

Dark-field photographs

Same as Mungal ${ }^{4}$ ?

Schlieren photograph

Time-resolved LIF visualization along a line crossing the flow.

Same as Koochesfahani ${ }^{51}$

Blue and UV shadow-graphs.

Pitot-tube rake (1.7 $\mathrm{mm}$ OD tubes). Resistance wire temperature probe ( $0.0025 \mathrm{~mm}$ dia. $\times 1.5 \mathrm{~mm}$ long)

Same as Mungal ${ }^{47}$
Same as Mungal ${ }^{47}$

L IF $(0.10 \times 0.35 \mathrm{~mm}$ probe volume) along a $23 \mathrm{~mm}$ line.

Same as Koochesfahani ${ }^{51}$

Fiber-optics probe $(1 \times 25$ $\mathrm{mm}$ probe volume.

Pitot probe $(0.3 \times 3 \mathrm{~mm}$ inlet): bare-wire thermocouple (0.013 $\mathrm{mm}$ wires).

\author{
Side walls adjusted to \\ give zero-static \\ pressure gradient.
}

\author{
Same as Mungal ${ }^{4}$ \\ Same as Mungal ${ }^{4}$ \\ Measurements in region \\ of mixing transition.
}

Same as Koochesfahani $i^{51}$ 
Stevens $^{39}$ also provide structure measurements for carbon monoxide/air fiames-both using vertical upflow. The measurements of Razdan and Stevens are most complete, involving: mean and fluctuating velocities using LDA, mean temperatures using a thermocouple and mean concentrations of major species using gas sampling. However, initial and boundary conditions for this flow are unknown and there are density weighting uncertainties for the sampling measurements. Clearly, additional work with carbon monoxide/air flames is warranted, particularly since this reactant combination reduces problems of differential diffusion in comparison to hydrogen/air flames.

The last studies in Table 2 involve work carried out at Cal. Tech. (Dahm ${ }^{52}$ and, Dahm and Dimotakis ${ }^{84}$ ). These measurements considered dilute acid/base reactions in water; therefore, effects of property variations near the reaction sheet were small. As a result, these results cannot test critical variable property effects on analysis. The measurements provide extensive information on mixture fraction; however, virtually no information is available concerning flow velocities.

Clearly, the round free jet configuration has attracted many investigators. These studies have helped to develop our understanding of turbulent flames at the fast-reaction limit. However, only a few have potential application for definitive evaluation of analysis. The recent study of hydrogen/air flames in vertical upflow, using nonintrusive diagnostics, by Dibble et al. ${ }^{23,29}$ appears to be adequate for evaluation of analysis, although effects of buoyancy near the flame tip should be considered. Similar measurements by Drake and coworkers ${ }^{14-18}$ are felt to be satisfactory for model development, and perhaps for evaluation as well. However, additional study to determine the extent of asymmetries, due to buoyancy in a horizontal flow, is warranted.

\subsection{Plane Free Shear Layers}

Table 3 is a summary of past studies of turbulent reaction in plane free shear layers, where conditions approach the fast-reaction limit. Most of this work was carried out at the California Institute of Technology. Two independent studies (Batt ${ }^{53}$ and Wallace ${ }^{50}$ ) are also listed. Wallace's investigation was closely associated with the Cal. Tech. studies.

\subsubsection{Cal. Tech. studies}

The reacting flow studies at Cal. Tech. were preceded by extensive work concerning passive scalar mixing in shear layers. Gouldin et al. ${ }^{2}$ review the passive mixing studies; only the reacting flow studies are discussed here. Two reactant combinations were considered: (1) dilute hydrogen/fluorine mixtures in nitrogen or helium, and (2) acid/base reactions in water.
The hydrogen/fluorine studies are described by Mungal $^{47}$ and Mungal et al. ${ }^{48,49}$ The objective of this work was to provide a diffusion flame structure with relatively small heat release, e.g. the maximum temperature rise was less than $120 \mathrm{~K}$. This causes difficulties in approach to the fast-reaction limit, as discussed earlier. Well-known hydrogen/fluorine kinetics were also complicated somewhat, since nitric oxide had to be added to the fluorine-containing stream to initiate the reaction. The side walls of the flow channel were adjusted to achieve a zerostreamwise pressure gradient. Static pressures, however, were measured with liquid-filled manometers whose resolution is $c a 100 \mathrm{kPa}$, at best. Thus effects of pressure gradients at lower levels, seen in Figs 12 and 13 from Stårner and Bilger, ${ }^{59}$ are probably present. Relatively low Reynolds numbers also suggest problems with the effects of transition and buoyancy. Initial conditions for these tests were not measured directly, although sufficient information is reported for reasonable estimates. Finally, the data reported are relatively limited, consisting of mean velocity and temperature traverses (the former for noncombusting conditions) at one location.

Work on hydrogen/fluorine flames is continuing at Cal. Tech., but with higher maximum temperatures in the flow. These experiments provide conditions progressively moving towards conditions representative of the variable scalar property effects of flame environments. If more complete measurements can be conducted for these conditions, in spite of the corrosion problems with fluorine at high temperatures, the entire study would be a very useful source of information for reaction in free shear ayers.

The investigation of acid/base reactions in water, by Koochesfahani ${ }^{51}$ and Koochesfahani and Dimotakis $^{85}$ involves negligible changes in scalar properties when reaction occurs. Thus, this experiment is more relevant to passive scalar mixing, with the reactants primarily serving as a marker for the extent of mixing. Measurements defining initial and boundary conditions, as well as the flow structure itself, are relatively limited. Thus, even though these results approach the fast-reaction limit, they don't really address the issues of major interest in this review.

\subsubsection{Other studies}

Wallace's ${ }^{50}$ study is generally similar to Mungal. ${ }^{47}$ Differences involve use of dilute nitric oxide/ozone as reactants and a reduction of apparatus size by roughly a factor of two. Only weak property variations were considered, e.g. maximum temperature changes were less than $200 \mathrm{~K}$. Problems of initial and boundary conditions, low Reynolds numbers and buoyancy, and relatively limited structure data are similar to Mungal. ${ }^{47}$

Batt's ${ }^{53}$ study of nitrogen in tetroxide dissociation followed an extensive study of passive scalar mixing 
in the same apparatus. The reaction experiment involved dissociation of nitrogen tetroxide (in a cool wall jet) to nitrogen dioxide upon mixing with room temperature air. Temperature changes in the flow were small, ca $50 \mathrm{~K}$; therefore, variable property effects are not very representative of flame environments. Vertical downflow in a stagnant environment was considered, simplifying problems of specifying boundary conditions and treating buoyancy. Initial conditions could be inferred from the passive mixing tests, even though they were not specifically reported for the reacting flows. The authors also presents a careful evaluation of approach to the fact-reaction limit. Data reported, however, are relatively limited, e.g. mean and fuctuating concentrations of nitrogen dioxide. These results were obtained with a relatively bulky probe, suggesting large measurement uncertainties near the edge of the flow, where turbulence intensities are high in a stagnant environment.

All the plane free shear layer flows have significant limitations for definitive evaluation of turbulent reaction analysis. Clearly, additional systematic experimentation with plane free shear layers is merited-particularly for conditions having greater energy release rates, Reynolds numbers, and preferably in vertical upflow to simplify treating effects of buoyancy. Such experiments will be costly, since plane flows involve relatively large rates of reactant consumption, for adequate aspect ratios, in comparison to round jets. The test arrangement used by $\mathrm{Kremer}^{86}$ to study hydrocarbon diffusion flames offers advantages for experiments of this type, but curiously has not been used by subsequent workers.

\subsection{Wall Boundary Layers}

Reasonable turbulence levels and aspect ratios in wall boundary layers cause the greatest problems of reactant consumption; therefore, relatively few studies have been reported for this flow at the fastreaction limit. This is surprising, in spite of the cost, since the configuration is important for natural fires and solid rocket applications. Table 4 is a summary of the studies that could be found, all are by Ueda and coworkers. ${ }^{87-89}$

The test arrangement of Ueda and coworkers ${ }^{87-89}$ involved a hydrogen/nitrogen mixture flowing from a porus plane surface. The porous surface formed the bottom of an air flow channel at some distance from the inlet. The combined studies provide mean and fluctuating streamwise velocities and the Reynolds stress. However, these measurements used an LDA with particle averages; therefore, the results involve uncertain levels of velocity bias. The mean and fluctuating temperatures are reported - the latter for only the first study. The mean temperatures are not corrected for radiation; however, sufficient information is available to make reasonable estimates of this effect. The temperature fluctuation measurements are difficult to assess for uncertainties until more is known concerning the accuracy of compensation networks in flame environments. The authors did not provide a zero streamwise pressure gradient during their experiments, although they did estimate the pressure gradient. The effect was sufficient to accelerate reaction zone velocities to values greater than the free-stream velocity. This and wall effects present significant challanges for analysis of turbulence in this flow.

The main difficulty with this configuration is that past measurements are too sparse, really only one test condition, to adequately test analysis. Measurement of species concentrations would also be desirable, to assess the approach to the fast-reaction limit and effects of differential diffusion. Frequent cross-stream traverses are also needed to properly characterize the flow from the leading edge of the porous plate. More experimentation for this important flow is clearly needed.

\section{CONCLUDING REMARKS}

Developing data for evaluating analysis of turbulent reacting flow, even at the apparently simple fastreaction limit, represents a substantial experimental challenge. Measurements of flow structure involve many variables, including hydrodynamic and scalar properties, their correlations, and their spectral properties (to ensure that systematic large-scale perturbations are not mistaken for turbulence, as recommended by Libby et al. ${ }^{4}$ ). Boundary and initial conditions must be known and controlled over lengthy periods of experimentation. Large Reynolds numbers are desirable to minimize effects of transition and buoyancy which can complicate both analysis and interpretation of measurements. At the same time, requirements for flame attachment, approach to the fast-reaction limit, and the cost of apparatus and reactants impose limitations on the practical range of conditions available for testing. Costly nonintrusive intrumentation is to be preferred over the use of probes, to avoid uncertainties concerning the type of averages measured and to obtain information on fluctuating properties which are the hallmark of turbulent flows. Finally, a sufficient number of operating conditions, and traverses at a given operating condition, are needed to reduce the possibility of fortuitous agreement between predictions and measurements.

It is also essential that this information be available for several flow geometries-even within the relatively limited class of parabolic flows. For example, axisymmetric and plane free shear flows require different empirical constants for many current turbulence models, $c f$. Pope. ${ }^{90}$ The presence of surfaces also clearly modifies turbulence structure due to low Reynolds number effects. Practical problems involve this range of conditions; therefore results are needed for round jets, free plane shear layers and wall boundary layers - at a minimum. 
TABLE 4. Measurements in wall boundary layers

\begin{tabular}{|c|c|c|c|}
\hline Reference & Flow & Velocity & Scalars \\
\hline Ueda et al..$^{87.88}$ & $\begin{array}{l}\text { Fuel injected from porous } \\
\text { wall on floor of a duct; } \\
\text { dilute hydrogen }(4 \% \text { by } \\
\left.\text { mass in } \mathrm{N}_{2}\right) / \text { air; } 96 \times 200 \\
\text { mm plate; horizontal-facing } \\
\text { upward; } 100 \times 200 \mathrm{~mm} \text { duct; } \\
(\overline{\rho v})_{w} /(\overline{\rho u})_{e}=0.01 ; u_{e}= \\
10 \mathrm{~m} / \mathrm{sec} ; \bar{u}_{e}^{\prime} / \bar{u}_{e}=0.7 \% \\
\text { streamwise static pressure } \\
\text { gradient }-61 \mathrm{~Pa} / \mathrm{m} \text { (est.) }\end{array}$ & $\begin{array}{l}\bar{u} \text { and } \bar{u} \text { traverses at } \\
x=60,120 \text { and } 180 \\
\mathrm{~mm} .\end{array}$ & $\begin{array}{l}\bar{T} \text { and } \bar{T}^{\prime} \text { traverses at } \\
x=60,120 \text { and } 180 \\
\mathrm{~mm} .\end{array}$ \\
\hline Ueda et al. ${ }^{89}$ & Same as Ueda et al. ${ }^{87,88}$ & $\begin{array}{l}\bar{u}, \bar{u}^{\prime} \text { and } \overline{u^{\prime} v^{\prime}} \text { profiles } \\
\text { at } x=150 \text { and } \\
180 \mathrm{~mm} .\end{array}$ & $\begin{array}{l}\bar{T} \text { profiles at } x=150 \\
\text { and } 180 \mathrm{~mm} .\end{array}$ \\
\hline
\end{tabular}

Thus, all the difficulties for different flow configurations, highlighted by the Stanford conferences for turbulent fluid flow modeling, are present for reacting flows-with the additional complications of evaluating mixing and a host of scalar properties.

From this perspective, it is clear that in spite of significant progress in gaining a better understanding of turbulent fast-reacting flows, based on the studies discussed here, we are far from the experimental goal of providing an adequate data base for the evaluation of analysis. Work completed thus far has provided a background to help avoid experimental pitfalls. We have a much better understanding of the types of averages to be defined; effects of systematic biases; the importance of seemingly modest changes in initial and boundary conditions; and the ubiquitous, but complex, effects of buoyancy on even relatively high speed flows.

Clearly, work providing a proper data base will involve careful consideration of both hydrodynamic and chemical effects, which is the nature of practical combustion processes. Skills and interest in these disparate areas are rarely found in one individual; thus we agree with Libby et $a .^{4}$ that teams of workers will be needed to develop this data base. The work should also be coordinated with theoreticians, so that the sensitivity of analysis to various experimental parameters can be determined. Past work also suggests that a series of experiments, using an apparatus over an extended period of time, is needed to fully develop an adequate range of test conditions and measured variables.

At present, only the most recent work, exclusively using nonintrusive diagnostics, comes close to meeting these needs. In particular, measurements by Dibble and coworkers ${ }^{23.29}$ at Sandia can be recommended at this time for evaluation of analysis at the fast-reaction limit. The test case is summarized in Table 5. Test conditions involve hydrogen/air combustion in a round jet configuration in coflow. Reynolds numbers are reasonably high and vertical upflow is used, minimizing complications due to relaminarization and buoyancy. Initial and boundary conditions are well-defined, a range of test conditions is available, and flow structure is reasonably defined with frequent traverses. Experimental uncertainties are known so that discrepancies between theory and experiment can be rationally evaluated. Clearly, this work has benefitted from the experience of these workers during earlier studies, as well as by past work by other investigators. Data provided by Dibble and coworkers ${ }^{23.29}$ can be found from original sources and are also summarized in the report by Strahle and Lekoudis ${ }^{91}$ upon which the present series of articles is based.

Complementary work by Drake ${ }^{14-20}$ can also be recommended for development of analysis. These tests, summarized in Table 6, also involve a hydrogen/air diffusion flame in the round-jet coflow configuration. However, the measurements involve several difficulties, as follows: Reynolds numbers are relatively low $\left(R e_{j}=8500\right)$; the flow was horizontal, suggesting loss of symmetry of at least turbulence properties due to buoyancy; the scale of the experiments is relatively small $(d=3 \mathrm{~mm})$, so that approach to the fast-reaction limit is marginal over much of the flow field; and velocity measurements and velocity/scalar correlations are relatively incomplete. While recognizing these problems, it is still felt that the measurements provide a useful extension of the range of conditions for which data are available; therefore, these data are also summarized in Strahle and Lekoudis ${ }^{91}$ for use during development of analysis.

\section{ADDiITIONAL DATA NEEDS}

Additional work is clearly needed. Experiments using carbon monoxide/air should be considered, since these reactants offer application of nonintrusive diagnostics similar to hydrogen/air, but are less influenced by low Reynolds number and differential diffusion difficulties. While data are still needed for the round jet configuration, greater 


\begin{tabular}{lcc}
\hline Other & \multicolumn{1}{c}{ Instrument properties } & \multicolumn{1}{c}{ Comments } \\
\hline $\begin{array}{c}\text { Dark-field } \\
\text { photograph }\end{array}$ & $\begin{array}{c}\text { Single-channel LDA using particle- } \\
\text { averaged properties; bare-wire } \\
\text { thermocouple }(0.05 \mathrm{~mm} \text { bead } \\
\text { diameter) uncorrected for radiation } \\
\text { with a compensation circuit. }\end{array}$ & $\begin{array}{c}\bar{u} \text { and } \bar{u}^{\prime} \text { measurements are } \\
\text { velocity biased. }\end{array}$ \\
& $\begin{array}{l}\bar{T}^{\prime} \text { uncertainties largely due } \\
\text { to use of compensated } \\
\text { thermocouple. }\end{array}$
\end{tabular}

TABLE 5. Data summary

\begin{tabular}{ll}
\hline Flow & Hydrogen/air diffusion flame. \\
Cases & Dibble et al. ${ }^{23.29}$ \\
Geometry & Round hydrogen jet in coflowing air: \\
& $R e=9,00018,000,27,000$. \\
& Jet velocity: $75,150,225 \mathrm{~m} / \mathrm{sec}$; Air \\
& velocity: $9.2 \mathrm{~m} / \mathrm{sec}$. \\
$\begin{array}{c}\text { Mean quantities } \\
\text { measured }\end{array}$ & $\bar{u}, \bar{v}, \bar{\rho}$ equilibrium temperatures, \\
$\begin{array}{c}\text { Turbulence } \\
\text { quantities } \\
\text { concentration of species. }\end{array}$ & $\bar{u}^{\prime}, \bar{v}^{\prime}, \bar{\rho}^{\prime}$, intermittency, flatness \\
$\begin{array}{c}\text { Notes } \\
\text { and skewness. }\end{array}$ & LDV, Rayleigh and Raman Scattering \\
& used. Vertical flame. initial condit- \\
& ions mea sured.
\end{tabular}

TABLE 6. Data summary

\begin{tabular}{ll}
\hline Flow & Hydrogen/air diffusion flame. \\
Case & Drake et al. $.^{14}-21$ \\
Geometry & Round hydrogen jet in coflowing air; \\
& $R e=8,500$, exit jet diameter: $3 \mathrm{~mm}$. \\
$\begin{array}{c}\text { Mean quantities } \\
\text { measured }\end{array}$ & $\bar{u}, \bar{\rho}, \bar{T}$ and concentration $\mathrm{H}_{2}, \mathrm{H}_{2} \mathrm{O}$, \\
$\begin{array}{c}\text { Turbulence } \\
\text { quantities } \\
\text { measured }\end{array}$ & $\bar{u}_{2}^{\prime}, \bar{T}^{\prime}, \bar{\rho}^{\prime}$, skewness and flatness \\
Notes & of mixture fractions. \\
& LDV, Raman and saturated fluoresc- \\
& ence used. Horizontal flow.
\end{tabular}

attention should be given to plane layers and wall boundary layers than in the past.

Data obtained using probes involves unacceptable uncertainties for definitive evaluation of analysis, except for routine monitoring applications. Only nonintrusive measurements should be seriously considered for benchmark experiments.

The present effort has demonstrated the need for a format for documenting data in order to provide accessibility for potential users. A suggested format and example case study are presented in the appendix to this paper. The recommended format reflects issues discussed in this paper concerning the use of a data base for model development, verification and general application.

\section{REFERENCES}

1. Burke, S. P. and Schuman, T. E. W., Ind. Engng Chem. 20,998 (1928).

2. Gouldin, F. C., Johnson, S. C., KollmanN, W. and Schefer, R. W., Prog. Energy Combust. Sci., in press.

3. Drake, M. C. and Kollmann, W., Prog. Energy Combust. Sci., in press.

4. Libay, P. A., Sivasegaram, S. and Whitelaw, J. H., Prog. Energy Combust. Sci., in press.

5. Buckmaster, J. D. and Ludford, G. S. S., Theory of Laminar Flames, Cambridge University Press, Cambridge (1982).

6. BILGER, R. W., AIAA J. 20, 962 (1982)

7. Bilger, R. W., Prog. Energy Combust. Sci. 1, 87 (1976).

8. Bilger, R. W., Combust. Flame 30, 277 (1977).

9. LuEw, S. K., Bray, K. N. C. and Moss, J. B., Combust. Sci. Technol. 27, 69 (1981)

10. Luew, S. K., Bray, K. N. C. and Móss, J. B., Combust. Flame 56, 199 (1984).

11. LIEw, S. K., Ph.D Thesis, Southampton University, U.K. (1983)

12. HAHN, W. A. and WeNDT, J. O. L., Eighteenth Symposium (International) on Combustion, pp. 121-131, The Combustion Institute. Pittsburgh (1981).

13. Gordon, A. S. and MCBrudE, B. J., Computer program for calculation of complex chemical equilibrium compositions, rocket performance, incident and reflected shocks and Chapman-Jouguet detonations. NASA SP. 273, Washington (1971).

14. Drake, M. C., Lapp, M., Penny, C. M., Warshaw, S. and Gerhold, B. W., Eighteenth Symposium (International) on Combustion, pp. 1521-1531, The Combustion Institute, Pittsburgh (1981).

15. Drake, M. C., Lapp, M., Penney, C. M., Warshaw, S. and Gerhold, B. W.. Probability density functions and correlations of temperature and molecular concentrations in turbulent diffusion flames, AIAA Pap. No. 81 0103 (1981)

16. Drake, M. C., Bllger, R. W. and Sti̊nner, S. H., Nineteenth Symposium (International) on Combustion, pp. 459-467. The Combustion Institute, Pittsburgh (1983).

17. Drake, M. C. and Pitz, R. W., Intermittency and conditional averaging in a turbulent nonpremixed flame by Raman scattering, AIAA Pap. No. 84-0197 (1984).

18. Drake, M. C., Pitz, R. W. and Lapp, M., Laser measurements on nonpremixed hydrogen-air flames for a ssessment of turbulent combustion models, $A I A A$ Pap. No. 84-0544 (1984). 
19. Drake, M. C., Pitz, R. W., Lapp, M., Fenimore, C. P., LuCht, R. P., SWeEney, D. W. and Laurendeau, N. M., Twentieth Symposium (International) on Combustion, pp. 327-335, The Combustion Institute, Pittsburgh (1985)

20. Drake, M. C., Shyy, W. and Pitz, R. W., Superlayer contributions to conserved-scalar PDF's in an $\mathrm{H}_{2}$ turbulent jet diffusion flame. Fifth Symposium on Turbulent Shear Flows (1985).

21. Driscoll, J. F., Schefer, R. W. and Dibble, R. W., Nineteenth Symposium (International) on Combustion, pp. 477-485, The Combustion Institute, Pittsburgh (1983).

22. SCHEFER, R. W. and Dibble, R. W., Simultaneous measurements of velocity and density in a turbulent non premixed flame, Sandia Rep. SAND82-8810 (1983).

23. Dibble, R. W., Hartmann, V., Schefer, R. W. and KollmanN, W., An investigation of temperature and velocity correlations in turbulent flames. Experimental Measurements and Techniques in Turbulent Reacting and Nonreacting Flows (So, R. M. C., Whitelaw, J. H. and Lapp, M., Eds), AMD, Vol. 66, ASME, New York. Also Experiments in Fluids, in press, and Sandia Rep. SAND84-8860 (1984).

24. Dibble, R. W., KollmanN, W. and Schefer, R. W., Combust. Flame 55, 307 (1984).

25. Dibble, R. W., Schefer, R. W., Hartman, V. and KollmanN, W., Velocity and density measurements in a turbulent nonpremixed flame, Sandia Rep. SAND858233 (1985).

26. Schefer, R. W. and Dibble, R. W., AIAA J. 23, 1070 (1985).

27. Johnston, S. C., Dibble, R. W., Schefer, R. W. Ashurst, W. T. and KollmanN, W., Laser measurements and stochastic simulations of turbulent reacting flows, AIAA Pap. No. 84-0543 (1984).

28. Dibile, R. W., Schefer, R. W. and Kollmann, W. Twentieth Symposium (International) on Combustion, pp. 345-352, The Combustion Institute, Pittsburgh (1985).

29. Dibble, R. W., Schefer, R. W., Hartman, V. and KollmanN, W. Simultaneous velocity and concentration measurements in a turbulent nonpremixed flame, Sandia Rep. SAND85-8234 (1985).

30. Dibble, R. W. and SChefER, R. W., Turbulent Shear Flows 4 (Bradbury, L. J. S., et al., Ed.) pp. 319-327, Springer-Verlag. Berlin (1985).

31. Gore, J. P., Jeng, S.-M. and FAeth, G. M., Spectral and total radiation properties of hydrogen/air diffusion flames, J. Heat Transfer, in press.

32. Aeschliman, D. P., Cummings, J. C. and Hill, R. S., J. Quant. Spectrosc. Radiat. Trans. 21, 293 (1979)

33. Miller, J. A. and KeE, R. J., J. Phys. Chem. 81, 2534 (1977).

34. Lockwood, F. C. and NAGUiB, A. S. Combust. Flame 24, 109 (1975).

35. Edelman, R. B. and Fortune, O. F., A quasi-global chemical kinetic model for the finite rate combustion of hydrocarbon fuels with application to turbulent buming and mixing in hypersonic engines and nozzles, AIAA Pap. No. 69-086 (1969).

36. Westarook, C. K. and Dryer, F. L., Combust. Sci. Technol. 27, 31 (1981).

37. Glassman, I., Combustion, p. 34, Academic Press, New York (1977)

38. Gore, J. P., Jeng, S. -M. and Faeth, G. M., Spectral and total radiation properties of carbon monoxide/air diffusion flames, ALAA Pap. No. 86-0294 (1986).

39. Razdan, M. K. and Stevens, J. G., Combust. Flame 59, 289 (1985).

40. Tsui, $H$. and YAMAOKA, I., Eleventh Symposium (International) on Combustion, pp. 979-984, The Combustion Institute, Pittsburgh (1967).

41. TsuJI, $H$. and YamaOKA, I., Twelfth Symposium
(International) on Combustion, pp. 997-1005, The Combustion Institute, Pittsburgh (1969).

42. TsuII, $H$. and YAMAOKA, I., Thirteenth Symposium (International) on Combustion, pp. 723-731, The Combustion Institute, Pittsburgh (1971).

43. Abdel-Khaluk, S. I., Tamuru, T. and El-Wakil, M. M., Fifteenth Symposium (International) on Combustion, pp. 389-399, The Combustion Institute, Pittsburgh (1975).

44. Jeng, S.-M. and Faeth, G. M., J. Heat Transfer 106, $721(1984)$.

45. Jeng, S.-M. and Faeth, G. M., J. Heat Transfer 106, 891 (1984).

46. GORE, J. P. and FAETH, G. M., Structure and radiation properties of turbulent ethylene/air diffusion tlames. Twenty-First Symposium (International) on Combustion, The Combustion Institute, Pittsburgh, in press.

47. Mungal, M. C., Experiments on mixing and combustion with low heat release in a turbulent shear flow, $\mathrm{Ph} . \mathrm{D}$ Thesis, California Institute of Technology (1983).

48. Mungal, M. C., Dimotakis, P. E. and Broadwell, J. E., AIAA J. 22, 797 (1984).

49. Mungal, M. C., Dimotakis, P. E. and Hermanson, J. C., Reynolds number effects on mixing and combustion in a reacting shear layer, $A I A A$ Pap. No. 84-0371 (1984).

50. WALLACE, A. K., Experimental investigation on the effects of chemical heat release in the reacting plane shear layer, Ph.D. Thesis, University of Adelaide (1981).

51. KoOChesfahaNI, M. M., Experiments on turbulent mixing and chemical reactions in a liquid mixing layer, Ph.D. Thesis, Califomia Institute of Technology (1984).

52. DАHM, W. J. A., Experiments on entrainment, mixing and chemical reactions in turbulent jets at large Schmidt number, Ph.D. Thesis, California Institute of Technology (1985).

53. BATt, R. G., J. Fluid Mech. 82, 53 (1977).

54. SPALDING. D. B., Seventeenth Symposium (Intemational) on Combustion, pp. 431-440, The Combustion Institute, Pittsburgh (1979).

55. JeNG, S.-M., CheN, L.-D. and FAETH, G. M., Nineteenth Symposium (International) on Combustion, pp. 349-358, The Combustion Institute, Pittsburgh (1983).

56. TAKaGI, T., ShIN, H.-D. and IshIO, A., Combust. Flame 37, $163(1980)$.

57. Takagi, T., Shin, H.-D. and Ishio. A., Combust. Flame 40, $121(1981)$.

58. KeNt, J. H. and BILGeR, R. W., Fourteenth Symposium (International) on Combustion, pp. 615-625, The Combustion Institute. Pittsburgh (1973).

59. Stårner. S. H. and Bilger, R. W., Combust. Sci. Technol. 21, 259 (1980).

60. StARner. S. H. and BILger, R. W., Eighteenth Symposium (International) on Combustion, pp. 921-930, The Combustion Institute, Pittsburgh (1981).

61. Brown, G. L. and Roshko, A., J. Fluid Mech. 64, 775 (1974).

62. Chandrasuda, C., Mehta, R. D., Wer, A. D. and Bradshaw, P., J. Fluid Mech. 85, 693 (1978).

63. BeCker, H. A. and Liang, D., Combust. Flame 32, 115 (1978)

64. Becker, H. A. and Yamazaki, S., Combust. Flame 33, 123 (1978).

65. Liburdy, J. A., Groff, E. G. and FAeth, G. M., J. Heat Transfer 101, 249 (1979).

66. LAI, M.-C. and FAETH, G. M., Turbulence properties of adiabatic wall plumes, to be published.

67. Becker, H. A. and Brown, A. P. G., J. Fluid Mech. 62, 85 (1974).

68. Bilger, R. W., Prog. Astronaut. Aeronaut. 53, 49 (1977).

69. STEVENSON, W. H., THOM PSON, H. D. and ROESLER, T. C. AI AA J. 20, $1720(1982)$ 
70. Crayg, R. R., Nejad, A. S., Hahn, E. Y. and SCHW ARTZKOPF, K. E., A general approach for obtaining unbiased LDV data in highly turbulent nonreacting and reacting flows, $A I A A$ Pap. No. 84-0366 (1984).

71. Brum, R. D. and Samuelsen, G. S., Two-component laser anemometry measurements in nonreacting and reacting complex flows in a swirl-stabilized combuster. Experimental Techniques in Turbulent Reacting and NonReacting Flows (So, R. M. C., Whitelaw, J. H, and Lapp, M., Eds), AMD, Vol. 66, ASME, New York (1984).

72. Glass, M. G. and Bilger, R. W., Combust. Sci. Technol. 18, $165(1978)$.

73. STARNER, S. H.. Investigation of turbulent diffusion flames, Ph.D. Thesis, The University of Sydney $(1980)$.

74. Stárner, S. H., Combust. Sci. Technol. 30, 145 (1983).

75. Kennedy, I. M. and Kent, J. H.. Combust. Sci. Technol. 25, 109 (1981).

76. LaI, M.-C., Jeng, S.-M. and FaETH, G. M., Structure of Adiabatic wall plumes, $J$. Heat Transfer, in press.

77. BILGER. R. W, and BECK, R. E., Fifteenth Symposium (International) on Combustion, pp. 541-552, The Combustion Institute, Pittsburgh (1975).

78. Stárner, S. H.. Combust. Sci. Technol. 42, 283 (1985).

79. Takagi, T., Ogasawara, M., Fumi, K. and Diazo, M., Fifteenth Symposium (International) on Combustion, pp. 1051-1059. The Combustion Institute, Pittsburgh (1975)

80. Takagi, T., Shin, H.-D. and Ishio, A., Combust. Flame 41, 261 (1981).

81. Hawthorne, W. R., Weddel L, D. S. and Hotter, H. C., Third Symposium on Combustion. Flame and Explosion Phenomena, p. 266-288, The Combustion Institute, Pittsburgh (1949).

82. Takeno. T. and Kotani, I., Acta Astronaut. 2, 999 (1975).

83. Schoenung. S. M. and Hanson, R. K., Nineteenth Symposium (International) on Combustion, pp. 449-458, The Combustion Institute, Pittsburgh (1983).

84. Daнm, W. J. A. and Dimotakis, P. E., Measurements of entrainment and mixing in turbulent jets. AIAA Pap. No. 85-0056 (1985).

85. Koochesfahani. M. M. and Dimotakis, P. E., Laser induced fluorescence measurements of concentration in a plane mixing layer. AIAA Pap. No. 84-0198 (1984).

86. KREMER. H.. Eleventh Symposium (International) on Combustion, pp. 799-806, The Combustion Institute, Pittsburgh (1967).

87. Ueda, T. Mizomoto, M. and IkaI, S., Combust. Sci. Technol. 27, 133 (1982).

88. Ueda, T., Mizomoto. M. and IKAI, S., Bull. J.S.M.E. 26, $399(1983)$

89. Ueda. T.. Mizomoto, M., Matsubayashi, Y. and IKal, S., $A I A A$ J. 22, 664 (1984).

90. POPE. S. G. AlAA J. 16, 279 (1978).

91. Strahle, W. C. and Lekoudis, S. G., Evaluation of data on simple turbulent reacting flows, Rep. No. AFOSR TR-85 0880. Washington, DC (1985).

\section{APPENDIX A. RECOMMENDED FORMAT FOR DATA BASE} DOCUMENTATION

1. Experimental Facility

- general description of facility.

2. Experimental Configurations

- detailed description of experimental configurations; figures.

3. Test Conditions

- identification of test conditions including table listing conditions.
4. Inlet and Boundary Conditions

- identification and explanation of inlet and boundary conditions including axial pressure gradient.

5. Quantities Measured

- delineation of quantities measured, quantities tabulated, and quantities archived on tape and/or disk.

- identification of diagnostic(s) used for each measurement.

6. Diagnostics

- description of diagnostics used; figures of configuration.

7. Unusual Measurements Methods

- description of methodology used in the acquisition of data with attention to techniques unique to the present experiment.

8. Experimental Protocol

- a description of the protocol adopted in the acquisition of the data; the order in which the data were collected; the elapsed period of time.

9. Quality Control

a delineation of steps taken to assure accuracy of the data; mass balances; repeatability tests; reproducibility tests; diagnostic(s) performance including seeding uniformity and consistency in the case of laser anemometry; steps taken to assure identical test conditions throughout the duration of the study; tests of sensitivity of experiment to boundary conditions (e.g. exhaust suction).

10. Error Analysis

- an estimate of the uncertainty (in percent) associated with each of the measurements due to undertainty in the measurement method, flow conditions, and so forth.

11. Availability of Data

- explanation of the availability of the data (report number, source, ordering information) and the media (magnetic tape, floppies) on which the data are available.

12. References

- citations of (1) reports and publications referred to in item 11 , and (2) references referred to in text.

13. Data

- still photographs of flame for the purposes of (1) identifying the physical nature of the experiment, and (2) the time-averaged structure of the flame

- presentation of successive frames from a highspeed photographic sequence for the purposes of (1) describing the dynamic behavior of the flame, and (2) providing an indication of the scales of turbulent mixing

- description of the format in which the data are presented

tables of data. 


\section{APPENDIX B. EXAMPLE CASE STUDY}

\section{B.1. Experimental Facility}

These data were obtained in the Turbulent Combustion Tunnel Facility which is located at the Combustion Research Facility of Sandia National Laboratories, Livermore, California. The data base is formally documented in Dibble et al. ${ }^{1}$ and Dibble et al., ${ }^{2}$ both of which are available from NTIS. Papers presented and published as a result of this work are listed in Table 2 under "Sandia-Livermore Studies (vertical tunnel)".

\section{B.2. Experimental Configuration}

The measurements were made in a forced draft, vertical wind tunnel with an axisymmetric fuel jet located at the upstream end of a test section (Fig. B.1). The fully windowed test section is $200-\mathrm{cm}$ long, with a $300-\mathrm{mm}$ square cross section. The test section empties into an exhaust hood which draws air from the room in addition to flow from the test section. The fuel nozzle consists of two concentric tubes with an inside diameter $d$ of $5.2 \mathrm{~mm}$ and an outside diameter of $9.5 \mathrm{~mm}$; the tube walls are $0.7-\mathrm{mm}$ thick. The annular void region has no gas flow. The fuel tube is straight for more than $\mathbf{5 0 0}$ diameters. The coflow air originates from the building air-conditioning and is therefore at a consistent temperature and humidity $\left(T=20 \pm 2{ }^{\circ} \mathrm{C}, R H=31 \pm 9 \%\right)$.

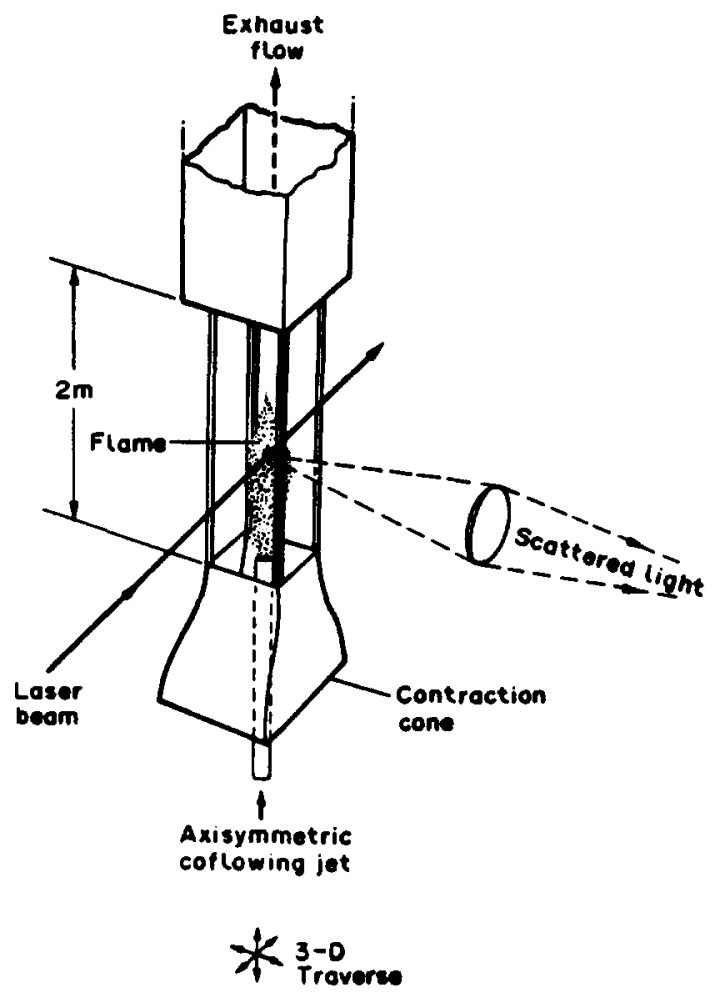

FIG. B.1. Sketch of the Sandia turbulent combustion tunnel facility (Dibble et al. ${ }^{1}$ ).

\section{B.3. Test Conditions}

Data are provided for the three cases presented in Table B.1. The fuel mixture injected through the jet is $22 \mathrm{~mol} . \%$ argon-in-hydrogen. The fuel has a density of $0.421 \mathrm{~kg} / \mathrm{m}^{3}$ and viscosity of $186 \mu \mathrm{P}(180 \times$ $10^{-7} \mathrm{~kg} \mathrm{~m}^{-1} \mathrm{sec}$ ) at $300 \mathrm{~K}$ and $1 \mathrm{~atm}$. The jet Reynolds number tabulated above is based on the pipe inside diameter, the bulk fuel velocity, and the above referenced density and viscosity. A listing of the equilibrium temperatures, concentrations, and physical properties of this fuel mixed with air is given in Table B.2. The tunnel is operated at atmospheric pressure.

TABLE B.1. Test cases

\begin{tabular}{lccc}
\hline Case & $\begin{array}{c}\text { Jet Reynolds } \\
\text { number }\end{array}$ & $\begin{array}{c}\text { Jet velocity } \\
(\mathrm{m} / \mathrm{sec})\end{array}$ & $\begin{array}{c}\text { Coflow air } \\
\text { velocity } \\
\text { (m/sec) }\end{array}$ \\
\hline A & 9,000 & 75 & 9.2 \\
C & 18,000 & 150 & 9.2 \\
\hline
\end{tabular}

\section{B.4. Inlet and Boundary Conditions}

The radial profile of coflow air velocity at the nozzle plane $(x / d=0)$ was measured with a hot-wire anemometer (Data FILENAME "INPUT."). A 6-mm and $8-\mathrm{mm}$ boundary layer resides on the test section walls, and on the outer wall of the fuel tube respectively.

The length of the straight fuel tube (500 diameters) allows the assumption of a developed velocity profile in the fuel tube. The axial pressure gradient $\mathrm{d} p / \mathrm{d} x$ in the wind tunnel is $6 \mathrm{~Pa} / \mathrm{m}$. This gradient is determined by measuring, with a capacitance manometer (Validyne Model DP103-18), the pressure drop between a pressure tap at the nozzle plane $(x / d=0)$, and at the exit of the test section, which is located $2 \mathrm{~m}$ from the nozzle plane. The pressure gradient of $6 \mathrm{~Pa} / \mathrm{m}$ does not change for the different flame cases, and increases to $6.5 \mathrm{~Pa} / \mathrm{m}$ when the fuel flow is zero.

\section{B.5. Quantities Measured}

The quantities measured, tabulated, and archived are presented in Table B.3.

\section{B.6. Diagnostics}

\section{Laser Doppler anemometer}

The axial and radial components of velocity are measured with a two-component laser Doppler anemometer (Fig. B.2). Two beams (488 and $514.5 \mathrm{~nm}$ ) from a 4-W laser are split and focused in an optical volume having a diameter of $0.5 \mathrm{~mm}$ and a 
TABLE B.2. Equilibrium temperatures, concentrations, and fuel properties of $22 \%$, by mole, argon-in-hydrogen

\begin{tabular}{|c|c|c|c|c|c|c|}
\hline Fmass & ZIstomic & RHO & RHO/RHDO & KELVIMS & $\begin{array}{l}\text { CES } \\
\text { VISCOSITY }\end{array}$ & FUE/AIR \\
\hline $\begin{array}{l}0.0000 \\
0.0043 \\
0.0088 \\
0.0132 \\
0.0178 \\
0.0224 \\
0.0271 \\
0.0319 \\
0.0367 \\
0.0417 \\
0.0467 \\
0.0518 \\
0.0570 \\
0.0622 \\
0.0676 \\
0.0731 \\
0.0786 \\
0.0843 \\
0.0900 \\
0.0959 \\
0.1019 \\
0.1079 \\
0.1141 \\
0.1204 \\
0.1268 \\
0.1334 \\
0.1491 \\
0.1656 \\
0.1829 \\
0.2010 \\
0.2201 \\
0.2401 \\
0.2611 \\
0.2833 \\
0.3068 \\
0.3315 \\
0.3577 \\
0.3856 \\
0.4151 \\
0.4466 \\
0.4801 \\
0.5160 \\
0.5544 \\
0.5957 \\
0.6401 \\
0.6881 \\
0.7401 \\
0.7966 \\
0.8582 \\
0.9257 \\
1.0000\end{array}$ & $\begin{array}{l}0.0000 \\
0.0107 \\
0.0214 \\
0.0322 \\
0.0430 \\
0.0538 \\
0.0646 \\
0.0755 \\
0.0864 \\
0.0973 \\
0.1082 \\
0.1192 \\
0.1302 \\
0.1413 \\
0.1523 \\
0.1634 \\
0.1746 \\
0.1857 \\
0.1969 \\
0.2081 \\
0.2194 \\
0.2307 \\
0.2420 \\
0.2533 \\
0.2647 \\
0.2761 \\
0.3028 \\
0.3298 \\
0.3568 \\
0.3841 \\
0.4115 \\
0.4391 \\
0.4669 \\
0.4949 \\
0.5230 \\
0.5514 \\
0.5790 \\
0.6086 \\
0.6375 \\
0.6666 \\
0.6959 \\
0.7254 \\
0.7551 \\
0.7850 \\
0.8151 \\
0.8454 \\
0.8759 \\
0.9066 \\
0.9375 \\
0.9686 \\
1.0000\end{array}$ & $\begin{array}{l}1.1720 \\
0.9279 \\
0.7673 \\
0.6539 \\
0.5698 \\
0.5049 \\
0.4534 \\
0.4115 \\
0.3767 \\
0.3474 \\
0.3222 \\
0.3004 \\
0.2813 \\
0.2644 \\
0.2494 \\
0.2359 \\
0.2237 \\
0.2127 \\
0.2027 \\
0.1936 \\
0.1852 \\
0.1775 \\
0.1704 \\
0.1639 \\
0.1579 \\
0.1524 \\
0.1413 \\
0.1338 \\
0.1320 \\
0.1320 \\
0.1323 \\
0.1328 \\
0.1337 \\
0.1347 \\
0.1361 \\
0.1377 \\
0.139 \\
0.245 \\
0.1429 \\
0.1423 \\
0.1453 \\
0.1489 \\
0.1534 \\
0.1588 \\
0.1655 \\
0.1738 \\
0.1944\end{array}$ & $\begin{array}{l}1.0000 \\
0.7920 \\
0.6549 \\
0.5581 \\
0.4863 \\
0.4309 \\
0.3870 \\
0.3512 \\
0.3216 \\
0.2965 \\
0.2750 \\
0.2564 \\
0.2401 \\
0.2257 \\
0.2128 \\
0.2013 \\
0.1910 \\
0.1816 \\
0.1730 \\
0.1652 \\
0.1581 \\
0.1515 \\
0.1455 \\
0.1399 \\
0.1348 \\
0.1301 \\
0.1206 \\
0.1142 \\
0.1127 \\
0.1126 \\
0.1129 \\
0.1134 \\
0.1141 \\
0.1150 \\
0.1161 \\
0.1176 \\
0.1193 \\
0.1214 \\
0.1240 \\
0.1271 \\
0.1309 \\
0.1355 \\
0.1412 \\
0.1484 \\
0.1574 \\
0.1691 \\
0.1845 \\
0.2056 \\
0.2355 \\
0.2812 \\
0.3591\end{array}$ & $\begin{array}{l}300 . \\
378 . \\
456 . \\
533 . \\
610 . \\
686 . \\
761 . \\
836 . \\
910 . \\
984 . \\
1057 . \\
1130 . \\
1202 . \\
1274 . \\
1346 . \\
1418 . \\
1490 . \\
1561 . \\
1632 . \\
1702 . \\
1772 . \\
1842 . \\
1910 . \\
1977 . \\
2044 . \\
2108 . \\
2246 . \\
2332 . \\
2301 . \\
2234 . \\
2161 . \\
2085 . \\
2006 . \\
1926 . \\
1843 . \\
1759 . \\
1673 . \\
1585 . \\
1496 . \\
1405 . \\
1312 . \\
1217 . \\
1121 . \\
1023 . \\
923 . \\
821 . \\
718 . \\
614 . \\
509 . \\
405 . \\
300 .\end{array}$ & $\begin{array}{l}1.867 E-04 \\
2.200 E-04 \\
2.505 E-04 \\
2.789 E-04 \\
3.055 E-04 \\
3.307 E-04 \\
3.546 E-04 \\
3.775 E-04 \\
3.995 E-04 \\
4.208 E-04 \\
4.414 E-04 \\
4.615 E-04 \\
4.812 E-04 \\
5.004 E-04 \\
5.193 E-04 \\
5.379 E-04 \\
5.561 E-04 \\
5.741 E-04 \\
5.919 E-04 \\
6.094 E-04 \\
6.266 E-04 \\
6.436 E-04 \\
6.603 E-04 \\
6.766 E-04 \\
6.926 E-04 \\
7.081 E-04 \\
7.413 E-04 \\
7.624 E-04 \\
7.561 E-04 \\
7.416 E-04 \\
7.256 E-04 \\
7.087 E-04 \\
6.909 E-04 \\
6.723 E-04 \\
6.529 E-04 \\
6.327 E-04 \\
6.117 E-04 \\
5.098 E-04 \\
5.670 E-04 \\
5.433 E-04 \\
5.185 E-04 \\
4.927 E-04 \\
4.655 E-04 \\
4.370 E-04 \\
4.071 E-04 \\
3.754 E-04 \\
3.420 E-04 \\
3.066 E-04 \\
2.690 E-04 \\
2.285 E-04 \\
1.840 E-04\end{array}$ & $\begin{array}{l}0.000 E+00 \\
1.215 E-02 \\
2.459 E-02 \\
3.734 E-02 \\
5.042 E-02 \\
6.383 E-02 \\
7.759 E-02 \\
9.170 E-02 \\
1.062 E-01 \\
1.211 E-01 \\
1.364 E-01 \\
1.521 E-01 \\
1.682 E-01 \\
1.848 E-01 \\
2.019 E-01 \\
2.195 E-01 \\
2.376 E-01 \\
2.563 E-01 \\
2.755 E-01 \\
2.953 E-01 \\
3.158 E-01 \\
3.369 E-01 \\
3.587 E-01 \\
3.812 E-01 \\
4.045 E-01 \\
4.286 E-01 \\
4.881 E-01 \\
5.528 E-01 \\
6.234 E-01 \\
7.007 E-01 \\
7.657 E-01 \\
8.797 E-01 \\
9.841 E-01 \\
1.101 E+00 \\
1.232 E+00 \\
1.381 E+00 \\
1.551 E+00 \\
1.747 E+00 \\
1.976 E+00 \\
2.247 E+00 \\
2.571 E+00 \\
2.968 E+00 \\
3.464 E+00 \\
4.102 E+00 \\
4.952 E+00 \\
6.143 E+00 \\
7.929 E+00 \\
1.090 E+01 \\
1.686 E+01 \\
3.471 E+01 \\
1.000 E+04\end{array}$ \\
\hline
\end{tabular}


TABLE B.2. (continued)

\begin{tabular}{|c|c|c|c|c|c|c|}
\hline Finass & KEIVI & $N_{2}$ & 02 & H2 & $\mathrm{H} 2 \mathrm{O}$ & ARGON \\
\hline $\begin{array}{l}0.0000 \\
0.0043 \\
0.0088 \\
0.0132 \\
0.0178 \\
0.0224 \\
0.0271 \\
0.0319 \\
0.0367 \\
0.0417 \\
0.0467 \\
0.0518 \\
0.0570 \\
0.0622 \\
0.0676 \\
0.0731 \\
0.0786 \\
0.0843 \\
0.0900 \\
0.0959 \\
0.1019 \\
0.1079 \\
0.1141 \\
0.1204 \\
0.1268 \\
0.1334 \\
0.1491 \\
0.1656 \\
0.1829 \\
0.2010 \\
0.2201 \\
0.2401 \\
0.2611 \\
0.2833 \\
0.3068 \\
0.3315 \\
0.3577 \\
0.3856 \\
0.4151 \\
0.4466 \\
0.4801 \\
0.5160 \\
0.5544 \\
0.5957 \\
0.6401 \\
0.6881 \\
0.7401 \\
0.7966 \\
0.8582 \\
0.9257 \\
1.0000\end{array}$ & 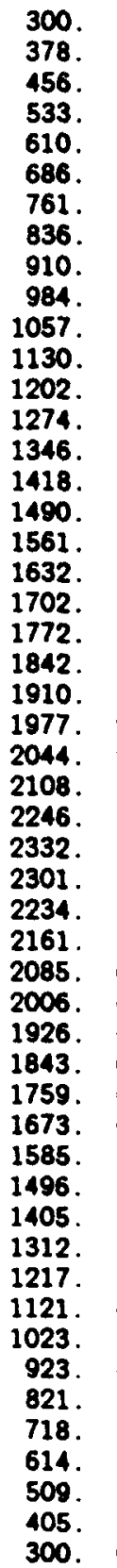 & $\begin{array}{l}7.900 E-01 \\
6.229 E-01 \\
5.128 E-01 \\
4.351 E-01 \\
3.774 E-01 \\
3.328 E-01 \\
2.974 E-01 \\
2.686 E-01 \\
2.447 E-01 \\
2.245 E-01 \\
2.071 E-01 \\
1.920 E-01 \\
1.789 E-01 \\
1.672 E-01 \\
1.568 E-01 \\
1.474 E-01 \\
1.390 E-01 \\
1.313 E-01 \\
1.244 E-01 \\
1.180 E-01 \\
1.122 E-01 \\
1.067 E-01 \\
1.018 E-01 \\
9.723 E-02 \\
9.294 E-02 \\
8.902 E-02 \\
8.105 E-02 \\
7.527 E-02 \\
7.272 E-02 \\
7.109 E-02 \\
6.956 E-02 \\
6.805 E-02 \\
6.659 E-02 \\
6.508 E-02 \\
6.360 E-02 \\
6.208 E-02 \\
6.052 E-02 \\
5.896 E-02 \\
5.729 E-02 \\
5.556 E-02 \\
5.375 E-02 \\
5.183 E-02 \\
4.971 E-02 \\
4.738 E-02 \\
4.476 E-02 \\
4.168 E-02 \\
3.789 E-02 \\
3.303 E-02 \\
2.638 E-02 \\
1.650 E-02 \\
0.000 E+00\end{array}$ & $\begin{array}{l}2.100 E-01 \\
1.619 E-01 \\
1.301 E-01 \\
1.076 E-01 \\
9.094 E-02 \\
7.790 E-02 \\
6.766 E-02 \\
5.924 E-02 \\
5.221 E-02 \\
4.626 E-02 \\
4.111 E-02 \\
3.662 E-02 \\
3.271 E-02 \\
2.919 E-02 \\
2.606 E-02 \\
2.322 E-02 \\
2.064 E-02 \\
1.829 E-02 \\
1.613 E-02 \\
1.415 E-02 \\
1.230 E-02 \\
1.058 E-02 \\
8.984 E-03 \\
7.485 E-03 \\
6.075 E-03 \\
4.758 E-03 \\
2.060 E-03 \\
3.189 E-04 \\
2.224 E-05 \\
2.953 E-06 \\
5.255 E-07 \\
1.024 E-07 \\
2.002 E-08 \\
3.702 E-00 \\
6.232 E-10 \\
9.191 E-11 \\
1.145 E-11 \\
1.153 E-12 \\
8.913 E-14 \\
4.958 E-15 \\
1.822 E-16 \\
3.948 E-18 \\
4.313 E-20 \\
1.902 E-22 \\
2.472 E-25 \\
0.000 E+00 \\
0.000 E+00 \\
0.000 E+00 \\
0.000 E-00 \\
0.000 E+00 \\
0.000 E+00\end{array}$ & $\begin{array}{l}0.000 E+00 \\
0.000 E+00 \\
0.000 E+00 \\
1.768 E-23 \\
2.196 E-20 \\
5.383 E-18 \\
4.262 E-16 \\
1.510 E-14 \\
2.941 E-13 \\
3.637 E-12 \\
3.160 E-11 \\
2.074 E-10 \\
1.086 E-09 \\
4.714 E-09 \\
1.753 E-08 \\
5.721 E-08 \\
1.672 E-07 \\
4.447 E-07 \\
1.090 E-06 \\
2.493 E-06 \\
5.360 E-06 \\
1.092 E-05 \\
2.127 E-05 \\
3.983 E-05 \\
7.224 E-05 \\
1.277 E-04 \\
4.658 E-04 \\
1.950 E-03 \\
6.149 E-03 \\
1.133 E-02 \\
1.690 E-02 \\
2.286 E-02 \\
2.925 E-02 \\
3.610 E-02 \\
4.354 E-02 \\
5.163 E-02 \\
6.050 E-02 \\
7.036 E-02 \\
8.132 E-02 \\
9.373 E-02 \\
1.079 E-01 \\
1.244 E-01 \\
1.436 E-01 \\
1.667 E-01 \\
1.950 E-01 \\
2.305 E-01 \\
2.765 E-01 \\
3.380 E-01 \\
4.249 E-01 \\
5.566 E-01 \\
7.800 E-01\end{array}$ & $\begin{array}{l}0.000 E+00 \\
7.470 E-03 \\
1.245 E-02 \\
1.604 E-02 \\
1.878 E-02 \\
2.097 E-02 \\
2.278 E-02 \\
2.432 E-02 \\
2.566 E-02 \\
2.683 E-02 \\
2.788 E-02 \\
2.881 E-02 \\
2.971 E-02 \\
3.053 E-02 \\
3.126 E-02 \\
3.196 E-02 \\
3.259 E-02 \\
3.322 E-02 \\
3.380 E-02 \\
3.438 E-02 \\
3.490 E-02 \\
3.542 E-02 \\
3.592 E-02 \\
3.640 E-02 \\
3.685 E-02 \\
3.730 E-02 \\
3.821 E-02 \\
3.875 E-02 \\
3.834 E-02 \\
3.765 E-02 \\
3.691 E-02 \\
3.616 E-02 \\
3.538 E-02 \\
3.459 E-02 \\
3.382 E-02 \\
3.300 E-02 \\
3.218 E-02 \\
3.134 E-02 \\
3.045 E-02 \\
2.954 E-02 \\
2.857 E-02 \\
2.757 E-02 \\
2.643 E-02 \\
2.518 E-02 \\
2.379 E-02 \\
2.215 E-02 \\
2.014 E-02 \\
1.756 E-02 \\
1.402 E-02 \\
8.770 E-03 \\
0.000 E+00\end{array}$ & $\begin{array}{l}0.000 E+00 \\
2.107 E-03 \\
3.512 E-03 \\
4.525 E-03 \\
5.298 E-03 \\
5.917 E-03 \\
6.427 E-03 \\
6.862 E-03 \\
7.236 E-03 \\
7.567 E-03 \\
7.864 E-03 \\
8.132 E-03 \\
8.379 E-03 \\
8.607 E-03 \\
8.818 E-03 \\
9.014 E-03 \\
9.196 E-03 \\
9.374 E-03 \\
9.542 E-03 \\
9.707 E-03 \\
9.863 E-03 \\
1.001 E-02 \\
1.017 E-02 \\
1.032 E-02 \\
1.047 E-02 \\
1.062 E-02 \\
1.102 E-02 \\
1.159 E-02 \\
1.263 E-02 \\
1.388 E-02 \\
1.522 E-02 \\
1.667 E-02 \\
1.825 E-02 \\
1.996 E-02 \\
2.182 E-02 \\
2.387 E-02 \\
2.615 E-02 \\
2.868 E-02 \\
3.153 E-02 \\
3.477 E-02 \\
3.850 E-02 \\
4.286 E-02 \\
4.795 E-02 \\
5.412 E-02 \\
6.170 E-02 \\
7.126 E-02 \\
8.367 E-02 \\
1.003 E-01 \\
1.238 E-01 \\
1.595 E-01 \\
2.200 E-01\end{array}$ \\
\hline
\end{tabular}


TABLE B.2. (continued)

\begin{tabular}{|c|c|c|c|c|c|c|}
\hline Fmass & KEL VIN & INS & H & $\mathrm{OH}$ & RAY* & RHO/RAY \\
\hline $\begin{array}{l}0.0000 \\
0.0043 \\
0.0088 \\
0.0132 \\
0.0178 \\
0.0224 \\
0.0271 \\
0.0319 \\
0.0367 \\
0.0417 \\
0.0467 \\
0.0518 \\
0.0570 \\
0.0622 \\
0.0676 \\
0.0731 \\
0.0786 \\
0.0843 \\
0.0900 \\
0.0959 \\
0.1019 \\
0.1079 \\
0.1141 \\
0.1204 \\
0.1268 \\
0.1334 \\
0.1491 \\
0.1656 \\
0.1829 \\
0.2010 \\
0.2201 \\
0.2401 \\
0.2611 \\
0.2833 \\
0.3068 \\
0.3315 \\
0.3577 \\
0.3856 \\
0.4151 \\
0.4466 \\
0.4801 \\
0.5160 \\
0.5544 \\
0.5957 \\
0.6401 \\
0.6881 \\
0.7401 \\
0.7966 \\
0.8582 \\
0.9257 \\
1.0000\end{array}$ & 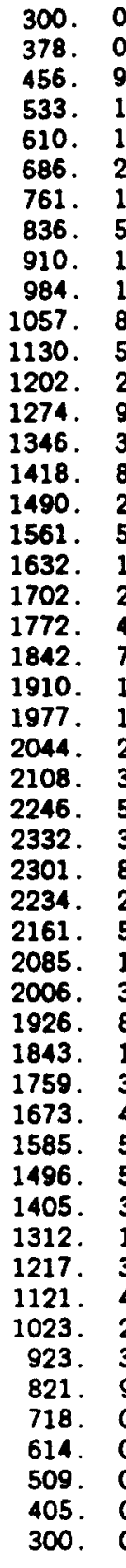 & $\begin{array}{l}0.000 E+00 \\
0.000 E+00 \\
9.276 E-27 \\
1.149 E-22 \\
1.235 E-19 \\
2.657 E-17 \\
1.860 E-15 \\
5.838 E-14 \\
1.011 E-12 \\
1.112 E-11 \\
8.603 E-11 \\
5.033 E-10 \\
2.347 E-09 \\
9.076 E-09 \\
3.003 E-08 \\
8.700 E-08 \\
2.252 E-07 \\
5.283 E-07 \\
1.137 E-06 \\
2.268 E-06 \\
4.219 E-06 \\
7.361 E-06 \\
1.210 E-05 \\
1.878 E-05 \\
2.750 E-05 \\
3.787 E-05 \\
5.910 E-05 \\
3.803 E-05 \\
8.436 E-06 \\
2.088 E-06 \\
5.620 E-07 \\
1.501 E-07 \\
3.804 E-08 \\
8.805 E-09 \\
1.811 E-09 \\
3.206 E-10 \\
4.736 E-11 \\
5.610 E-12 \\
5.069 E-13 \\
3.281 E-14 \\
1.401 E-15 \\
3.521 E-17 \\
4.457 E-19 \\
2.284 E-21 \\
3.451 E-24 \\
9.543 E-28 \\
0.000 E+00 \\
0.000 E+00 \\
0.000 E+00 \\
0.000 E+00 \\
0.000 E+00\end{array}$ & $\begin{array}{l}0.000 E+00 \\
0.000 E+00 \\
0.000 E+00 \\
0.000 E+00 \\
9.542 E-27 \\
1.754 E-23 \\
6.841 E-21 \\
8.829 E-19 \\
5.010 E-17 \\
1.522 E-15 \\
2.845 E-14 \\
3.614 E-13 \\
3.366 E-12 \\
2.422 E-11 \\
1.406 E-10 \\
6.821 E-10 \\
2.838 E-09 \\
1.036 E-08 \\
3.371 E-08 \\
9.932 E-08 \\
2.679 E-07 \\
6.685 E-07 \\
1.556 E-06 \\
3.405 E-06 \\
7.049 E-06 \\
1.386 E-05 \\
5.689 E-05 \\
1.800 E-04 \\
2.739 E-04 \\
2.638 E-04 \\
2.165 E-04 \\
1.615 E-04 \\
1.116 E-04 \\
7.163 E-05 \\
4.269 E-05 \\
2.346 E-05 \\
1.178 E-05 \\
5.322 E-06 \\
2.124 E-06 \\
7.301 E-07 \\
2.087 E-07 \\
4.735 E-08 \\
7.964 E-09 \\
9.044 E-10 \\
6.060 E-11 \\
1.945 E-12 \\
2.184 E-14 \\
5.036 E-17 \\
9.149 E-21 \\
1.872 E-26 \\
0.000 E+00\end{array}$ & $\begin{array}{l}0.000 E+00 \\
3.148 E-22 \\
2.324 E-18 \\
1.183 E-15 \\
1.183 E-13 \\
4.082 E-12 \\
6.719 E-11 \\
6.520 E-10 \\
4.278 E-09 \\
2.083 E-08 \\
8.049 E-08 \\
2.587 E-07 \\
7.170 E-07 \\
1.757 E-06 \\
3.886 E-06 \\
7.879 E-06 \\
1.484 E-05 \\
2.622 E-05 \\
4.378 E-05 \\
6.958 E-05 \\
1.057 E-04 \\
1.541 E-04 \\
2.164 E-04 \\
2.930 E-04 \\
3.825 E-04 \\
4.812 E-04 \\
6.889 E-04 \\
5.969 E-04 \\
2.727 E-04 \\
1.273 E-04 \\
6.128 E-05 \\
2.918 E-05 \\
1.341 E-05 \\
5.832 E-06 \\
2.366 E-06 \\
8.793 E-07 \\
2.942 E-07 \\
8.655 E-08 \\
2.177 E-08 \\
4.518 E-09 \\
7.368 E-10 \\
8.853 E-11 \\
7.158 E-12 \\
3.432 E-13 \\
8.135 E-15 \\
7.225 E-17 \\
1.578 E-19 \\
4.139 E-23 \\
0.000 E+00 \\
0.000 E+00 \\
0.000 E+00\end{array}$ & $\begin{array}{l}1.003 E+00 \\
1.002 E+00 \\
9.994 E-01 \\
9.975 E-01 \\
9.955 E-01 \\
9.935 E-01 \\
9.914 E-01 \\
9.893 E-01 \\
9.872 E-01 \\
9.852 E-01 \\
9.830 E-01 \\
9.808 E-01 \\
9.788 E-01 \\
9.765 E-01 \\
9.744 E-01 \\
9.721 E-01 \\
9.698 E-01 \\
9.675 E-01 \\
9.651 E-01 \\
9.627 E-01 \\
9.603 E-01 \\
9.577 E-01 \\
9.551 E-01 \\
9.524 E-01 \\
9.496 E-01 \\
9.465 E-01 \\
9.381 E-01 \\
9.250 E-01 \\
9.012 E-01 \\
8.747 E-01 \\
8.480 E-01 \\
8.215 E-01 \\
7.952 E-01 \\
7.693 E-01 \\
7.436 E-01 \\
7.181 E-01 \\
6.930 E-01 \\
6.683 E-01 \\
6.438 E-01 \\
6.195 E-01 \\
5.956 E-01 \\
5.721 E-01 \\
5.487 E-01 \\
5.257 E-01 \\
5.030 E-01 \\
4.805 E-01 \\
4.583 E-01 \\
4.363 E-01 \\
4.147 E-01 \\
3.932 E-01 \\
3.721 E-01\end{array}$ & $\begin{array}{l}9.966 E-01 \\
9.956 E-01 \\
9.946 E-01 \\
9.933 E-01 \\
9.921 E-01 \\
9.910 E-01 \\
9.900 E-01 \\
9.887 E-01 \\
9.877 E-01 \\
9.863 E-01 \\
9.853 E-01 \\
9.844 E-01 \\
9.826 E-01 \\
9.812 E-01 \\
9.796 E-01 \\
9.785 E-01 \\
9.778 E-01 \\
9.763 E-01 \\
9.748 E-01 \\
9.732 E-01 \\
9.722 E-01 \\
9.709 E-01 \\
9.695 E-01 \\
9.677 E-01 \\
9.669 E-01 \\
9.656 E-01 \\
9.621 E-01 \\
9.594 E-01 \\
9.589 E-01 \\
9.583 E-01 \\
9.587 E-01 \\
9.591 E-01 \\
9.591 E-01 \\
9.594 E-01 \\
9.589 E-01 \\
9.598 E-01 \\
9.597 E-01 \\
9.595 E-01 \\
9.602 E-01 \\
9.605 E-01 \\
9.609 E-01 \\
9.605 E-01 \\
9.613 E-01 \\
9.622 E-01 \\
9.621 E-01 \\
9.626 E-01 \\
9.628 E-01 \\
9.638 E-01 \\
9.639 E-01 \\
9.646 E-01 \\
9.651 E-01\end{array}$ \\
\hline
\end{tabular}

"RAY is the mole fraction weighted sum of Rayleigh cross sections. 
TABLE B.3. Quantities measured

\begin{tabular}{|c|c|c|c|c|c|c|}
\hline \multirow[b]{2}{*}{$\begin{array}{l}\text { Quantity } \\
\text { measured }\end{array}$} & \multirow[b]{2}{*}{$\begin{array}{l}\text { Quantity } \\
\text { tabulated }\end{array}$} & \multirow[b]{2}{*}{$\begin{array}{l}\text { Quantity } \\
\text { archived* }\end{array}$} & \multirow[b]{2}{*}{ Case } & \multicolumn{2}{|c|}{ Locations } & \multirow[b]{2}{*}{ Diagnostic } \\
\hline & & & & $\begin{array}{l}\text { Axial } \\
(x / d)\end{array}$ & $\begin{array}{c}\text { Radial } \\
\text { (number points) }\end{array}$ & \\
\hline inlet $u, v$ & $\begin{array}{l}u, u^{\prime} \\
\text { cotlow air only }\end{array}$ & $\leftarrow$ & & $0(B)+$ & Half $\ddagger$ & Hot-wire \\
\hline$u, v$ & $u, v, u^{\prime}, v^{\prime}, u^{\prime} v^{\prime}$ & $\leftarrow$ & $\mathbf{A}$ & $\begin{array}{l}5,10,20,30,40, \\
50,60,70,80,90 \\
(\mathrm{~B}) \\
15,30,50,70, \\
(\mathrm{~B}, \mathrm{~J}, \mathrm{~A}) \\
3.5,4,10,15,20, \\
25,30,40,45,50, \\
60,70,80(\mathrm{~J}) \\
3,70,(\mathrm{~B}) \\
30,50,70(\mathrm{~J}, \mathrm{~A})\end{array}$ & $\begin{array}{l}\text { CL } \\
\text { Full } \\
\text { CL } \\
\text { Full } \\
\text { Full }\end{array}$ & $\begin{array}{l}\text { Two-component } \\
\text { LDA }\end{array}$ \\
\hline \multirow[t]{6}{*}{$\rho$} & $\rho, \rho^{\prime}, \%$ Turb. & $\leftarrow$ & A & $\begin{array}{l}5,7,9,11,13 \\
15,17,19,20,25 \\
30,35,40,45,50 \\
60,70\end{array}$ & CL & $\begin{array}{l}\text { Rayleigh } \\
\text { scattering }\end{array}$ \\
\hline & $\begin{array}{l}\rho, \rho^{\prime}, \% \text { Turb. } \\
\text { - Skew, Flat, Int } \$\end{array}$ & $\leftarrow$ & & $15,30,50$ & Full & \\
\hline & $\rho, \rho^{\prime}, \%$ Turb. & $\leftarrow$ & B & $\begin{array}{l}5,6,7,8,9,10 \\
11,12,13,14,15 \\
20,25,30,35,40 \\
45,50,55,60,70 \\
85,104,150\end{array}$ & $\mathrm{CL}$ & \\
\hline & $\begin{array}{l}\bar{\rho}, \overline{\rho^{\prime}}, \% \text { Turb. } \\
\text { Skew, Flat, Int. }\end{array}$ & $\leftarrow$ & & $15,30,50$ & & \\
\hline & $\rho, \rho^{\prime}, \%$ Turb. & & C & $\begin{array}{l}5,6,7,8,9,10 \\
11,12,13,14,15 \\
16,17,18,19,20 \\
25,30,35,40,45 \\
50,60,70,80\end{array}$ & $\mathrm{CL}$ & \\
\hline & $\begin{array}{l}\bar{\rho}, \overline{\rho^{\prime}}, \% \text { Turb. } \\
\text { Skew, Flat, Int. }\end{array}$ & $\leftarrow$ & & $15,30,50$ & Half $†$ & \\
\hline$u, v, f$ & $\begin{array}{l}u, v, u^{\prime}, v^{\prime}, \\
u^{\prime} f, v^{\prime} f\end{array}$ & $u, v, f$ & A & 30,50 & $\begin{array}{l}\text { Three points } \\
\text { (middle and } \\
\text { edge of } \\
\text { shear layer) }\end{array}$ & $\begin{array}{l}\text { Simultaneous } \\
\text { Raman/LDA }\end{array}$ \\
\hline $\begin{array}{l}\text { Light } \\
\text { emission }\end{array}$ & Mean, rms & & A & $\begin{array}{r}1,5,9,14,19 \\
24,28,35,40,44 \\
49,50,55,60,65 \\
70,74,79,84,89 \\
15,30,50,70\end{array}$ & Full & $\begin{array}{l}\text { Line-of-sight } \\
\text { emission }\end{array}$ \\
\hline
\end{tabular}

*Format of data archived on magnetic tape and floppy disk ( - indicates data archived as presented in column "Quantity Tabulated").

$f(B)$, (J) and (A) refer to LDA seed in Both streams, the fuel Jet stream only, and the coflow Air stream only.

$\ddagger$ Half: radial traverse from stream layer on one edge to centerline. Halft: radial traverse from shear layer on one edge to a few points beyond the centerline, toward the opposite edge. Full: traverse from shear layer on one edge, to shear layer on opposite edge CL: axial traverse at the geometric centerline.

\$\% Turb.: rms mean. Flat: flatness. Skew: skewness. Int: intermittency. 


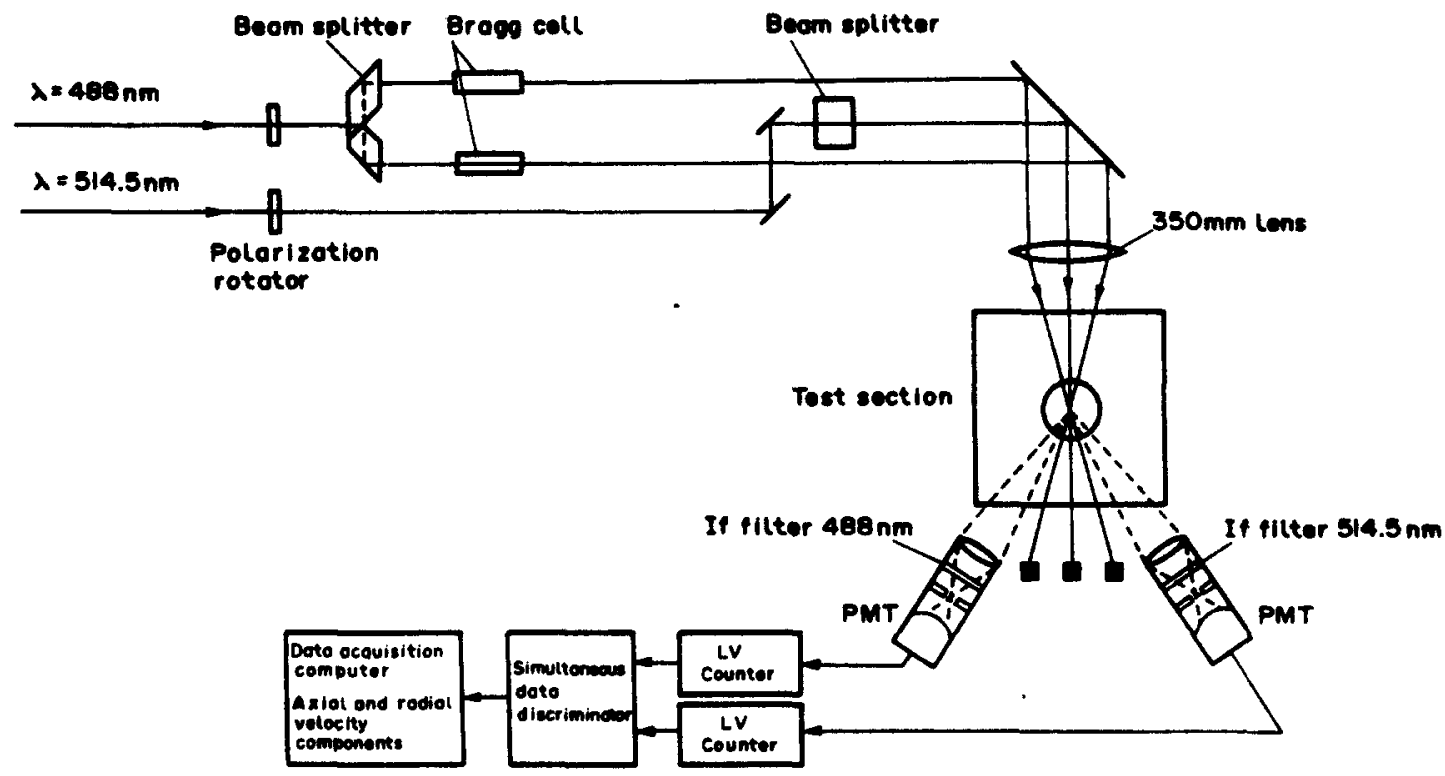

FIG B.2. Sketch of the two-component laser Doppler anemometer arrangement (Dibble et al. ${ }^{1}$ ).
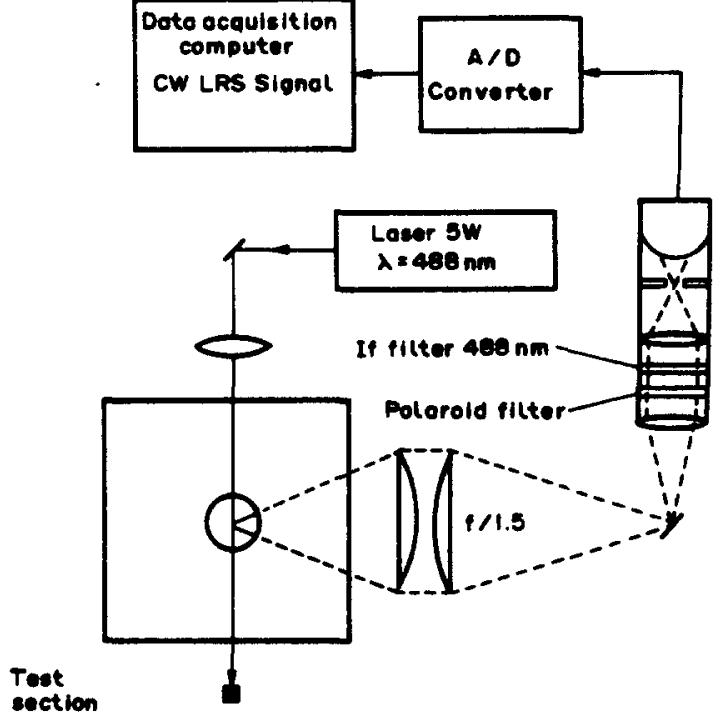

Fig. B.3. Sketch of laser Rayleigh scattering system (Dibble et $a .^{1}$ ).

length of $2.0 \mathrm{~mm}$. Dual Bragg cells, used for the radial velocity component, are driven by $30 \mathrm{MHz}$ and $40 \mathrm{MHz}$; the $10 \mathrm{MHz}$ difference allows unambiguous velocity determinations to $30 \mathrm{~m} / \mathrm{sec}$ in the radial component.

\section{Rayleigh scattering.}

The density is determined from the intensity of Rayleigh scattering from a laser beam. The laser Rayleigh scattering system (Fig. B.3) utilizes light from a 5-W laser beam $(488 \mathrm{~mm})$ collected by an $F / 2$ lens (focal length $=30 \mathrm{~cm}$ ) and relayed, at a magnifi- cation of 1.5 , to slits in front of a cooled photomultiplier tube (RCA 8575). With this magnification, a slit opening of $3 \mathrm{~mm}$ along the axis of the laser beam allows a 2-mm line segment of the laser beam to pass through to the photomultiplier tube.

The slit opening orthogonal to the laser beam is $4 \mathrm{~mm}$ which is larger than the laser beam diameter of 300 microns. The excessive opening ensures that a segment of the laser beam passes through the slit in spite of fluctuations in the position of the laser beam caused by density fluctuations in the turbulent flame. Between the slits and the photomultiplier tube, a 1$\mathrm{nm}$ bandpass interference filter $(488 \mathrm{~nm})$ and a polarizing filter are used to reduce background from flame luminescence. With the laser off, a signal change is undiscemable whether the flame is on or off. Current from the photomultiplier tube is integrated by an RC filter with a cutoff frequency of $8 \mathrm{kHz} \mathrm{A}$ time series of the Raleigh intensity, and hence gas density, is obtained by digitization, at $16 \mathrm{kHz}$, of the filtered signal.

\section{Simultaneous LDA-laser Raman scattering.}

Raman measurements of gas species concentrations are made using a high-power pulsed dye laser (1 J/pulse, $2-\mu \mathrm{sec}$ pulsewidth, $\lambda=514.5 \mathrm{~nm}, \Delta \lambda=$ $0.4 \mathrm{~nm}$ ). The beam is focused to a $500-\mu \mathrm{m}$ waist diameter which is aligned to overlap the LDA measurement volume. The width of the spectrometer entrance slit determines the length of the Raman probe volume $(1 \mathrm{~mm})$, while the height of the probe volume is determined by the laser beam diameter. The vibrational Raman scattered light from the major species $\left(\left[\mathrm{N}_{2}\right],\left[\mathrm{O}_{2}\right],\left[\mathrm{H}_{2} \mathrm{O}\right]\right.$, and $\left.\left[\mathrm{H}_{2}\right]\right)$ and the antiStokes of $\left[\mathrm{N}_{2}\right]$ is separated from the collected light with a 3/4-m grating spectrometer and measu- 
red on photomultiplier tubes at the exit plane of the spectrometer. As a measure of the overall efficiency of the collection system, 6000 photoelectrons/J of laser light are collected from nitrogen in room air. From the combined Raman measurements, the fuel mixture fraction $f$ can be determined for each signal laser pulse.

Simultaneous measurements of two-velocity components and species concentrations are made by combining the Raman scattering system with the two-color LDA system. The Raman laser is triggered by a pulse from the LDA electronics which indicates a valid radial and axial velocity event. The time between the LDA event and the Raman laser pulse is typically $40 \mu \mathrm{sec}$. At each spatial location, a minimum of 2500 simultaneous triplets of axial velocity, radial velocity, and mixture fraction are measured. These simultaneous measurements are made for the Case- $A$ flame at three radial locations and at two axial locations $(x / d=30$ and $x / d=50)$.

\section{line-of-sight emission}

Line-of-sight emission is measured with the laser Rayleigh scattering collection system. The laser line interference filter is removed so that all of the emission collected by the $F / 2$ optics is relayed to the photomultiplier tube (RCA 8575).

\section{Photography}

The framing speed of the high-speed photography is limited by the total amount of light emission from the flame. The hydrogen flame has little light emission relative to hydrocarbon flames of comparable conditions. For the high-speed films, the luminosity of the flame is increased by replacing the argon diluent with dichloro-difluoro-methane (freon12). The flow conditions are those of Case $A$ with one exception. The replacement of the argon in the fuel with freon-12, which has a higher molecular weight, doubles the pipe Reynolds number. For this condition, 200 frames/sec are possible with ASA 500 film using a Redlake LOCAM framing camera. A $4 \times 5$ format Calumet camera is used for the time-averaged picture.

\section{B.7. Unusual Measurement Methods}

No special or unusual measurement methods, in addition to those described above, were employed.

\section{B.8. Experimental Protocol}

The laser Rayleigh, laser Doppler anemometry, and simultaneous laser Doppler anemometry and laser Raman experiments described in this report span a period from September 1983 to August 1985. Other experiments, not reported here, were performed in the Combustion Tunnel Facility during this period. The laser Rayleigh data were collected, in the Fall of 1983, prior to the laser Doppler anemometry experiments which were collected in the Spring of 1984. In this manner, the laser Rayleigh experiments, which demand a minimal presence of particles in the flow, were completed before the wind tunnel was contaminated with particles needed for the laser Doppler anemometry experiments. (It has since been determined that the particle contamination due to residual laser Doppler velocimetry seed particles is not severe. A day of operation without LDA seed is sufficient to reduce the residual particles to a level acceptable for laser Rayleigh scattering.) The laser Raman system was combined with the laser Doppler velocimeter and used for simultaneous measurements in the Summer of 1984. Axial profiles of density were remeasured in the Spring of 1985

\section{B.9. Quality Control}

Mass balances.

Mass balances on the total throughput were attempted using the laser Doppler anemometry (LDA) data. The results established that mass was conserved. However, because the mass balance is dominated by the mass flux in the outer region of the tunnel, such a mass balance was not a critical test of mass balance in the core of the flow. A mass balance on hydrogen, the critical test of interest, could not be conducted due to the few radial measurements made of mixture fraction.

\section{Reproducibility and repeatability.}

No checks for reproducibility were conducted. A few repeatability checks, described under Error Analysis below, were completed.

\section{$L D A$ seeding}

Both the fuel jet and coflowing air were seeded. However, the concentration of seed in the two flows was not controlled. Hence, an evaluation of concentration bias was conducted. No attempt was made to remove velocity bias by equal time interval sampling. The errors associated with LDA seeding are delineated below.

\section{Control of test conditions.}

Test conditions were established by settings on the metering devices employed for the coflowing air and fuel. No additional checks were made for establishing flow test to test whether the conditions were repeated.

\section{Tests of sensitivity to boundary conditions.}

The principal boundary condition with a potential influence on the present experiment is exhaust suction. To establish the extent of influence, the exhaust hood flow-rate was varied while monitoring the velocity and density at one point in the flow. 


\section{B.10. Error Analysis}

Velocity.

In the present flow, the primary potential for error in velocity is 'velocity bias' which is due to the proportionality of particle flux, through the measurement volume, to the instantaneous velocity. Razdan and Stevens ${ }^{4}$ have shown in a comparable flow that for velocity fluctuations up to $10 \%$, this bias is negligible. As velocity fluctuations increase, the velocity statistics are increasingly biased toward higher velocities. At the maximum fluctuation levels measured in the present flow, a maximum bias error of $3 \%$ in the mean is estimated. The velocity data presented here are not modified for the effects of velocity bias.

Other potential sources of velocity error have also been estimated. The error due to velocity-gradient broadening is estimated to be less than $0.3 \%$. Errors in time measurement with a counter processor having $0.6-n s$ resolution are less than $0.2 \%$ at the highest burst frequencies measured, and the effects of variation in refractive index on movement of the measurement volume are negligible.

Since the velocity of a particle is actually measured with laser anemometry, particle-velocity lag is considered. Using the estimates of Durst et al., ${ }^{3}$ a 0.85 micron particle can follow the flow up to a frequency of $8 \mathrm{kHz}$ with a slip velocity of $1 \%$ Based on previous measurements in the current flow, this frequency response is sufficient.

In mixing flows, such as the nonpremixed flame herein described, the measured velocity depends on the density of LDA seed particles added to each of the inlet streams. In this study, the velocity bias resulting from the origin of LDA seed particles is bounded by measurements of velocity when seed particles are added to the fuel only, followed by measurements when seed particles are added to the coflow air only. Table B.4 shows the results of some of these measurements. In all cases, the seeding of the fuel (*.JET) consistently produces slightly higher mean velocities than the seeding of the air (*.AIR). The true velocity lies between these two cases. The difference between these two cases, which is typically $3 \%$ of the mean axial velocity, is considered to be the largest source of uncertainty in the velocity data.

\section{Density via laser Rayleigh scattering.}

It is often the case in Rayleigh scattering experiments that a fraction of the light collected by the Rayleigh scattering system is not due to Rayleigh scattering from molecules in the probe volume. This non-Rayleigh signal is most commonly due to minute amounts of scattering of laser light from optical or diffuse surfaces throughout the laboratory. This background scattering can be measured in a variety of ways.

In most of these experiments, the background is inferred by moving the collection system above and below the horizontal laser beam. Once the laser beam is not imaged onto the slits, the remaining signal is only weakly sensitive to further movement of the collection system; this remaining signal is considered the background. Another method to determine the background scattering takes advantage of the fact that the Rayleigh scattering intensity, from the fuelrich side of the laminar argon-in-hydrogen flame, is nearly constant and independent of position. Measurements made in room air and then in the fuelrich zone of the flame are used to determine the background contribution. When these two methods are compared, the former method produces a background that is $10 \%$ lower than the latter; in either case, the background is typically $4 \%$ of the Rayleigh signal from room air.

A comparison of measurements of density from three different experiments conducted on different days is presented in Table B.5. The three experiments include data from axial and radial density profiles and, in addition, from measurements using the

TABLE B.4. Velocity data: effect of seed concentration bias*

\begin{tabular}{|c|c|c|c|c|c|}
\hline \multirow[b]{2}{*}{ Case } & \multirow{2}{*}{$\begin{array}{c}\text { Axial } \\
\text { location } \\
x / d\end{array}$} & \multicolumn{4}{|c|}{ Velocity $(\mathrm{m} / \mathrm{sec})$} \\
\hline & & AAX.BOT + & AXX.AIR & AXX.BOT & AXX.JET \\
\hline \multirow[t]{5}{*}{ A } & 15 & 74.6 & 70.2 & 72.6 & 73.5 \\
\hline & 30 & 51.4 & 47.7 & 48.8 & 50.9 \\
\hline & 50 & 35.1 & 32.0 & 33.5 & 33.4 \\
\hline & 70 & 24.0 & 21.8 & 23.3 & 23.8 \\
\hline & & BAX.BOT + & BOX.AIR & BOX.JET & BXX.BOT \\
\hline \multirow[t]{2}{*}{ B } & 30 & 91.6 & 85.6 & 87.99 & \\
\hline & 50 & $\begin{array}{l}54.3 \\
360\end{array}$ & $\begin{array}{l}53.7 \\
370\end{array}$ & $\begin{array}{l}55.3 \\
37.8\end{array}$ & 368 \\
\hline & & & & & \\
\hline
\end{tabular}

* Repeatability of velocity data by comparison of velocity $(\mathrm{m} / \mathrm{sec})$ at same spatial location and different seeding conditions.

+FILENAME. 
TABLE B.5. Density data: repeatability*

\begin{tabular}{|c|c|c|c|c|c|c|c|}
\hline \multirow[b]{2}{*}{ Case } & \multirow{2}{*}{$\begin{array}{c}\text { Axial } \\
\text { location } \\
x / d\end{array}$} & & \multicolumn{2}{|c|}{ Density } & \multicolumn{3}{|c|}{ Statistics } \\
\hline & & - & AAX.DAX\$ & AXX.DEN & MEAN & SIGN & $90 \%$ \\
\hline \multirow[t]{2}{*}{$\mathbf{A}$} & $\begin{array}{r}15 \\
30 \\
50 \\
70 \\
85 \\
104 \\
150\end{array}$ & $\begin{array}{l}0.194 \\
0.122 \\
0.118 \\
0.144 \\
0.20 \\
0.25 \\
0.40\end{array}$ & $\begin{array}{l}0.190 \\
0.123 \\
0.121 \\
0.153\end{array}$ & $\begin{array}{l}0.188 \\
0.141 \\
0.131\end{array}$ & $\begin{array}{l}0.1915 \\
0.127 \\
0.122\end{array}$ & $\begin{array}{l}0.00259 \\
0.0081 \\
0.0053\end{array}$ & $\begin{array}{l}0.0060 \\
0.019 \\
0.012\end{array}$ \\
\hline & & BAX.DEN\& & BXX.DEN & & & & \\
\hline B & $\begin{array}{r}15 \\
30 \\
50 \\
70 \\
85 \\
104 \\
150\end{array}$ & $\begin{array}{l}0.2316 \\
0.112 \\
0.120 \\
0.144 \\
0.201 \\
0.228 \\
0.375\end{array}$ & $\begin{array}{l}0.188 \\
0.134 \\
0.117 \\
0.138\end{array}$ & $\begin{array}{l}0.199 \\
0.131 \\
0.116\end{array}$ & $\begin{array}{l}0.2125 \\
0.122 \\
0.118\end{array}$ & $\begin{array}{l}0.0194 \\
0.0103 \\
0.00178\end{array}$ & $\begin{array}{l}0.044 \\
0.023 \\
0.0041\end{array}$ \\
\hline
\end{tabular}

* Repeatability of data by comparison of density at same spatial location measured on different days. †The data in this column were collected several months after the other density and velocity data; these data are weighted twice in the calculation of the MEAN in column six.

tDensity values are normalised to the inlet air density.

BFILENAME.

IThe $90 \%$ confidence interval is generated from the standard deviation, column seven, and student $t$-value (2.35) for four observations.

improved background measurement technique. Because of this improvement, the latter data are weighted twice in generation of statistics. The Table shows $90 \%$ confidence intervals which have been enlarged by $t$-value estimates associated with four observations. These confidence interval estimates, less than $15 \%$ of the mean, are considered satisfactory. These estimates are conservative since they do not take into account the lower limit of density (relative to air) which is 0.112 .

The inference of density from the Rayleigh scattering intensity assumes that the ratio of the gas density to the sum of the mole-fraction weighted Rayleigh scattering cross sections is a constant. As the right column in Table B.5 shows, this assumption systematically underpredicts the density by $4 \%$ on the fuelrich side of the flame.

\section{Raman scattering.}

The primary potential sources for error in the Raman scattering measurements are calibration of the light collection system and background fluorescence (from the windows where the laser beam enters and exits the test section). The Raman system is calibrated in the post-flame gases above flat-flame of hydrogen burning with air. Calibrations of the gases at various temperatures is conducted by operating the burner fuel-lean and then fuel-rich. When the burner is fuel-lean, the laser thermometer is calibrated to a radiation-corrected thermocouple. The laser thermometry is used when the flame is fuel-rich since thermocouple measurements are questionable under these conditions. The concentrations of the post-flame gases are determined from the mass flow meters and the assumption of chemical equilibrium in the combustion products. Through these calibrations, the relationship between Raman intensity and concentration is established. The shot noise associated with the 6000 photoelectrons is $1.2 \%$. However, in the flame zone, the concentrations of the major species are about an order of magnitude less than the concentration of nitrogen in room air; accordingly, the shot noise increases to $4 \%$. Since the mixture fraction $f$ is derived from various combinations of the major species concentrations, $f$ will have an associated shot noise of less than $6 \%$. The background fluorescence contribution to the Raman signal was measured by scanning the spectrometer away from the Raman line and was determined to be less than $0.5 \%$.

Pressure drop across a venturi is related to the air velocity in the wind tunnel. The relationship between the pressure drop and the coflow air velocity is determined with the laser Doppler anemometer. In the course of an experiment, the pressure drop may change slightly and therefore require manual readjustment of the rotational speed for the air supply fan. These excursions in the coflow air velocity of $9.2 \mathrm{~m} / \mathrm{sec}$ amount to a standard deviation of $0.12 \mathrm{~m} / \mathrm{sec}$. 


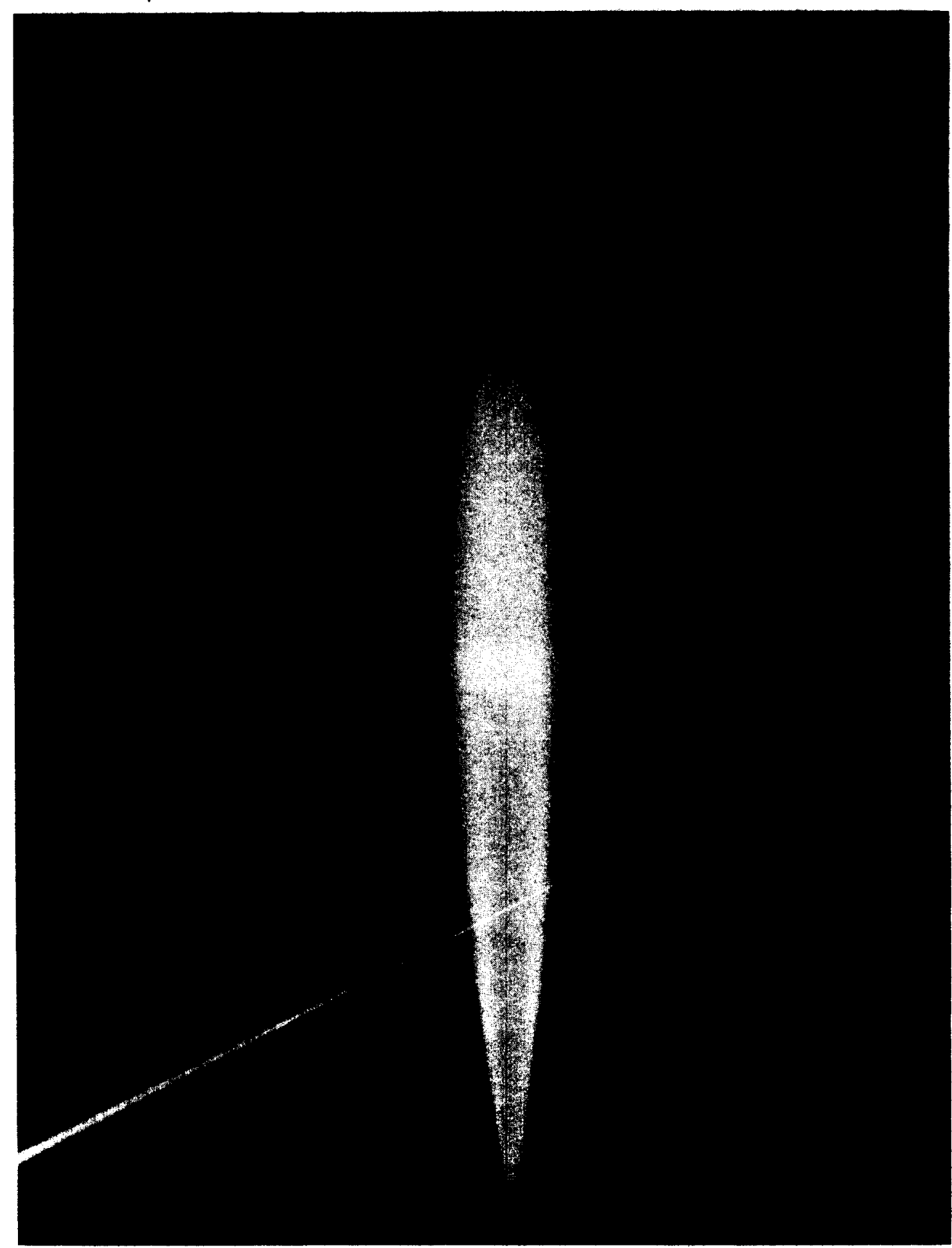

Fig. B.4. Time-averaged photograph of light emission (Case A) (Dibble et al. ${ }^{1}$ ). 


$$
11111
$$

$$
1111
$$


Other.

Changes in the exhaust hood flow rate by $\pm 25 \%$ have no effect on the velocity in the test section, or on the density, measured at $x / d=30$ and a radial position where the gradient is large and hence most sensitive to small changes in the flow field.

\section{B.11. Availability of Data}

The data base is formally documented in Dibble $e t$ al. ${ }^{1}$ and Dibble et al. ${ }^{2}$ Velocity (LDA) and density (laser-Rayleigh scattering) are provided in the former, and simultaneous LDA/Raman data are provided in the latter. Both reports are available from the National Technical Information Service (NTIS), 5285 Port Royal Road, Springfield, VA 22161. The data files may be obtained on either magnetic tape or floppy disk from the Combustion Research Facility, Sandia National Laboratories, Livermore, California, 94550.

\section{B.12. References}

1. Dibble, R. W., Schefer, R. W., Hartman, V. and Kollman, $W$. Velocity and density measurements in a turbulent nonpremixed flame, Sandia Rep. SAND858233; a aailable from NTIS (1985a).

2. Dibile, R. W., Schefer, R. W., Hartman, V. and KOLLMAN, W. Simultaneous velocity and concentration measurements in a turbulent nonpremixed flame, Sandia Rep. SAND85-8234; available from NTIS (1985b).

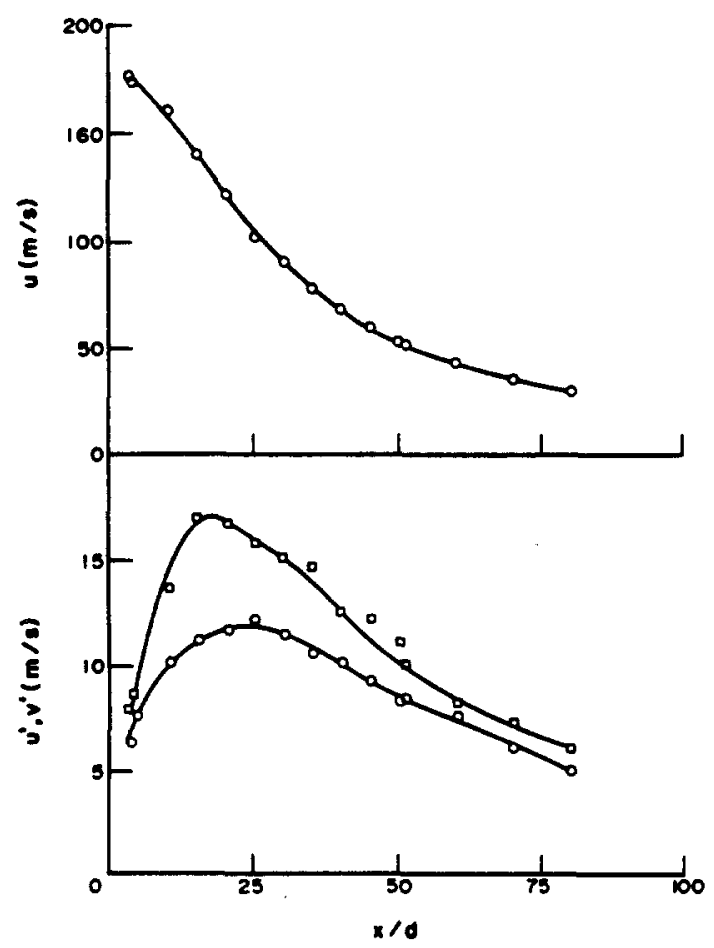

Fig. B.6. Axial centerline profiles of velocity (Case B). FILENAME: BAX.JET (Dibble et al. ${ }^{1}$ ).
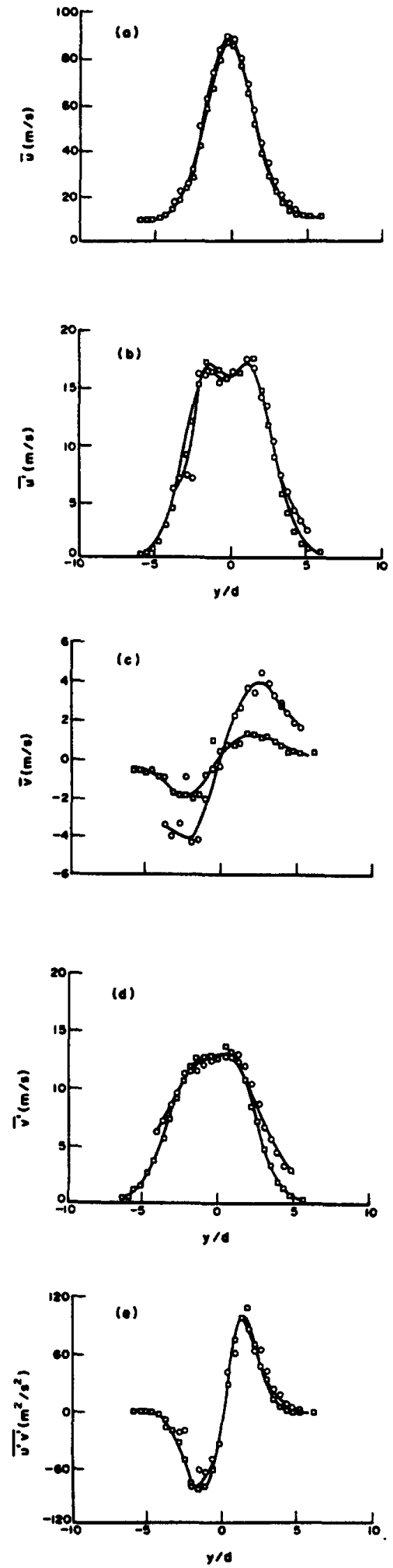

Fig. B.7. Radial profiles of velocity at $x / d=30$ (Case B) FILENAMES: B30.JET (O); B30.AIR (D) (Dibble et al. ${ }^{1}$ ). 


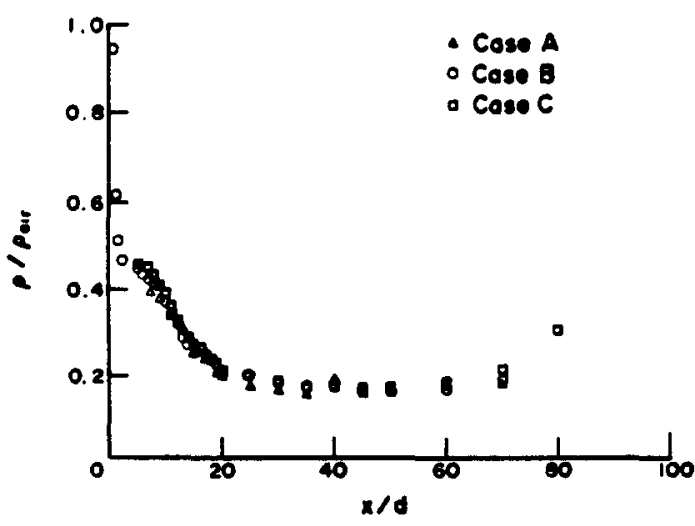

FIG B.8. Axial centerline profiles of density. FILENAMES: $\operatorname{AAX} . D E N(\triangle)$; BAX.DEN (O); CAX.DEN (口) (Dibble et al. ').
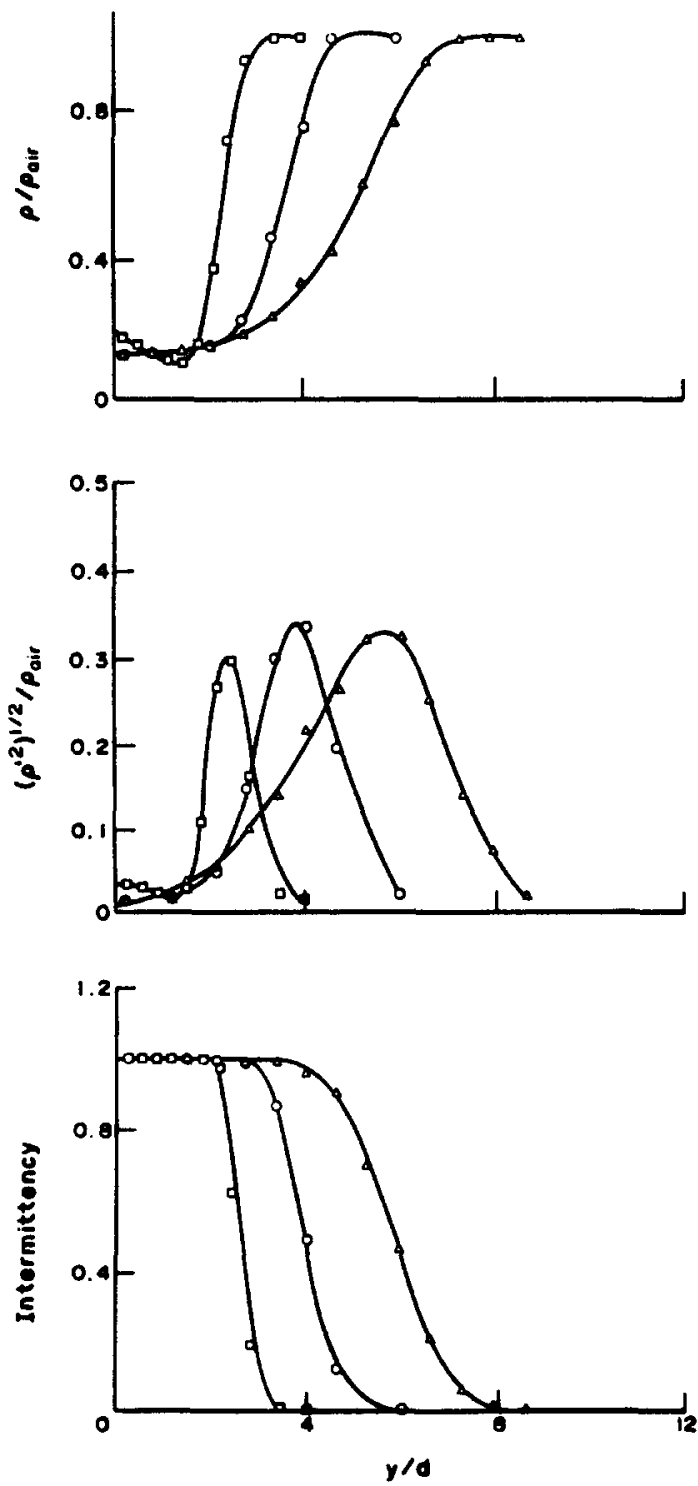

FIG. B.9.a. Radial profiles of density (Case A). FILENAMES: A15.DEN (口); A30.DEN (O); A50.DEN $(\triangle)$ (Dibble et al. ${ }^{1}$ ).
3. Durst, F., Melling, A. and Whitelaw, J. H., Principles and Practice of Laser Doppler Anemometry, Academic Press (1976).

4. Razdan, M. K. and Stevens, J. G., CO/air turbulent diffusion flame: measurements and modeling, Combust. Flame 59, 289 (1985).

\section{B.13. Data}

Static photograph.

Light emission from the flame for Case A photographed in a time-averaged mode, is presented in Fig. B.4. In addition, radial and axial profile data of the line-of-sight emission (mean and standard deviation) are reported below for this case.
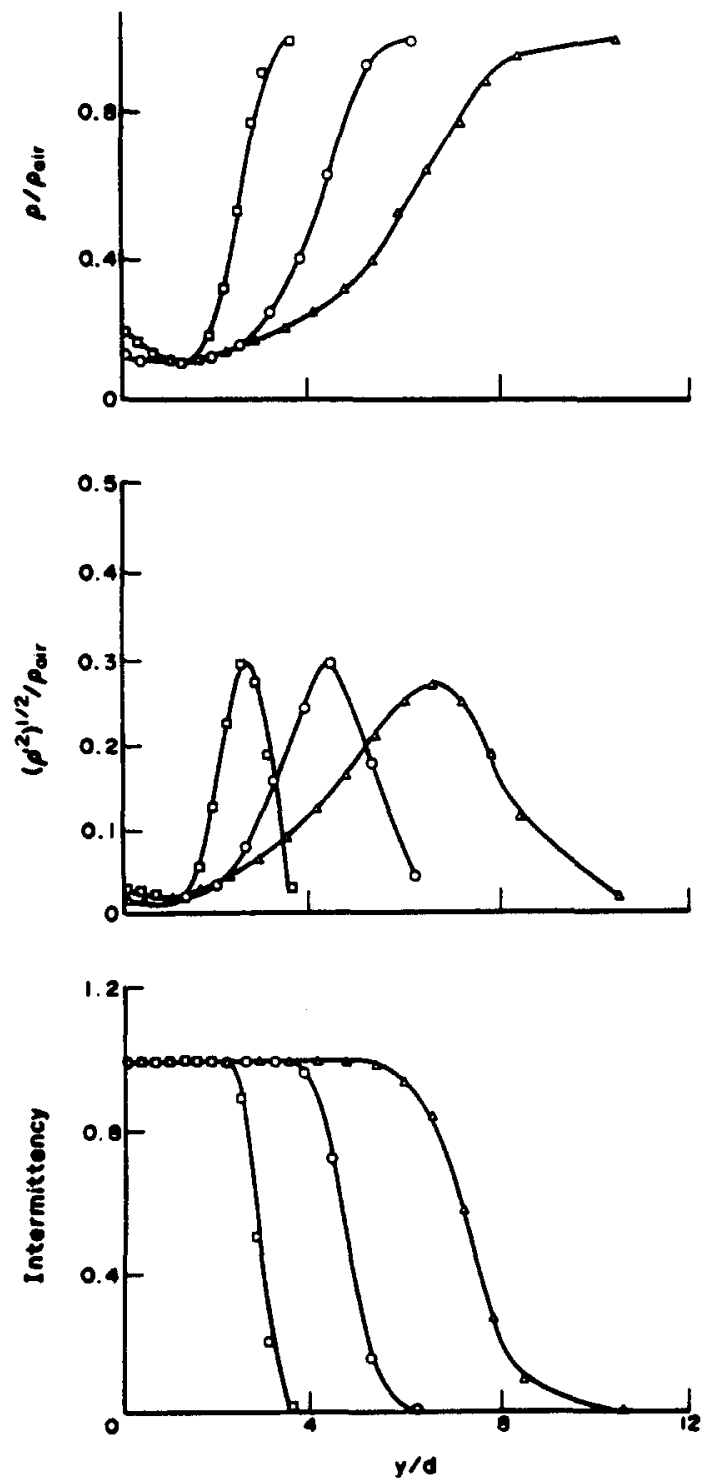

FiG. B.9.b. Radial profiles of density (Case B). FILENAMES: B15.DEN (口); B30.DEN (O); B50.DEN $(\Delta)$ (Dibble et al. ${ }^{1}$ ). 
Time-resolved photographs.

A sequence of 10 black and white photographs is presented in Fig. B.5. This framing speed is sufficient to capture large scale structures of the flame; however, with this framing speed, the evolution of these structures from one frame to the next is difficult to follow.

\section{Tabulated data.}

Data files are presented on the following pages. (To place the tabulated data into perspective, select data files are plotted in Figs B.6 through B.7.)
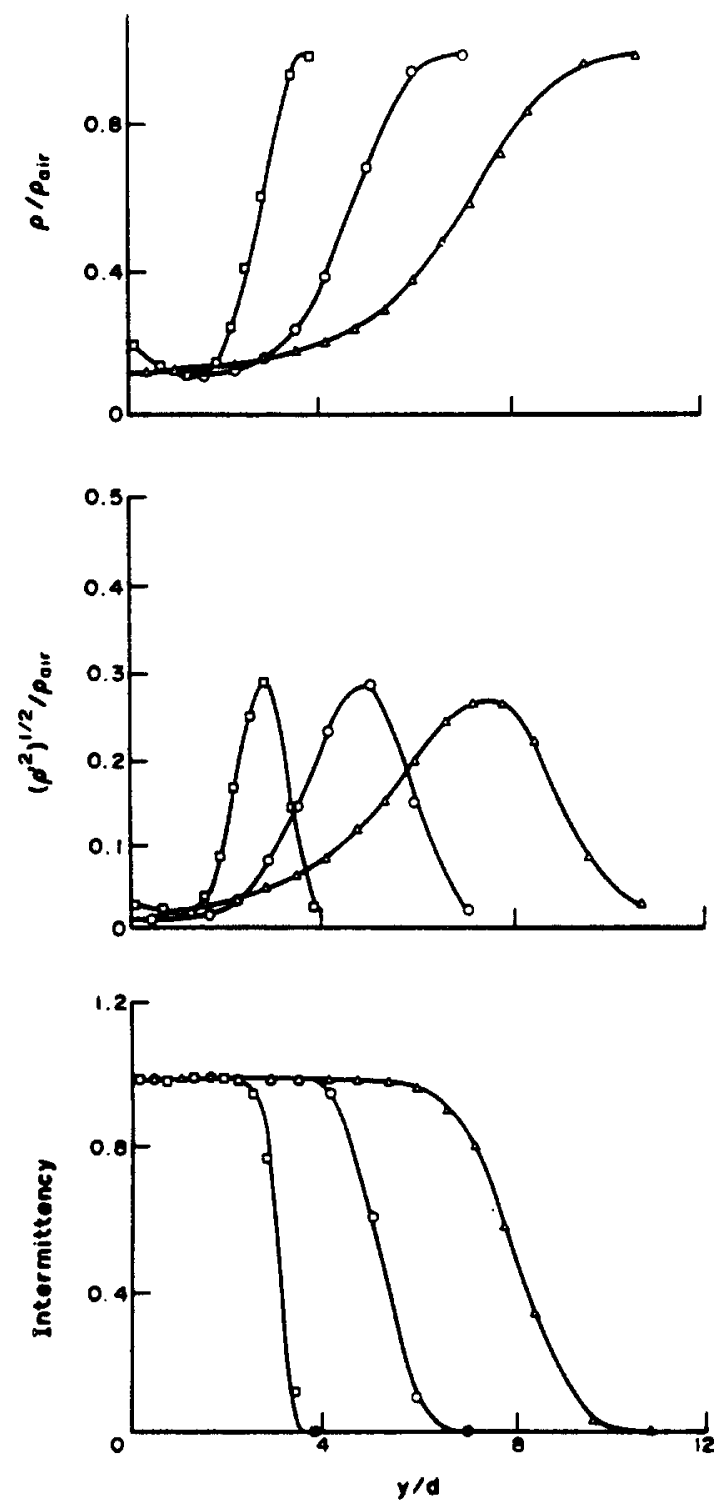

FIG. B.9.c. Radial profiles of density (Case C). FILENAMES: C15.DEN (口); C30.DEN (O); C50.DEN $(\Delta)$ (Dibble et al. ${ }^{1}$ ).

\section{FILE FORMAT}

Each table is headed with a FILENAME The FILENAMEs have the following format for the velocity and density data: AXX.YYY.

$$
\begin{aligned}
\text { If } A & =A, 75 \mathrm{~m} / \mathrm{sec} \text { is the average velocity at nozzle } \\
\text { exit } & \\
& =B, 150 \mathrm{~m} / \mathrm{sec} . \\
& =C, 225 \mathrm{~m} / \mathrm{sec} .
\end{aligned}
$$

In all cases (A, B, and $C$, the coflow air velocity is $9.2 \mathrm{~m} / \mathrm{sec}$.

If $\mathrm{XX}=$ a number, the file is a radial profile at axial position $\mathbf{X X}$

$=\mathrm{AX}, \quad$ the file is an axial profile along the jet centreline.

If $Y Y Y=D E N$, the file is a density profile

$=\mathrm{JET}$, the file is a velocity profile with LDA particles added to nozzle fuel only

$=A I R$, the file is a velocity profile with LDA particles added to the coflow air only

$=$ BOT, the file is a velocity profile with LDA particles added to both coflow air and nozzle fluid.

For the simultaneous LDA-laser Raman, the FILENAMEs have the following format: AXXNYY.UVF.

If $\mathrm{N}=\mathrm{J}$, the file contains data with LDA particles added to the nozzle fuel only

$\mathrm{N}=\mathrm{A}$, the file contains data with LDA particles added to the coflow air only

$\mathbf{N}=\mathbf{N}$, the file contains only scalar data, with no LDA particles added (laser Raman system triggered independent of LDA)

and

$Y Y=\quad$ radial position.

For the line-of-sight emission data, the FILENAMEs have the following format: ALITXX.DAT.

Units for velocity data are $\mathrm{m} / \mathrm{sec}$; the density data are normalized to the density of air at the inlet; the units for the light emission data are arbitrary.

\section{DATA FILES AVAILABLE}

Inlet profiles are provided in INPUT.

For Case A (bulk fuel velocity at nozzle exit of $75 \mathrm{~m} / \mathrm{sec}, R e=9000$ ), the following data files are provided: 
AAXBOT

AAX.DEN

A30.BOT

A50.BOT

A70.BOT

A1S.AIR

A50.JET

A70.JET

AAXDEN

A15.DEN

A30.DEN

A50.DEN

ALIT15.DAT ALIT30.DAT ALIT50.DAT ALIT70.DAT

For Case B (bulk fuel velocity at nozzle exit of $150 \mathrm{~m} / \mathrm{sec}, R e=18,000$ ), the following data files are provided:

BAX.HET

BAXDEN

B03.BOT

$\begin{array}{lll} & \text { B30.JET } & \text { B50.JET } \\ & \text { B30.AIR } & \text { B50.AIR } \\ \text { B15.DEN } & \text { B30.DEN } & \text { B50.DEN. }\end{array}$

B70.BOT

B70.JET

B70.AIR

For Case C (bulk fuel velocity at nozzle exit of $225 \mathrm{~m} / \mathrm{sec}, \operatorname{Re}=27,000$ ), the following data files are provided:

\section{CAXDEN}

\section{C15.DEN}

C30.DEN

C50.DEN.

Due to the voluminous data associated with the simultancous LDA-laser Raman, data are not tabulated in the present summary. Full data sets are available in Dibble et al. $^{2}$

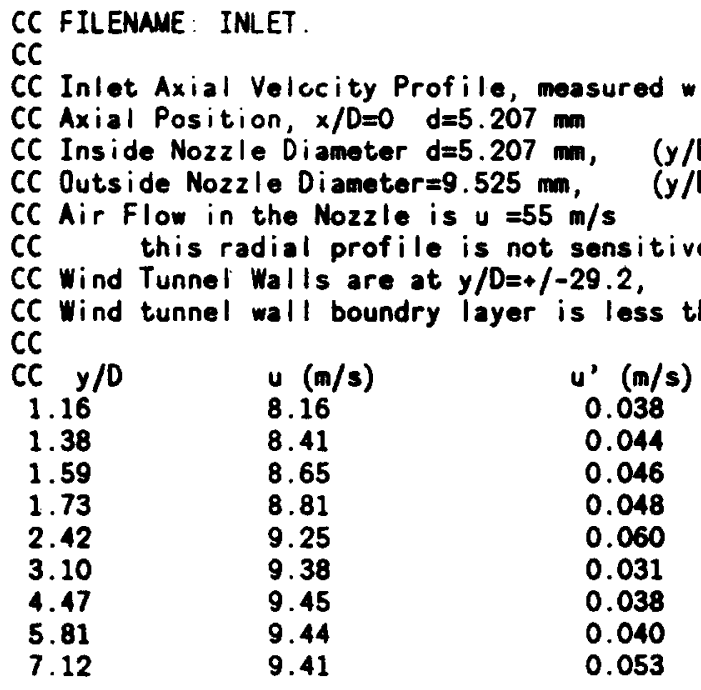

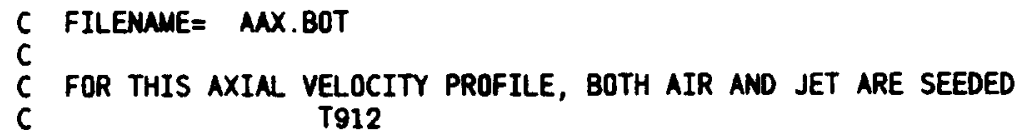

c

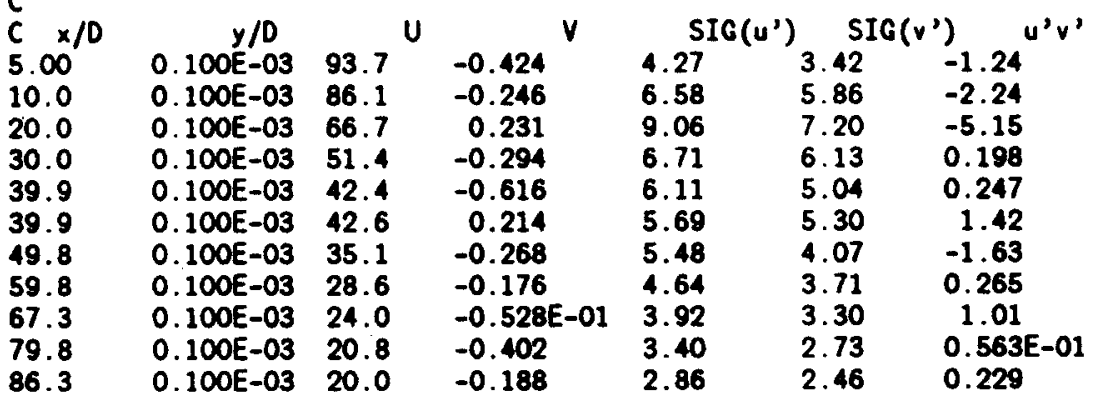


FILENAME $=$ A15.BOT

LOV SEED PARTICLES ADDED TO BOTH AIR AD JET. To00

\begin{tabular}{|c|c|c|c|c|c|c|}
\hline $\begin{array}{l}\times / D \\
5.2 \\
5.2 \\
5.3 \\
5.2 \\
5.2 \\
5.2 \\
5.2 \\
5.2 \\
5.2 \\
5.2 \\
5.2 \\
5.2 \\
5.2 \\
5.3 \\
5.2 \\
5.2 \\
5.2 \\
5.2 \\
5.2\end{array}$ & $\begin{array}{l}y / D \\
-4.35 \\
-3.99 \\
-3.54 \\
-3.10 \\
-2.66 \\
-2.22 \\
-1.78 \\
-1.34 \\
-0.820 \\
-0.460 \\
0.600 E-01 \\
0.500 \\
0.930 \\
1.37 \\
1.89 \\
2.33 \\
2.70 \\
3.14 \\
3.65 \\
4.09\end{array}$ & $\begin{array}{l}U \\
9.14 \\
9.12 \\
9.05 \\
8.90 \\
8.79 \\
9.43 \\
17.5 \\
34.9 \\
51.2 \\
67.3 \\
72.6 \\
63.5 \\
47.0 \\
29.5 \\
13.5 \\
8.87 \\
8.88 \\
9.02 \\
9.11 \\
9.15\end{array}$ & $\begin{array}{l}V \\
-0.438 \\
-0.456 \\
-0.473 \\
-0.510 \\
-0.520 \\
-0.576 \\
-1.25 \\
-2.65 \\
-2.35 \\
-2.26 \\
0.716 \\
2.05 \\
3.27 \\
2.25 \\
0.979 \\
0.339 \\
0.320 \\
0.313 \\
0.282 \\
0.261\end{array}$ & $\begin{array}{l}\text { SIG(u') } \\
0.166 \\
0.191 \\
0.306 \\
0.414 \\
0.593 \\
2.20 \\
6.67 \\
10.4 \\
11.6 \\
8.83 \\
7.30 \\
9.75 \\
11.9 \\
9.80 \\
5.53 \\
1.04 \\
0.440 \\
0.275 \\
0.167 \\
0.137\end{array}$ & $\begin{array}{l}\left.\text { SIG( } v^{\prime}\right) \\
0.234 \\
0.243 \\
0.280 \\
0.321 \\
0.540 \\
1.67 \\
4.25 \\
6.96 \\
7.71 \\
7.28 \\
6.84 \\
7.84 \\
8.28 \\
6.94 \\
3.60 \\
0.972 \\
0.401 \\
0.292 \\
0.217 \\
0.191\end{array}$ & $\begin{array}{l}u^{\prime} v^{\prime} \\
0.990 E-02 \\
0.128 E-01 \\
0.258 E-01 \\
0.374 E-01 \\
-0.116 E-01 \\
-1.88 \\
-12.7 \\
-39.8 \\
-37.7 \\
-17.6 \\
0.129 \\
26.5 \\
46.1 \\
34.4 \\
11.0 \\
0.340 \\
0.000 E+00 \\
0.000 E+00 \\
0.000 E+00 \\
0.000 E+00\end{array}$ \\
\hline
\end{tabular}

C FILENAME $=\quad$ A3O.BOT
C
C LDV SEED PARTICLES TO BOTH JET AND AIR.
C T850

C

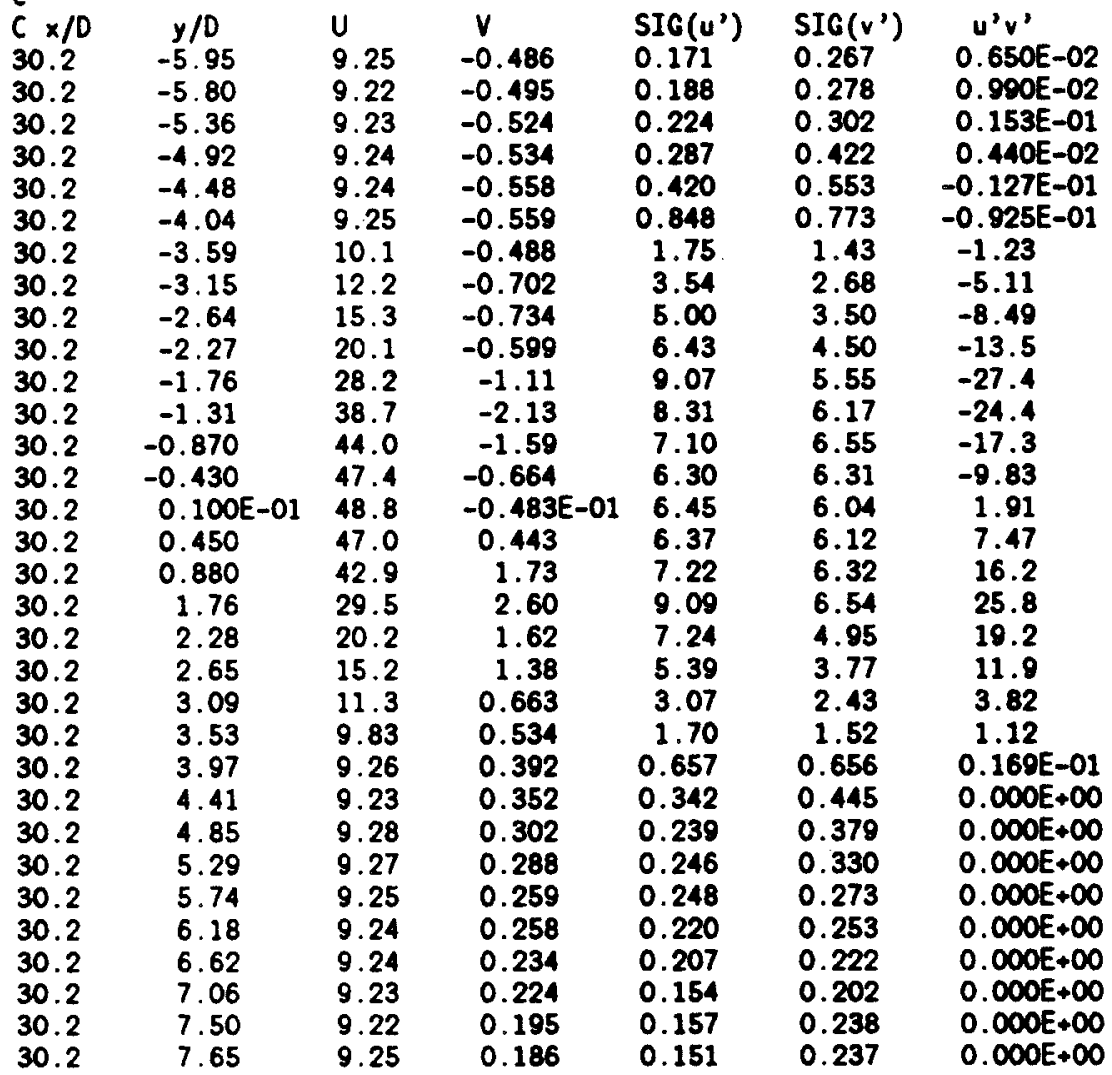




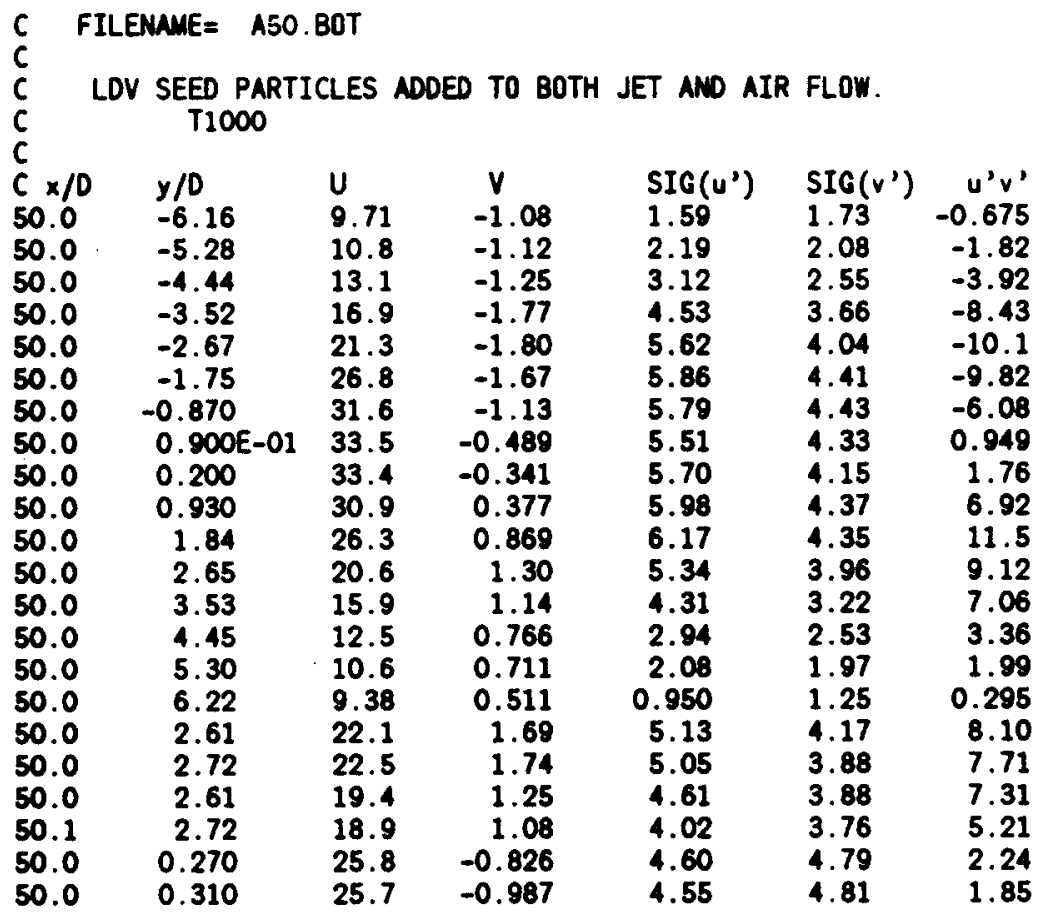

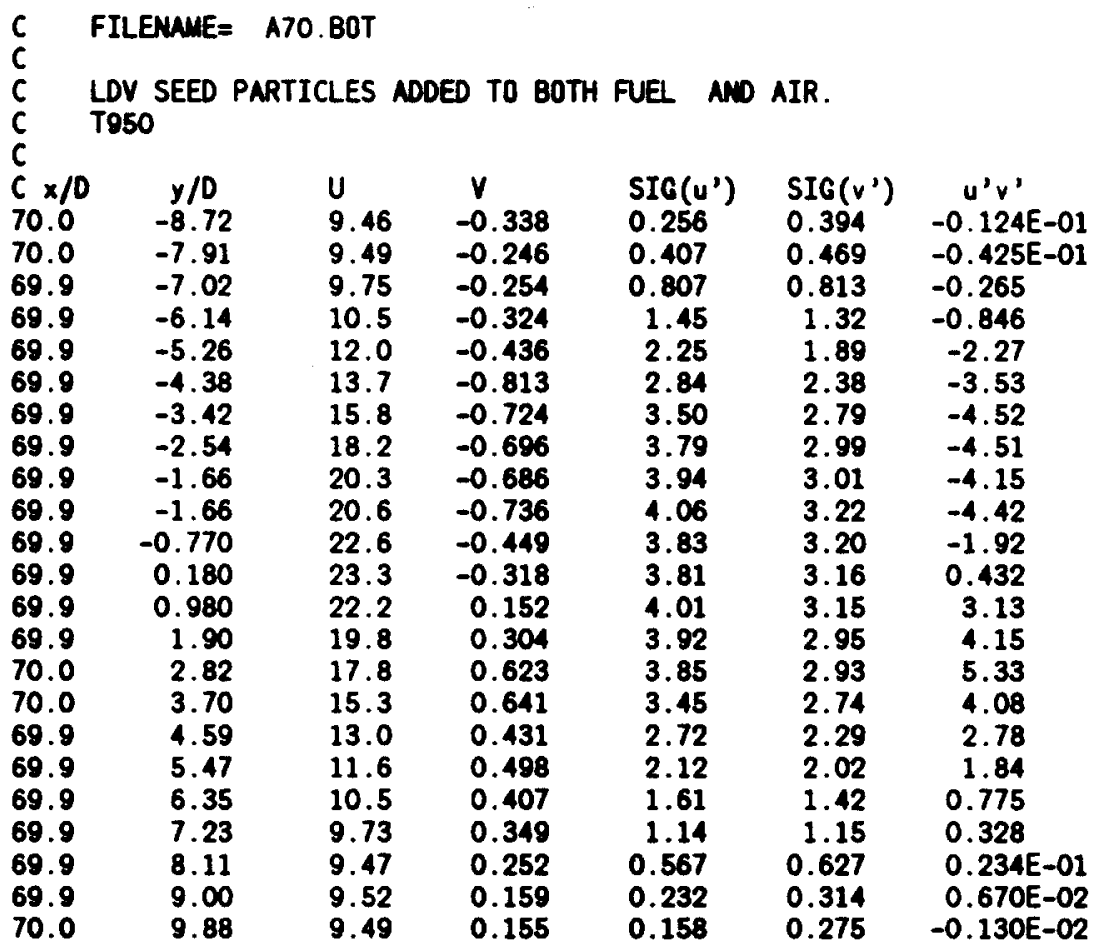




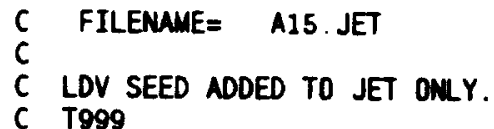

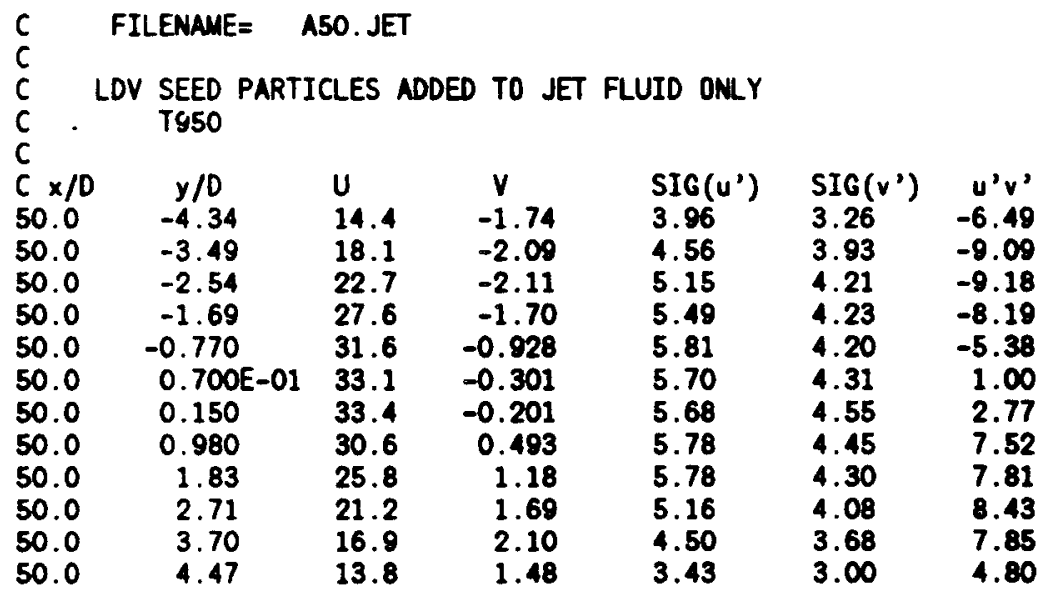




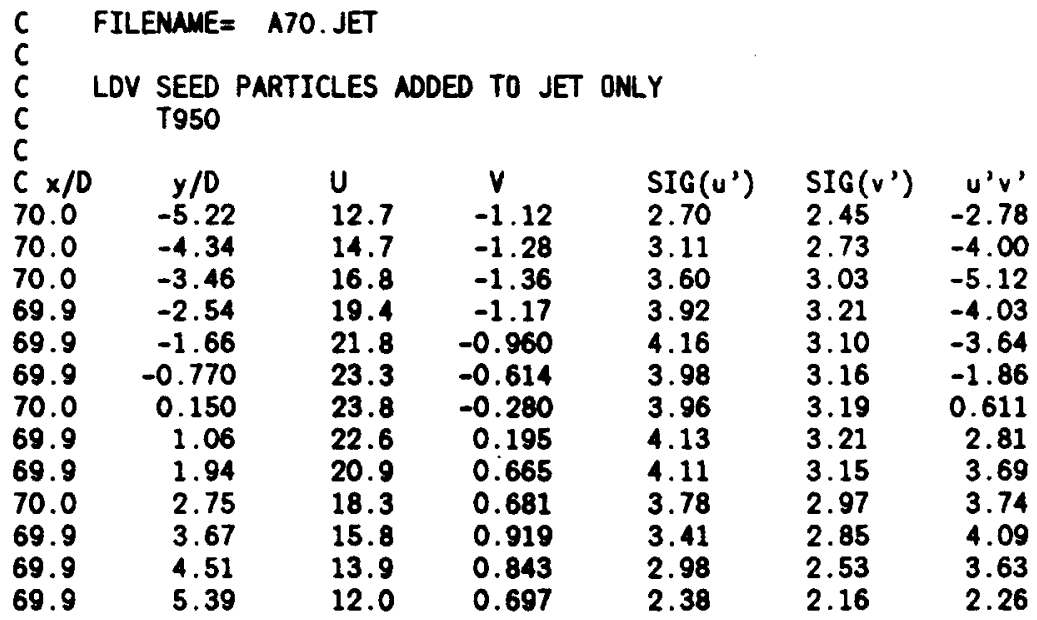

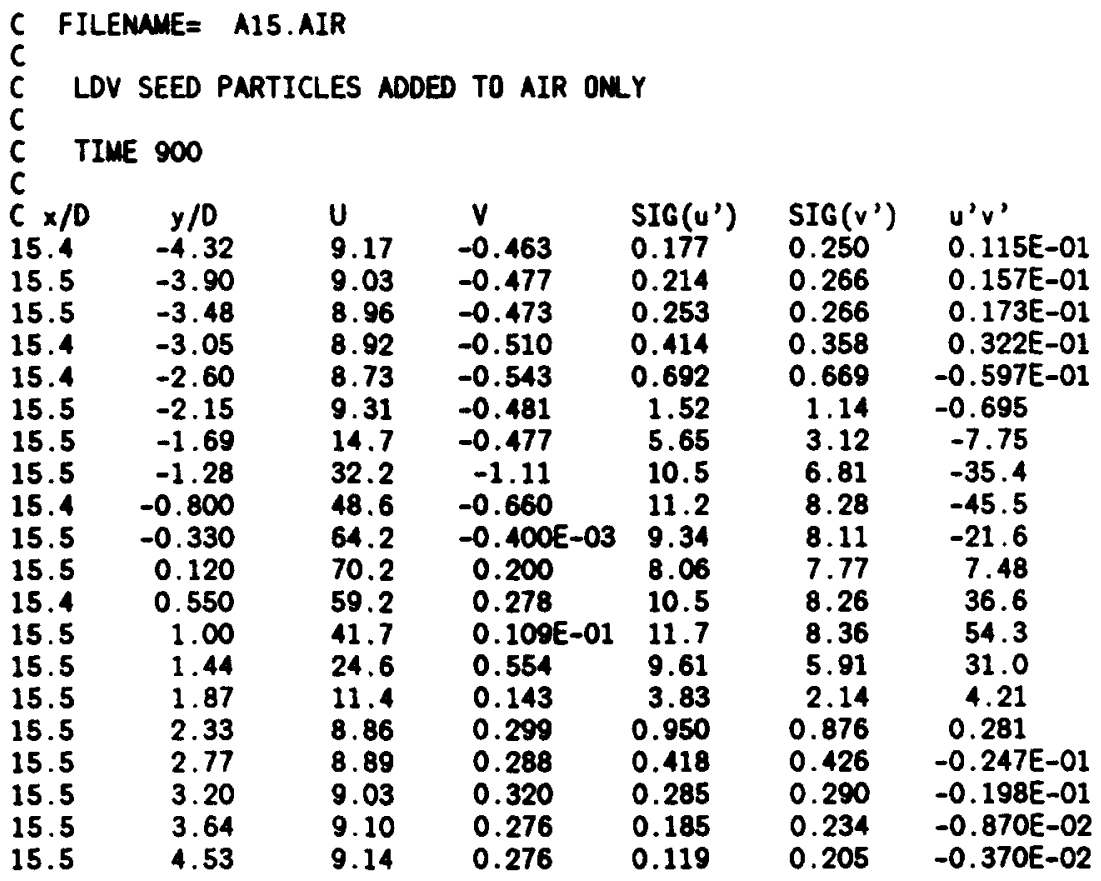



$\begin{array}{ll}C & \text { FILENAME }=\text { A30.AIR } \\ C & \text { LDV SEED PARTICLES ADDED TO AIR. } \\ \text { C } & \text { T920 }\end{array}$

$\mathrm{c}$

\begin{tabular}{lllllll}
$C \times / D$ & $y / D$ & $U$ & $v$ & $S I G\left(u^{\prime}\right)$ & \multicolumn{1}{l}{ SIG( $\left.v^{\prime}\right)$} & $U^{\prime} v^{\prime}$ \\
30.5 & -6.02 & 9.23 & -0.504 & 0.172 & 0.263 & $0.260 E-02$ \\
30.5 & -5.54 & 9.22 & -0.529 & 0.209 & 0.275 & $0.980 E-02$ \\
30.5 & -5.09 & 9.20 & -0.546 & 0.275 & 0.348 & $0.169 E-01$ \\
30.5 & -4.64 & 9.22 & -0.550 & 0.330 & 0.412 & $-0.200 E-02$ \\
30.5 & -4.21 & 9.24 & -0.549 & 0.683 & 0.726 & -0.116 \\
30.5 & -3.77 & 9.59 & -0.541 & 1.27 & 1.24 & -0.612 \\
30.5 & -3.33 & 10.6 & -0.473 & 2.15 & 1.80 & -2.04 \\
30.5 & -2.89 & 13.3 & -0.897 & 4.34 & 3.06 & -7.12 \\
30.5 & -2.39 & 17.5 & -0.900 & 5.70 & 3.80 & -11.1 \\
30.5 & -1.99 & 23.2 & -1.32 & 6.96 & 5.18 & -17.2 \\
30.5 & -1.51 & 31.0 & -1.36 & 8.90 & 5.95 & -24.2 \\
30.5 & -1.05 & 39.0 & -1.27 & 8.76 & 6.39 & -24.4 \\
30.5 & -0.610 & 45.1 & -0.929 & 7.31 & 6.22 & -12.0 \\
30.5 & -0.160 & 47.7 & -0.532 & 6.57 & 6.21 & -5.15 \\
30.5 & 0.240 & 46.9 & $-0.884 E-01$ & 6.75 & 6.60 & 7.61 \\
30.5 & 0.360 & 46.4 & -0.197 & 6.78 & 6.41 & 10.5 \\
30.5 & 0.800 & 42.9 & 0.705 & 7.52 & 6.47 & 18.3 \\
30.5 & 1.27 & 35.7 & 0.720 & 8.91 & 6.22 & 26.6 \\
30.5 & 1.72 & 26.6 & 0.340 & 8.89 & 5.41 & 23.1 \\
30.5 & 2.15 & 21.1 & 1.10 & 7.18 & 4.82 & 17.0 \\
30.5 & 2.55 & 14.7 & 0.223 & 4.96 & 3.31 & 8.38 \\
30.5 & 3.04 & 11.5 & 0.184 & 2.78 & 2.05 & 2.82 \\
30.5 & 3.50 & 10.0 & 0.268 & 1.75 & 1.37 & 0.804 \\
30.5 & 3.93 & 9.33 & 0.384 & 0.721 & 0.909 & 0.174 \\
30.5 & 4.34 & 9.21 & 0.363 & 0.366 & 0.483 & $0.103 E-01$ \\
30.5 & 4.75 & 9.25 & 0.362 & 0.255 & 0.333 & $0.100 E-03$
\end{tabular}

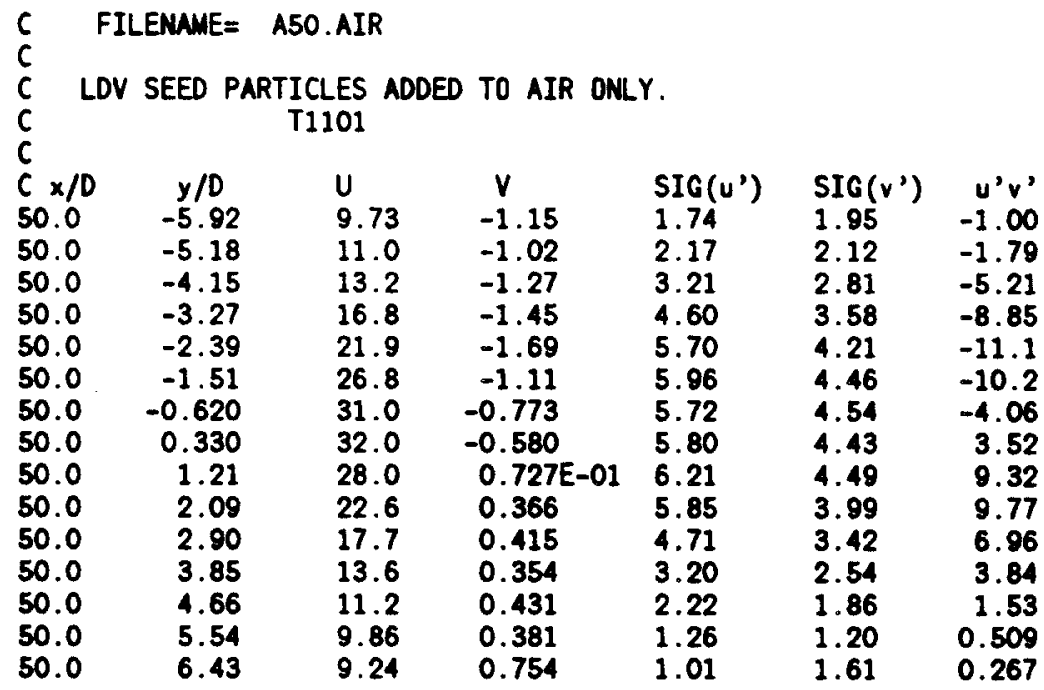




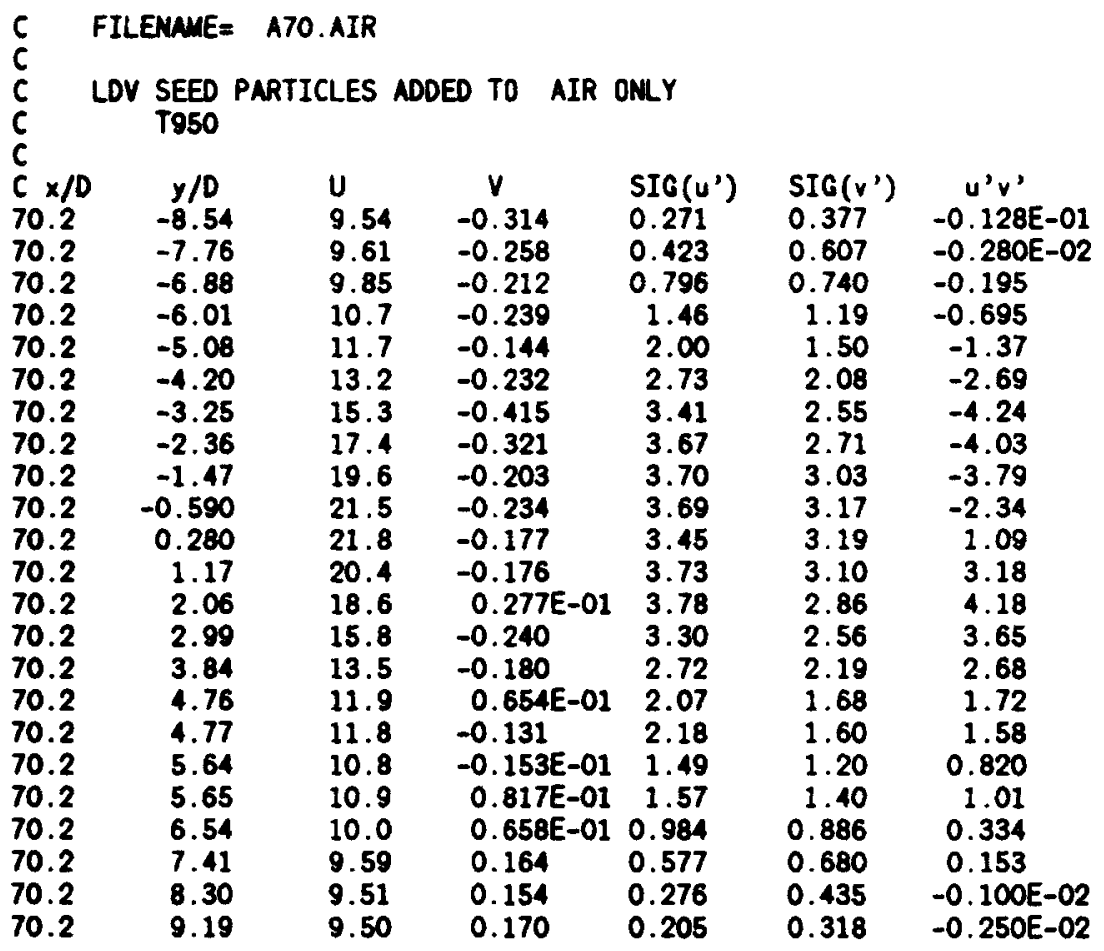

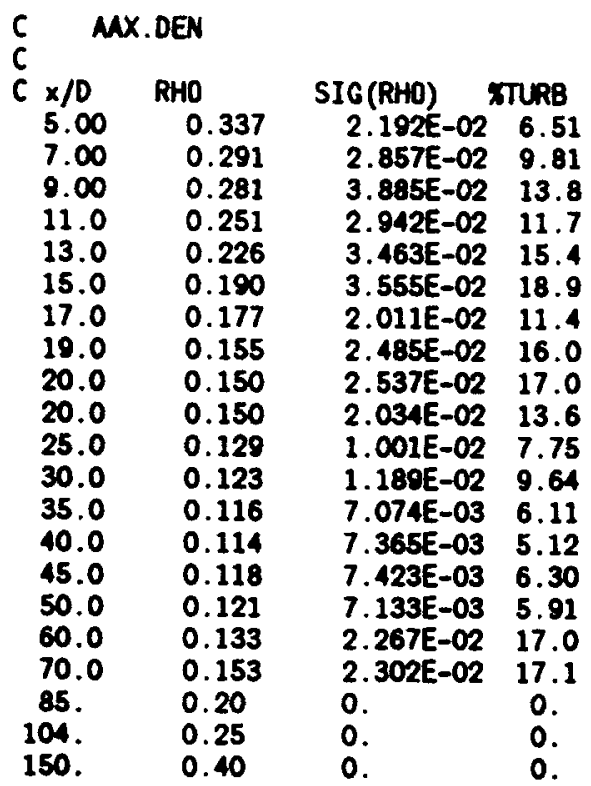


C FILENAME: A15.DEN

C DENSITY IS NORMALIZED BY DENSITY OF IMLET AIR

$c$

$\begin{array}{llllllll}C \times / D & y / D & \text { RHO } & \text { SIC(RHO) } & \text { XTURB } & \text { SKEW } & \text { FLAT } & \text { INT } \\ 15.6 & -3.40 & 1.00 & 2.033 E-02 & 2.02 & -0.603 & 7.23 & 5.680 E-03 \\ 15.6 & -3.14 & 1.00 & 4.336 E-02 & 4.32 & -9.89 & 145 . & 1.910 E-02 \\ 15.6 & -2.84 & 0.967 & 0.126 & 13.1 & -4.03 & 20.8 & 0.139 \\ 15.6 & -2.57 & 0.813 & 0.261 & 32.0 & -1.31 & 3.39 & 0.481 \\ 15.6 & -2.27 & 0.512 & 0.305 & 59.5 & 0.234 & 1.56 & 0.891 \\ 15.6 & -1.95 & 0.242 & 0.194 & 80.1 & 1.88 & 5.94 & 0.997 \\ 15.6 & -1.65 & 0.123 & 6.074 E-02 & 49.3 & 5.62 & 46.6 & 1.00 \\ 15.5 & -1.32 & 0.110 & 1.844 E-02 & 16.8 & 6.58 & 145 . & 1.00 \\ 15.6 & -1.06 & 0.120 & 2.385 E-02 & 19.9 & 8.89 & 264 . & 1.00 \\ 15.5 & -0.714 & 0.143 & 2.713 E-02 & 19.0 & 2.78 & 55.4 & 1.00 \\ 15.5 & -0.407 & 0.170 & 3.303 E-02 & 19.4 & 4.96 & 91.9 & 1.00 \\ 15.5 & -7.670 E-02 & 0.188 & 3.221 E-02 & 17.2 & 4.41 & 81.0 & 1.00 \\ 15.5 & 0.244 & 0.181 & 3.434 E-02 & 18.9 & 6.86 & 149 . & 1.00 \\ 15.5 & 0.556 & 0.157 & 3.098 E-02 & 19.7 & 4.73 & 98.3 & 1.00 \\ 15.5 & 0.858 & 0.131 & 2.451 E-02 & 18.6 & 1.79 & 20.7 & 1.00 \\ 15.5 & 1.17 & 0.115 & 1.910 E-02 & 16.7 & 3.25 & 63.4 & 1.00 \\ 15.5 & 1.49 & 0.110 & 2.959 E-02 & 26.9 & 9.59 & 190 . & 1.00 \\ 15.5 & 1.82 & 0.159 & 0.111 & 70.3 & 3.30 & 15.8 & 1.00 \\ 15.5 & 2.17 & 0.374 & 0.268 & 71.8 & 0.891 & 2.47 & 0.973 \\ 15.4 & 2.44 & 0.722 & 0.298 & 41.4 & -0.714 & 2.02 & 0.628 \\ 15.5 & 2.80 & 0.943 & 0.166 & 17.5 & -3.06 & 12.2 & 0.190 \\ 15.4 & 3.44 & 1.00 & 2.352 E-02 & 2.31 & -6.60 & 173 . & 2.570 E-03 \\ 15.4 & 4.00 & 1.00 & 1.639 E-02 & 2.30 & -6.60 & 17.3 & 0.000 E+\infty 0\end{array}$

C FILENAME: A30.DEN

$c$ C $x / D \quad$ y/D RHO 30

30.6

30.6

30.6

$30.5-\begin{aligned} & -2.31 \\ & -1.69\end{aligned}$

$30.5 \quad-1.07$

$30.5-0.450$

$30.5 \quad 0.192$

$30.5 \quad 0.824$

2.10

2.76

3.38

4.04

4.66

6.00
RHO

0.852

0.503

0.289

0.156

0.130

0.131

0.139

0.141

0.141

0.157

0.230

0.457

0.756

1.00

1.00
SIG(RHO) TTURB

0.139

0.279

0.312

0.209

7.975E-02

2. 467E-02

$1.852 \mathrm{E}-02$

$1.254 \mathrm{E}-02 \quad 9.01$

$1.459 E-02 \quad 10.3$

$1.762 E-02 \quad 12.5$

4.951E-02

0.149

0.302

31.5

65.2

66.1

0.337

44.5

0.198

19.7

2.295E-02 0.230
SKEW

$-4.48$

$-1.43$

0.415

1.64

3.87

9.23

20.3

1.93

13.8

21.3

5.25

2.61

0.757

$-0.597$

$-3.01$

$-6.60$
FLAT

23.2

3.47

1.64

4.97

22.7

210.

817.

36.8

677.

$1.040 \mathrm{E}+03$

42.4

10.4

2.11

1.67

11.0

17.3
INT

6.770E-02

0.326

0.840

0.987

1.00

1.00

1.00

1.00

1.00

1.00

1.00

0.996

0.867

0.495

0.119

$0.000 E+00$ 
C FILENME: A5O.DEN

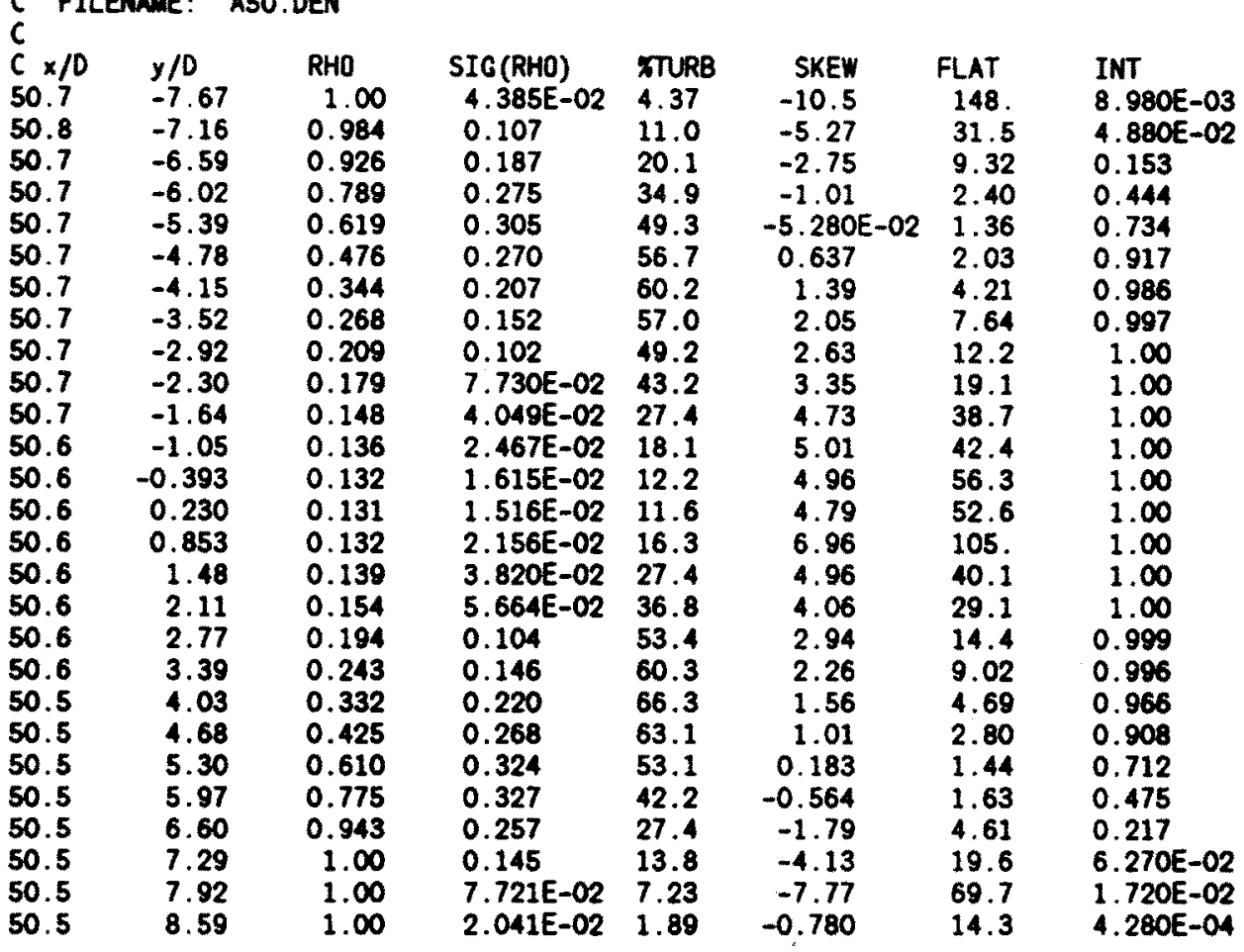

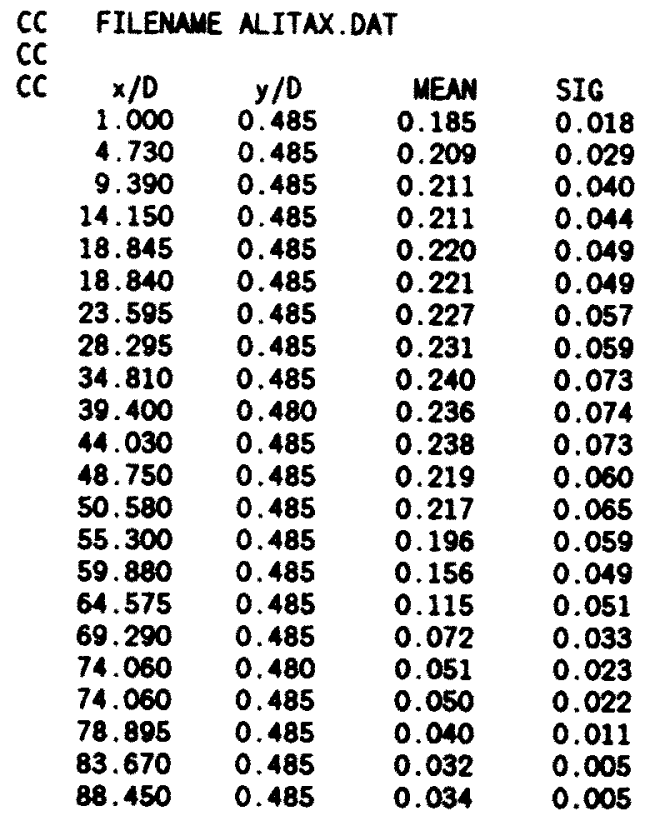

C FILENMME ALIT15.DAT

\begin{tabular}{llll}
$C$ & \multicolumn{3}{l}{$l$} \\
$C \times / D$ & $y / 0$ & \multicolumn{1}{l}{ MEN } & \multicolumn{1}{l}{ SIG } \\
15.3 & 3.30 & $0.416 E-01$ & $0.558 E-02$ \\
15.3 & 2.42 & $0.437 E-01$ & $0.617 E-02$ \\
15.3 & 1.95 & $0.795 E-01$ & $0.422 E-01$ \\
15.3 & 1.49 & 0.300 & $0.904 E-01$ \\
15.3 & 1.03 & 0.304 & $0.980 E-01$ \\
15.3 & 0.560 & 0.233 & $0.550 E-01$ \\
15.3 & 0.100 & 0.225 & $0.496 E-01$ \\
15.3 & -0.395 & 0.224 & $0.476 E-01$ \\
15.3 & -0.800 & 0.248 & $0.656 E-01$ \\
15.3 & -1.27 & 0.343 & 0.103 \\
15.3 & -1.73 & 0.159 & $0.714 E-01$ \\
15.3 & -2.18 & $0.528 E-01$ & $0.209 E-01$ \\
15.3 & -2.63 & $0.434 E-01$ & $0.597 E-02$
\end{tabular}




\section{FILENAME ALIT3O.DAT}

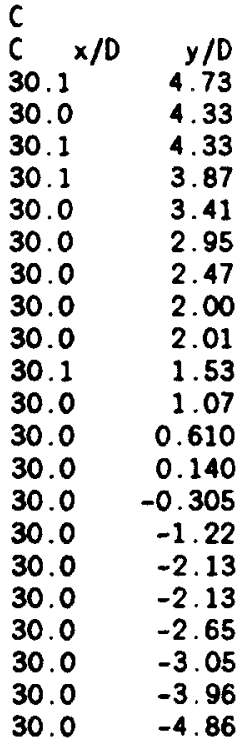

C FILENAME ALITSO.DAT

$c$

$C x / d y / d$ MEN SIC

$50.0 \quad 5.79 \quad 0.370 E-01 \quad 0.500 E-02$

$50.0 \quad 4.93 \quad 0.380 E-010.800 E-02$

$50.0 \quad 4.93 \quad 0.380 E-010.700 E-02$

$50.0 \quad 4.00 \quad 0.510 E-01 \quad 0.240 E-01$

$50.0 \quad 4.00 \quad 0.440 E-010.150 E-01$

$50.0 \quad 3.08 \quad 0.760 E-01 \quad 0.430 E-01$

$\begin{array}{llll}50.0 & 2.13 & 0.147 & 0.610 E-01\end{array}$

$\begin{array}{llll}50.0 & 1.21 & 0.209 & 0.620 E-01\end{array}$

$\begin{array}{llll}50.0 & 0.280 & 0.211 & 0.630 E-01\end{array}$

$\begin{array}{llll}50.0 & -0.240 & 0.214 & 0.600 E-01\end{array}$

$\begin{array}{llll}50.0 & -1.09 & 0.210 & 0.640 E-01\end{array}$

$\begin{array}{llll}50.0 & -2.01 & 0.167 & 0.640 E-01\end{array}$

$\begin{array}{llll}50.0 & -2.98 & 0.101 & 0.560 E-01\end{array}$

$50.0 \quad-2.99 \quad 0.980 E-01 \quad 0.540 E-01$

$50.0 \quad-3.84 \quad 0.520 E-01 \quad 0.270 E-01$

$50.0 \quad-4.74 \quad 0.380 E-01 \quad 0.700 E-02$

$50.0 \quad-5.64 \quad 0.360 E-01 \quad 0.500 E-02$

C FILENAME ALITTO.DAT

c

$x / D \quad y / D$ MEAN SIC

$70.2 \quad 6.24 \quad 0.310 E-010.400 E-02$

$\begin{array}{llll}70.2 & 5.39 & 0.320 E-01 & 0.400 E-02\end{array}$

$70.2 \quad 4.46 \quad 0.330 E-010.600 E-02$

$\begin{array}{llll}70.2 & 3.55 & 0.360 E-01 & 0.800 E-02\end{array}$

$70.2 \quad 2.61 \quad 0.420 E-01 \quad 0.160 E-01$

$\begin{array}{llll}70.2 & 1.68 & 0.550 E-01 & 0.260 E-01\end{array}$

$70.2 \quad 0.740 \quad 0.590 E-01 \quad 0.270 E-01$

$\begin{array}{lllll}70.2 & -0.260 & 0.770 E-01 & 0.340 E-01\end{array}$

$70.2 \quad-1.18 \quad 0.610 E-01 \quad 0.320 E-01$

$70.2 \quad-2.10 \quad 0.500 E-01 \quad 0.220 E-01$

$70.2 \quad-3.00 \quad 0.390 E-01 \quad 0.120 E-01$

$70.2 \quad-3.92 \quad 0.350 E-01 \quad 0.800 E-02$

$70.2 \quad-4.83 \quad 0.320 E-01 \quad 0.400 E-02$

$70.2 \quad-5.73 \quad 0.310 E-01 \quad 0.400 E-02$

$70.2 \quad-0.245 \quad 0.800 E-01 \quad 0.380 E-01$

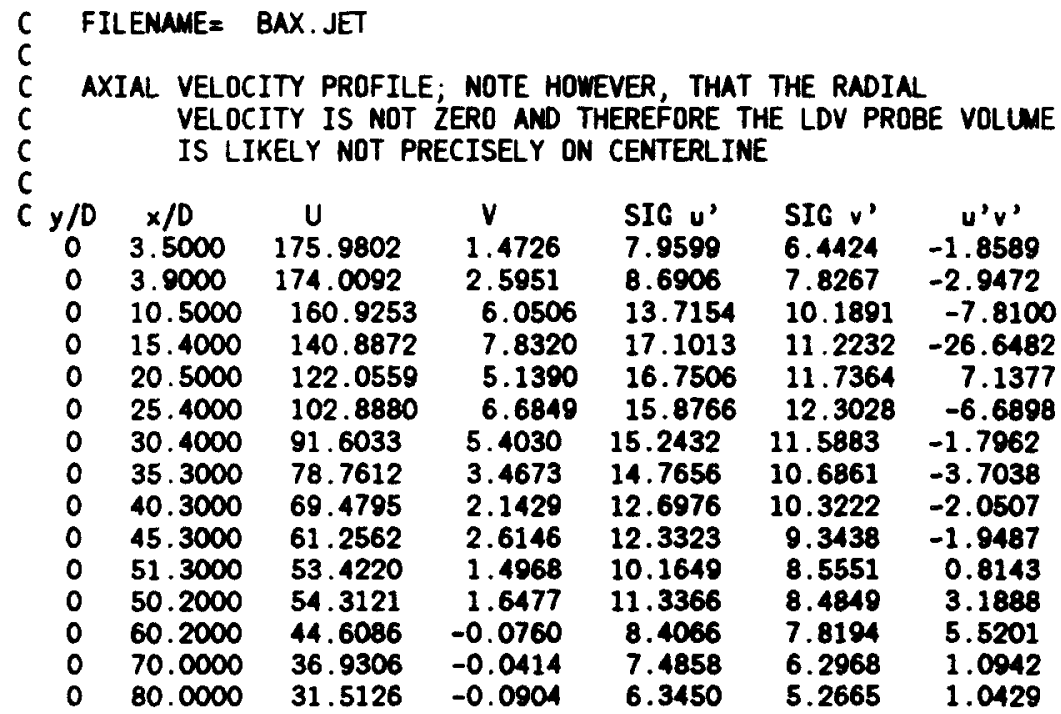




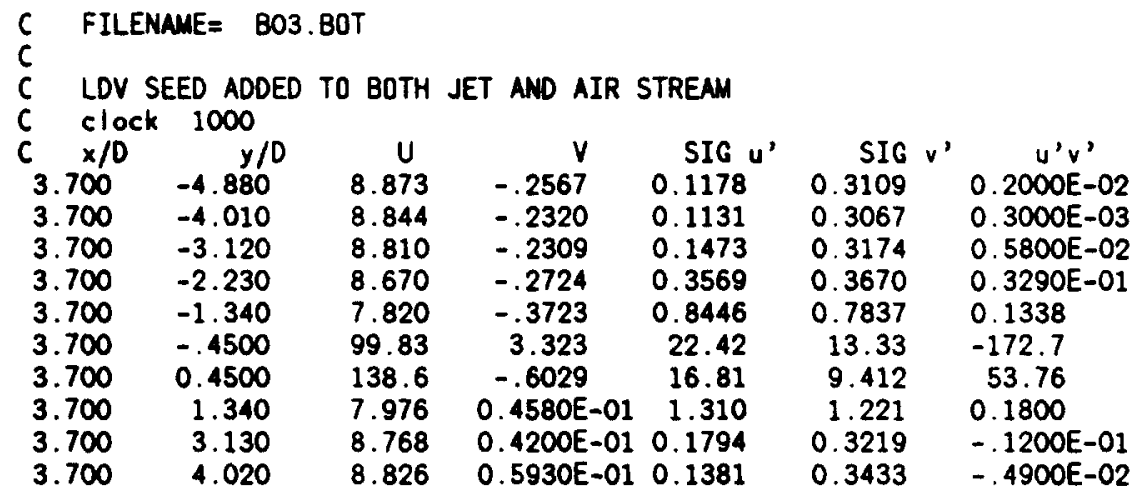

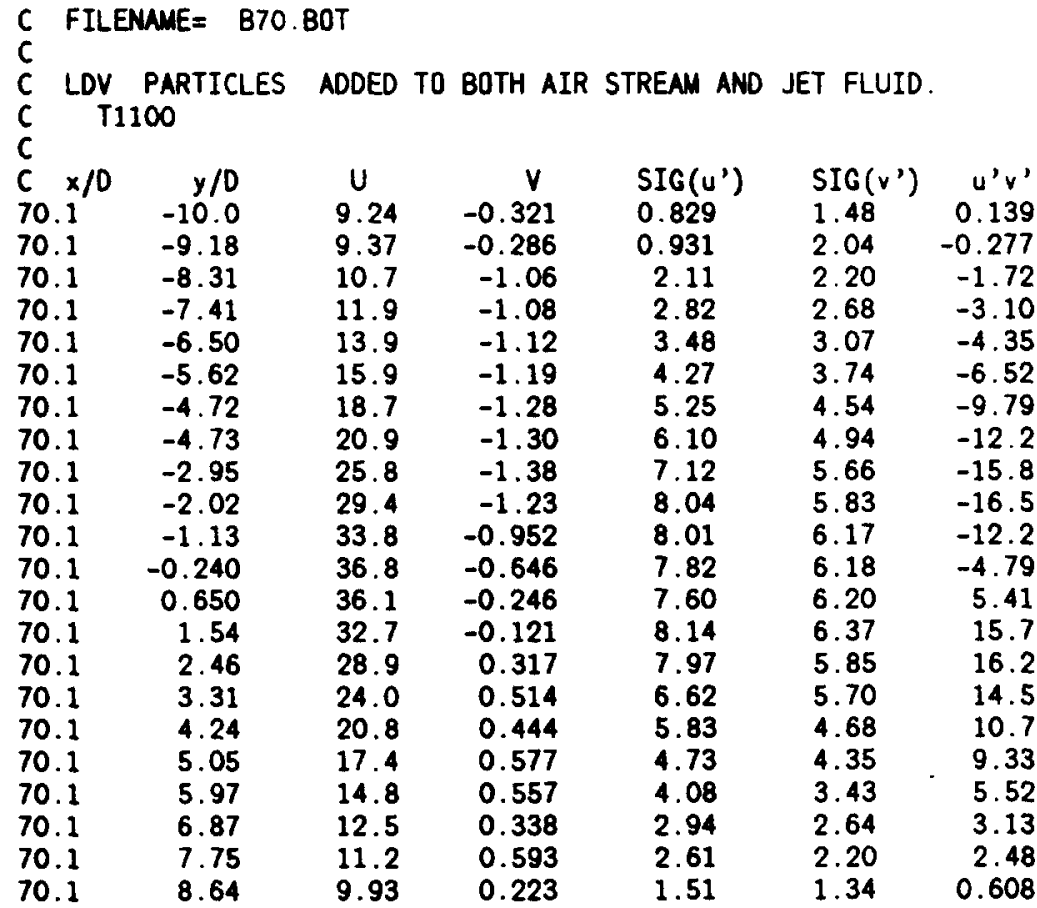

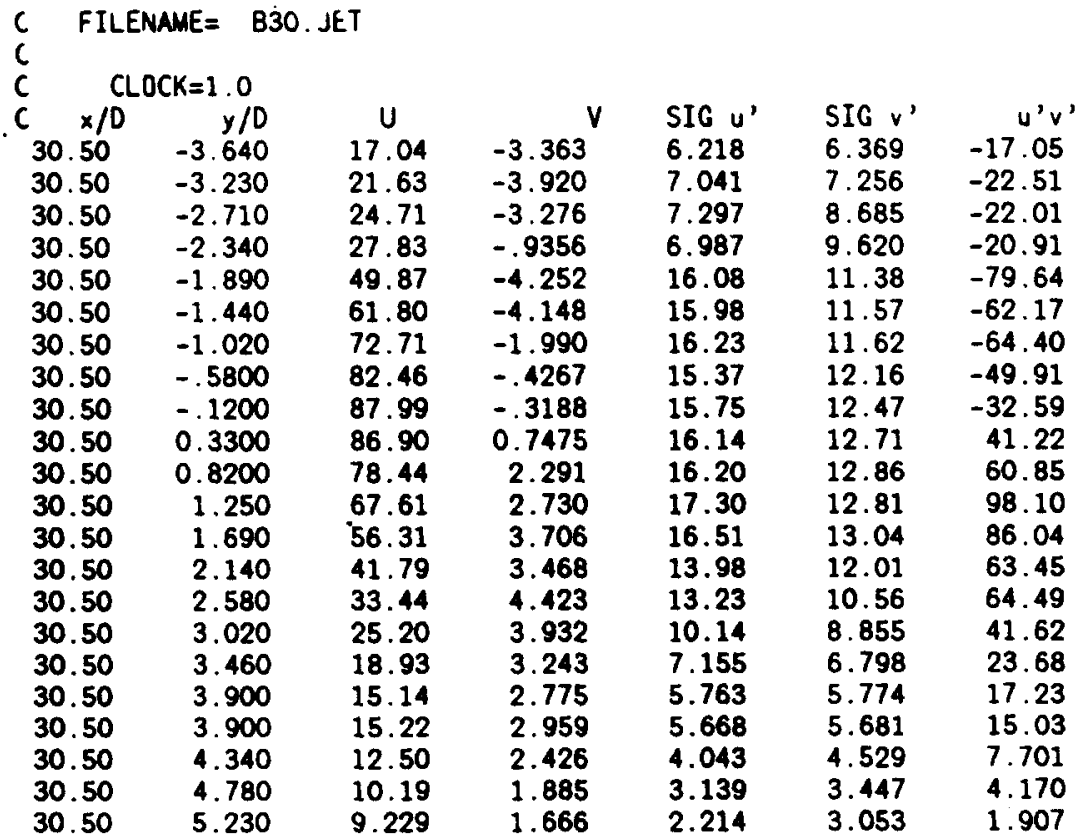


C FILENAME $=850$. JET

C CLOCK $=1100$

$\begin{array}{lrccccc}C \times / D & y / D & U & V & \text { SIG } & \text { SIG } & v^{\prime} \\ 50.30 & -4.820 & 18.27 & -2.973 & 5.653 & 5.892 & -14.85 \\ 50.30 & -3.940 & 22.68 & -2.983 & 6.748 & 6.975 & -20.61 \\ 50.30 & -3.050 & 26.96 & -2.213 & 6.686 & 7.469 & -15.93 \\ 50.30 & -2.170 & 40.59 & -3.362 & 10.77 & 8.519 & -34.09 \\ 50.30 & -1.260 & 48.98 & -2.825 & 10.70 & 9.038 & -26.52 \\ 50.30 & -.3300 & 55.25 & -1.788 & 11.11 & 9.370 & -11.85 \\ 50.30 & 0.5500 & 55.16 & 0.7289 & 11.63 & 9.289 & 7.976 \\ 50.30 & 1.430 & 47.77 & 1.356 & 10.88 & 8.846 & 27.09 \\ 50.30 & 2.310 & 38.68 & 2.010 & 11.79 & 8.392 & 36.88 \\ 50.30 & 3.230 & 29.98 & 2.922 & 9.823 & 8.003 & 34.09 \\ 50.30 & 4.070 & 22.64 & 2.386 & 7.117 & 6.546 & 17.65 \\ 50.30 & 4.960 & 17.48 & 2.174 & 5.460 & 5.223 & 11.89 \\ 50.30 & 5.840 & 13.97 & 1.821 & 4.228 & 4.065 & 7.918\end{array}$

$\begin{array}{lcccccc}C & \text { FILENAME }=B 70 . J E T \\ C & & & & & \\ C \quad C L O C K & 1150 & & & & & \\ C \times / D & y / 0 & U & V & S I G u^{\prime} & \text { SIG } v^{\prime} & u^{\prime} v^{\prime} \\ 70.10 & -7.380 & 12.76 & -1.478 & 3.189 & 3.244 & -4.334 \\ 70.10 & -6.530 & 15.31 & -2.049 & 3.994 & 3.975 & -5.768 \\ 70.10 & -5.680 & 17.31 & -2.289 & 4.628 & 4.623 & -8.957 \\ 70.10 & -4.790 & 19.59 & -2.320 & 5.099 & 5.135 & -10.97 \\ 70.10 & -3.880 & 23.73 & -2.350 & 6.444 & 5.736 & -14.55 \\ 70.10 & -3.020 & 26.86 & -2.108 & 7.426 & 5.958 & -16.25 \\ 70.10 & -2.080 & 31.93 & -2.247 & 7.930 & 6.410 & -17.21 \\ 70.10 & -1.190 & 35.97 & -1.530 & 8.339 & 6.748 & -11.35 \\ 70.10 & -.2900 & 37.83 & -1.332 & 7.529 & 6.219 & -4.396 \\ 70.10 & 0.6000 & 37.68 & 0.1935 & 7.848 & 6.367 & 3.357 \\ 70.10 & 1.490 & 34.44 & 0.2664 & 8.238 & 6.184 & 12.46 \\ 70.10 & 2.380 & 29.28 & 0.6348 & 8.129 & 6.027 & 19.54 \\ 70.10 & 3.280 & 25.49 & 1.102 & 7.023 & 5.781 & 17.06 \\ 70.10 & 4.170 & 21.83 & 1.260 & 5.960 & 5.256 & 12.83 \\ 70.10 & 4.990 & 18.83 & 1.173 & 5.384 & 4.686 & 10.45 \\ 70.10 & 5.920 & 15.99 & 1.364 & 4.464 & 3.931 & 7.821 \\ 70.10 & 6.820 & 13.59 & 1.280 & 3.692 & 3.586 & 4.550 \\ 70.10 & 7.680 & 11.77 & 1.096 & 2.638 & 2.628 & 2.316 \\ 70.10 & 8.580 & 10.74 & 1.109 & 2.266 & 2.342 & 1.522 \\ 70.10 & 9.470 & 9.698 & 0.9465 & 1.657 & 2.332 & 0.7441\end{array}$




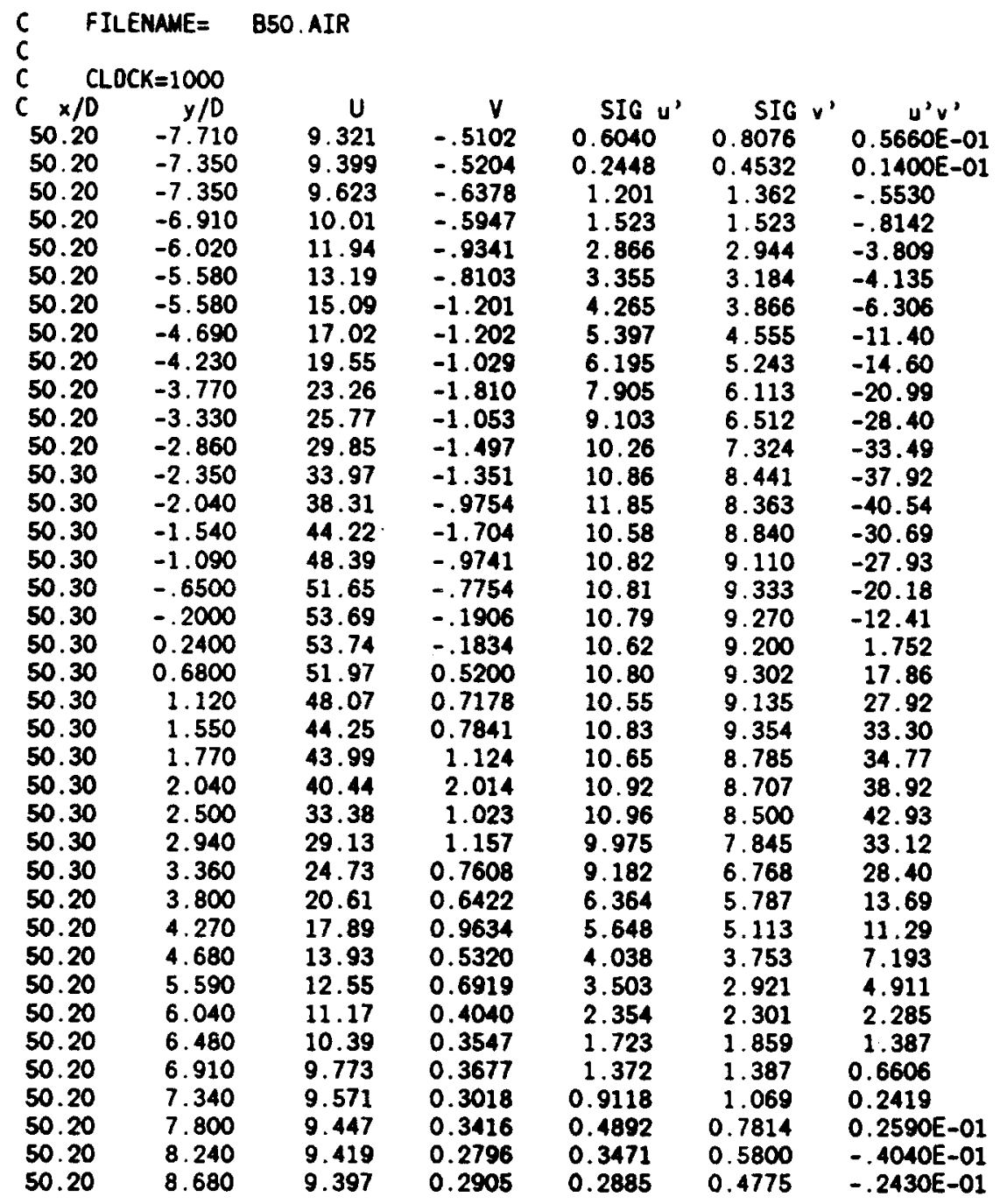


C FILENAME B30.AIR

C RADIAL VELOCITY PROFILES AT $\times / 0=30$,

LDV PARTICLES ADDED TO AIR ONLY

clock $=1.0$

$\begin{array}{ccccccc}C / D & y / D & U & V & \text { SIG } u^{\prime} & \text { SIG } v^{\prime} & U^{\prime} v^{\prime} \\ 30.50 & -5.880 & 9.172 & -.4865 & 0.2592 & 0.4372 & 0.540 O E-02 \\ 30.50 & -5.810 & 9.344 & -.6129 & 0.7818 & 1.188 & -.9300 E-01 \\ 30.50 & -5.450 & 9.189 & -.5150 & 0.4102 & 0.5934 & 0.2170 E-01 \\ 30.50 & -5.070 & 9.285 & -.6207 & 0.7305 & 1.194 & -.2373 \\ 30.50 & -4.630 & 9.724 & -.5211 & 1.424 & 1.512 & -.7383 \\ 30.50 & -4.170 & 11.16 & -.8154 & 2.953 & 2.658 & -3.528 \\ 30.50 & -3.730 & 13.83 & -.8689 & 4.468 & 3.809 & -7.948 \\ 30.50 & -3.230 & 18.19 & -1.667 & 6.842 & 5.870 & -19.69 \\ 30.50 & -2.790 & 23.02 & -1.785 & 9.048 & 7.413 & -32.39 \\ 30.50 & -2.340 & 31.21 & -1.809 & 11.95 & 9.205 & -50.43 \\ 30.50 & -1.900 & 41.40 & -1.998 & 15.27 & 10.74 & -76.39 \\ 30.50 & -1.460 & 56.95 & -1.795 & 17.12 & 11.90 & -82.43 \\ 30.50 & -1.020 & 66.25 & -.7552 & 16.21 & 12.70 & -78.29 \\ 30.50 & -.5700 & 78.30 & 1.024 & 16.44 & 12.93 & -61.26 \\ 30.50 & -.1100 & 85.64 & 0.4951 & 15.57 & 12.86 & -33.60 \\ 30.50 & 0.3100 & 84.04 & 0.8008 & 16.20 & 12.66 & 29.22 \\ 30.50 & 0.8200 & 75.41 & 0.7754 & 16.07 & 13.79 & 75.13 \\ 30.50 & 1.190 & 63.74 & 0.8758 & 17.00 & 13.30 & 97.99 \\ 30.50 & 1.650 & 50.39 & 1.375 & 17.38 & 12.43 & 107.3 \\ 30.50 & 2.130 & 37.38 & 1.320 & 14.56 & 10.76 & 70.44 \\ 30.50 & 2.580 & 27.38 & 1.189 & 11.54 & 8.525 & 47.50 \\ 30.50 & 3.020 & 20.57 & 1.243 & 8.761 & 7.274 & 33.09 \\ 30.50 & 3.460 & 15.41 & 0.9374 & 5.485 & 4.853 & 13.07 \\ 30.50 & 3.860 & 12.14 & 0.7515 & 3.766 & 3.423 & 5.943 \\ 30.50 & 4.340 & 10.34 & 0.4147 & 2.124 & 1.996 & 1.441 \\ 30.50 & 4.780 & 9.512 & 0.4680 & 1.017 & 1.298 & 0.4293 \\ 30.50 & 5.220 & 9.246 & 0.3782 & 0.5322 & 0.7121 & -.7700 E-02 \\ 30.50 & 6.110 & 9.214 & 0.4123 & 0.2351 & 0.4177 & -.5600 E-02\end{array}$

\footnotetext{
C FILENAME $=$ B70.AIR C
C LDV PARTICLES ADDED AIR ONLY
TI100
}

c

$\begin{array}{lrrrrrr}C \times / D & y / D & u & v & \text { SIG(u') } & \text { SIG(v') } & u^{\prime} v^{\prime} \\ 70.1 & -10.9 & 9.21 & -0.300 & 0.386 & 1.08 & -0.650 E-02 \\ 70.1 & -10.1 & 9.17 & -0.382 & 0.807 & 1.16 & 0.421 E-01 \\ 70.1 & -9.19 & 9.69 & -0.633 & 1.48 & 1.83 & -1.17 \\ 70.1 & -7.53 & 12.0 & -0.909 & 3.06 & 2.87 & -3.45 \\ 70.1 & -6.60 & 13.6 & -0.997 & 3.44 & 3.22 & -4.41 \\ 70.1 & -5.71 & 16.1 & -1.11 & 4.32 & 3.77 & -6.95 \\ 70.1 & -4.82 & 19.0 & -1.45 & 4.99 & 4.49 & -8.07 \\ 70.1 & -3.95 & 21.7 & -1.17 & 6.11 & 5.10 & -13.6 \\ 70.1 & -3.01 & 25.7 & -1.14 & 7.12 & 5.84 & -18.3 \\ 70.1 & -2.14 & 31.0 & -1.49 & 7.96 & 6.28 & -17.9 \\ 70.1 & -1.22 & 33.9 & -0.376 & 8.01 & 6.12 & -14.8 \\ 70.1 & -0.330 & 36.3 & -0.425 & 7.77 & 6.30 & -6.43 \\ 70.1 & 0.550 & 37.0 & -0.150 & 7.76 & 6.40 & 1.58 \\ 70.1 & 1.42 & 33.5 & 0.169 & 7.97 & 6.46 & 15.0 \\ 70.1 & 2.32 & 29.1 & 0.191 & 7.82 & 6.40 & 19.2 \\ 70.1 & 3.19 & 24.3 & 0.235 & 7.00 & 5.70 & 15.6 \\ 70.1 & 4.13 & 20.6 & 0.418 & 5.79 & 5.01 & 13.0 \\ 70.1 & 5.84 & 14.7 & 0.563 & 3.95 & 3.42 & 5.89 \\ 70.1 & 5.03 & 17.1 & 0.636 & 5.01 & 4.27 & 9.41 \\ 70.1 & 6.79 & 12.7 & 0.531 & 3.13 & 2.84 & 3.99 \\ 70.1 & 7.67 & 11.0 & 0.412 & 2.34 & 2.13 & 1.87 \\ 70.1 & 8.55 & 9.84 & 0.189 & 1.34 & 1.42 & 0.624 \\ 70.1 & 9.43 & 9.37 & 0.294 & 0.910 & 1.12 & 0.130 \\ 70.1 & 10.3 & 9.21 & 0.283 & 0.483 & 1.02 & -0.340 E-02 \\ 70.1 & 11.3 & 9.27 & 0.241 & 0.268 & 0.560 & -0.100 E-03\end{array}$




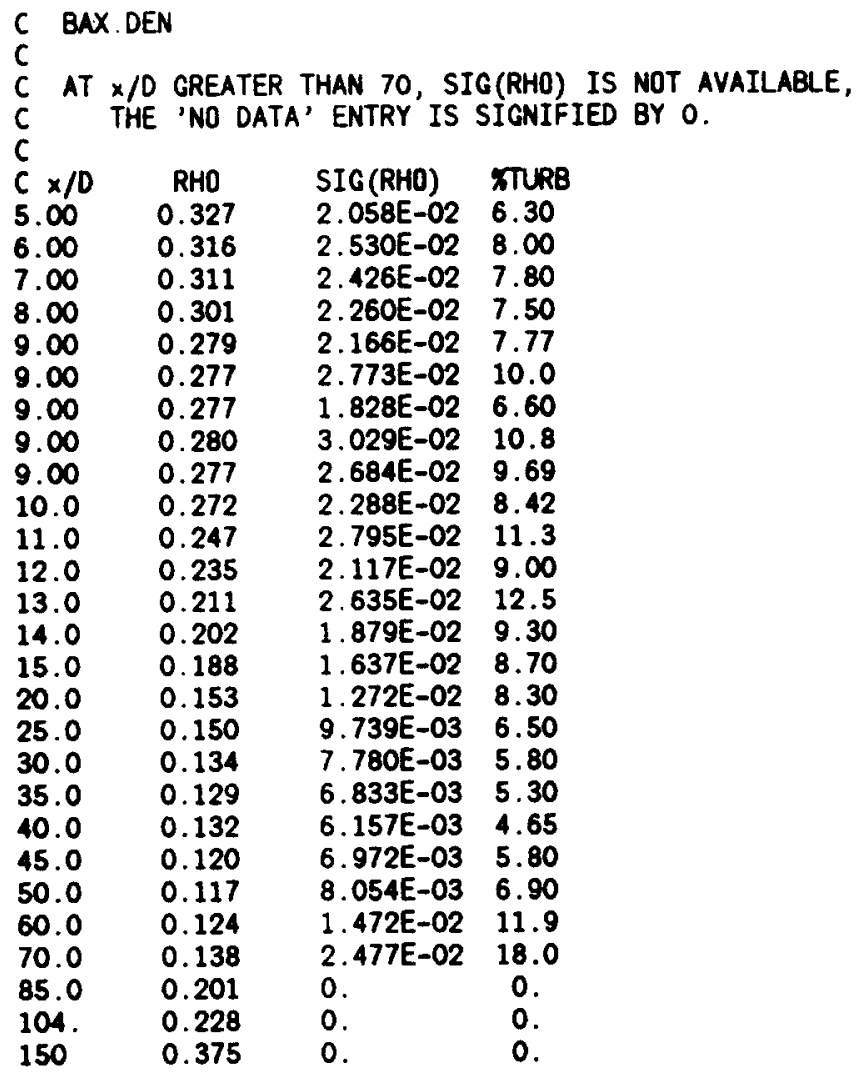

\begin{tabular}{|c|c|c|c|c|c|c|c|}
\hline FILENAME= & NAME $=$ & .DEN & & & & & \\
\hline $\begin{array}{l}C \times / D \\
15.5 \\
15.5 \\
15.5 \\
15.5 \\
15.5 \\
15.5 \\
15.5 \\
15.5 \\
15.5 \\
15.4 \\
15.5 \\
15.5 \\
15.4\end{array}$ & $\begin{array}{l}y / D \\
-3.66 \\
-3.12 \\
-2.83 \\
-2.56 \\
-2.25 \\
-1.93 \\
-1.63 \\
-1.30 \\
-1.03 \\
-0.676 \\
-0.383 \\
-6.710 E-02 \\
0.244 \\
0.580\end{array}$ & $\begin{array}{l}\text { RHO } \\
1.00 \\
0.918 \\
0.779 \\
0.530 \\
0.322 \\
0.189 \\
0.127 \\
0.112 \\
0.120 \\
0.143 \\
0.173 \\
0.199 \\
0.191 \\
0.161\end{array}$ & $\begin{array}{l}\text { SIG(RHO) } \\
3.016 E-02 \\
0.190 \\
0.275 \\
0.296 \\
0.225 \\
0.128 \\
5.590 E-02 \\
2.213 E-02 \\
1.803 E-02 \\
2.148 E-02 \\
2.508 E-02 \\
2.836 E-02 \\
2.639 E-02 \\
2.672 E-02\end{array}$ & $\begin{array}{l}\text { XTURB } \\
3.00 \\
20.7 \\
35.3 \\
55.7 \\
69.7 \\
67.8 \\
44.0 \\
19.7 \\
15.1 \\
15.1 \\
14.5 \\
14.2 \\
13.8 \\
16.6\end{array}$ & $\begin{array}{r}\text { SKEW } \\
-10.8 \\
-2.59 \\
-1.03 \\
0.194 \\
1.22 \\
2.40 \\
4.51 \\
11.0 \\
7.85 \\
4.77 \\
2.24 \\
7.85 \\
4.09 \\
6.88\end{array}$ & $\begin{array}{l}\text { FLAT } \\
214 . \\
8.71 \\
2.56 \\
1.56 \\
3.57 \\
9.72 \\
33.3 \\
260 . \\
217 . \\
183 . \\
41.0 \\
199 . \\
75.5 \\
178 .\end{array}$ & $\begin{array}{l}\text { INT } \\
6.230 \text { E-03 } \\
0.206 \\
0.510 \\
0.896 \\
0.994 \\
1.00 \\
1.00 \\
1.00 \\
1.00 \\
1.00 \\
1.00 \\
1.00 \\
1.00 \\
1.00\end{array}$ \\
\hline
\end{tabular}

\section{FILENAME $=$ 830.DEN}

$c$

$\mathrm{C} x / \mathrm{D} \quad \mathrm{y} / \mathrm{D} \quad \mathrm{RHO}$

$30.6 \quad-6.26$

$30.6 \quad-5.33 \quad 0.934$

$30.6 \quad-4.49$

$30.6 \quad-3.89$

$30.5 \quad-3.25$

$30.5 \quad-2.64$

$30.5 \quad-2.00$

$30.5 \quad-0.115$

$30.4 \quad 3.07$

30.3

0.630

0.399

0.250

0.163

0.129

0.131

0.225

0.684

SIG(RHO)
$4.139 E-02$
0.178
0.298
0.244
0.157
$8.066 \mathrm{E}-02$
$3.516 \mathrm{E}-02$
$1.352 \mathrm{E}-02$
0.130
0.300

XTURB
4.13
19.1
47.2
61.2
63.0
49.4
27.3
10.3
58.0
43.9

SKEW

$-12.8$

$-2.74$

$-0.108$

0.968

1.92

3.09

5.17

21.7

2.29

$-0.311$
FLAT

218.

9.47

1.47

2.85

7.02

16.3

49.9

1.00

$9.40 \quad 0.999$ 


\begin{tabular}{lcc}
$C$ & \multicolumn{1}{l}{ FILENAME $=$} & \multicolumn{1}{l}{$B 50 . D E N$} \\
$C$ & & \\
$C \times / D$ & $y / D$ & RHO \\
50.7 & -10.5 & 1.00 \\
50.7 & -8.45 & 0.959 \\
50.7 & -7.84 & 0.893 \\
50.7 & -7.24 & 0.775 \\
50.6 & -6.62 & 0.643 \\
50.7 & -6.01 & 0.523 \\
50.7 & -5.41 & 0.401 \\
50.6 & -4.80 & 0.313 \\
50.6 & -4.16 & 0.253 \\
50.6 & -3.56 & 0.209 \\
50.6 & -2.92 & 0.173 \\
50.6 & -2.30 & 0.148 \\
50.6 & -1.69 & 0.134 \\
50.6 & -1.06 & 0.125 \\
50.6 & -0.417 & 0.119 \\
50.6 & 0.187 & 0.116 \\
50.6 & 0.829 & 0.118 \\
50.5 & 2.74 & 0.146 \\
50.5 & 5.30 & 0.361
\end{tabular}

$\begin{array}{ll}\text { SIG (RHO) } & \text { XTURB } \\ 2.008 E-02 & 2.00 \\ 0.113 & 11.8 \\ 0.188 & 21.0 \\ 0.249 & 32.2 \\ 0.274 & 42.5 \\ 0.252 & 48.2 \\ 0.212 & 52.9 \\ 0.165 & 52.6 \\ 0.126 & 49.9 \\ 9.262 E-02 & 44.2 \\ 6.689 E-02 & 38.7 \\ 4.533 E-02 & 30.6 \\ 3.098 E-02 & 23.2 \\ 2.139 E-02 & 17.0 \\ 1.434 E-02 & 12.0 \\ 1.246 E-02 & 10.7 \\ 1.574 E-02 & 13.3 \\ 5.074 E-02 & 34.8 \\ 0.199 & 55.0\end{array}$

SKEW
$4.180 E-03$
-4.28
-2.17
-0.877
-0.178
0.463
1.03
1.52
1.87
2.26
2.74
3.26
3.14
4.02
3.73
2.38
4.51
3.03
1.23

FLAT

2.97

21.7

6.40

2.24

1.50

1.90

3.20

5.31

7.53

10.3

15.3

21.7

18.4

32.7

40.9

15.4

45.7

17.6

3.93
INT

3. $480 E-03$

9.580E-02

0.282

0.589

0.848

0.943

0.993

0.999

1.00

1.00

1.00

1.00

1.00

1.00

1.00

1.00

1.00

1.00

0.994

\begin{tabular}{llll}
$C$ & FILENAME & \multicolumn{4}{l}{ CAX.DEN } \\
$C$ & \multicolumn{4}{l}{} \\
$C \times / D$ & RHO & SIG(RHD) & TTURB \\
5.00 & 0.318 & $1.590 E-02$ & 5.00 \\
6.00 & 0.310 & $1.822 E-02$ & 5.88 \\
7.00 & 0.307 & $1.852 E-02$ & 6.04 \\
8.00 & 0.298 & $1.572 E-02$ & 5.27 \\
9.00 & 0.280 & $1.671 E-02$ & 5.96 \\
10.0 & 0.270 & $1.853 E-02$ & 6.85 \\
11.0 & 0.248 & $1.748 E-02$ & 7.06 \\
12.0 & 0.226 & $1.762 E-02$ & 7.79 \\
14.0 & 0.198 & $1.746 E-02$ & 8.80 \\
15.0 & 0.187 & $1.508 E-02$ & 8.07 \\
16.0 & 0.182 & $1.492 E-02$ & 8.20 \\
17.0 & 0.170 & $1.620 E-02$ & 9.50 \\
18.0 & 0.164 & $1.475 E-02$ & 9.00 \\
19.0 & 0.158 & $1.180 E-02$ & 7.46 \\
20.0 & 0.148 & $1.136 E-02$ & 7.70 \\
25.0 & 0.139 & $8.918 E-03$ & 6.40 \\
30.0 & 0.128 & $6.969 E-03$ & 5.45 \\
35.0 & 0.120 & $5.984 E-03$ & 5.00 \\
40.0 & 0.121 & $5.823 E-03$ & 4.80 \\
45.0 & 0.116 & $7.042 E-03$ & 6.05 \\
50.0 & 0.118 & $1.098 E-02$ & 9.30 \\
60.0 & 0.126 & $1.881 E-02$ & 14.9 \\
70.0 & 0.148 & $2.803 E-02$ & 19.0 \\
80.0 & 0.213 & $3.054 E-02$ & 14.3
\end{tabular}

\section{FIlenAME: C15.DEN}

\begin{tabular}{llllllll}
$C$ & & & & & \\
$C \times / D$ & $y / D$ & $R H O$ & SIG(RHO) & KTURB & \multicolumn{1}{l}{ SKEW } & FLAT & \multicolumn{1}{l}{ INT } \\
15.5 & -3.91 & 1.00 & $2.721 \mathrm{E}-02$ & 2.71 & -8.92 & 179. & $5.440 E-03$ \\
15.5 & -3.47 & 0.951 & 0.147 & 15.4 & -3.39 & 14.1 & 0.126 \\
15.5 & -2.87 & 0.628 & 0.289 & 45.9 & -0.156 & 1.55 & 0.785 \\
15.5 & -2.57 & 0.426 & 0.252 & 59.3 & 0.722 & 2.37 & 0.964 \\
15.5 & -2.25 & 0.261 & 0.170 & 65.0 & 1.64 & 5.56 & 0.999 \\
15.5 & -1.93 & 0.161 & $8.934 E-02$ & 55.4 & 2.89 & 14.3 & 1.00 \\
15.5 & -1.60 & 0.122 & $4.008 E-02$ & 32.8 & 4.46 & 34.5 & 1.00 \\
15.5 & -1.29 & 0.112 & $1.967 E-02$ & 17.5 & 14.5 & 492. & 1.00 \\
15.5 & -0.695 & 0.147 & $2.336 E-02$ & 15.9 & 13.3 & 519. & 1.00 \\
15.5 & $-6.710 E-02$ & 0.206 & $2.844 E-02$ & 13.8 & 8.37 & 225. & 1.00 \\
15.5 & 0.585 & 0.171 & $2.295 E-02$ & 13.4 & 4.59 & 109. & 1.00
\end{tabular}




\begin{tabular}{|c|c|c|c|c|c|c|c|}
\hline FII & WAME: & C30. DEN & & & & & \\
\hline $\begin{array}{l}C \times / D \\
30.6 \\
30.6 \\
30.6 \\
30.6 \\
30.5 \\
30.5 \\
30.5 \\
30.5 \\
30.5 \\
30.5\end{array}$ & $\begin{array}{l}y / 0 \\
-7.06 \\
-6.00 \\
-5.08 \\
-4.18 \\
-3.56 \\
-2.94 \\
-2.31 \\
-1.68 \\
-0.441 \\
0.824 \\
4.02\end{array}$ & $\begin{array}{l}\text { RHO } \\
1.00 \\
0.959 \\
0.702 \\
0.397 \\
0.250 \\
0.171 \\
0.134 \\
0.125 \\
0.134 \\
0.136 \\
0.319\end{array}$ & $\begin{array}{l}\text { SIG(RHO) } \\
2.049 E-02 \\
0.151 \\
0.289 \\
0.234 \\
0.148 \\
8.279 E-02 \\
3.541 E-02 \\
1.697 E-02 \\
1.303 E-02 \\
1.877 E-02 \\
0.190\end{array}$ & $\begin{array}{l}\text { XTURB } \\
2.04 \\
15.7 \\
41.0 \\
59.0 \\
59.0 \\
48.3 \\
26.5 \\
13.5 \\
9.69 \\
13.8 \\
59.6\end{array}$ & $\begin{array}{r}\text { SKEW } \\
-1.58 \\
-3.35 \\
-0.388 \\
0.995 \\
1.98 \\
2.78 \\
4.16 \\
18.9 \\
16.9 \\
29.0 \\
1.49\end{array}$ & $\begin{array}{c}\text { FLAT } \\
32.5 \\
13.6 \\
1.61 \\
3.06 \\
7.56 \\
13.8 \\
30.7 \\
1.080 E+03 \\
867 . \\
1.380 E+03 \\
4.90\end{array}$ & $\begin{array}{l}\text { INT } \\
2.750 E-03 \\
0.111 \\
0.624 \\
0.965 \\
0.998 \\
1.00 \\
1.00 \\
1.00 \\
1.00 \\
1.00 \\
0.989\end{array}$ \\
\hline
\end{tabular}

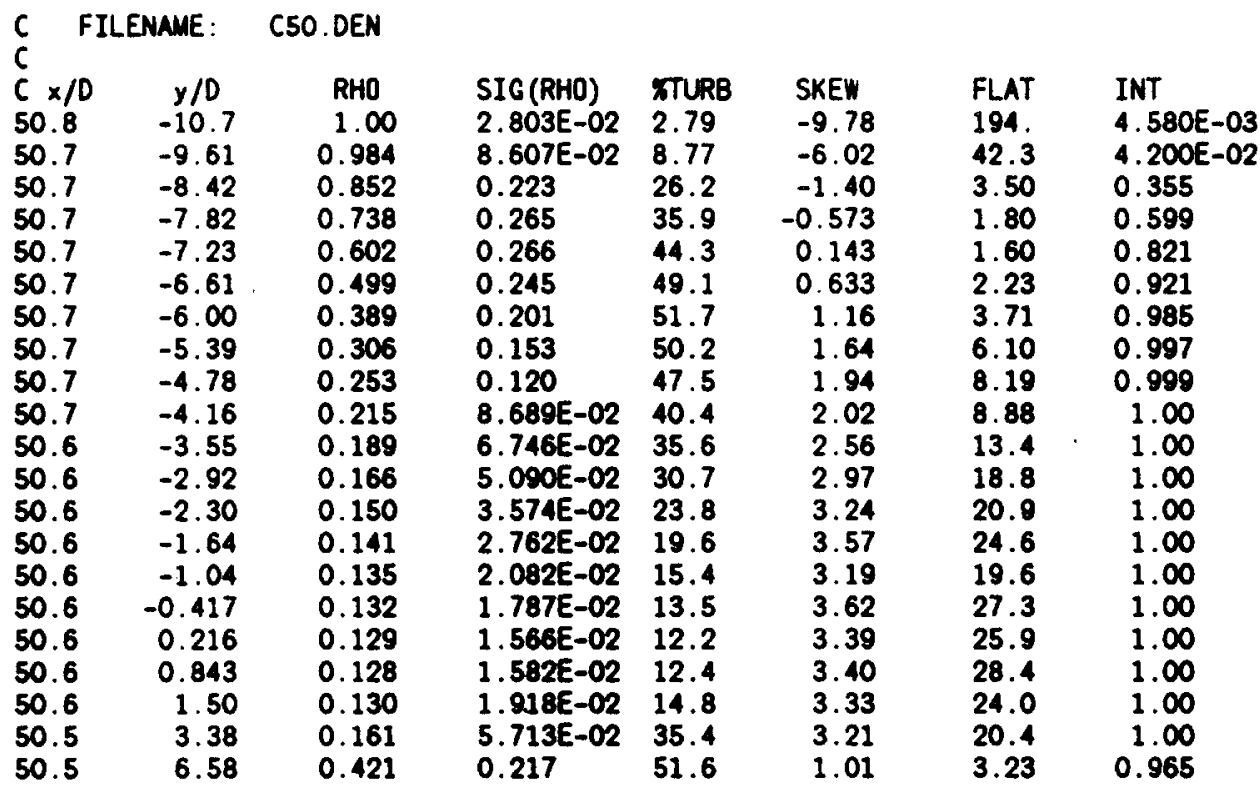

